\title{
ANÁLISE DE EXPERIMENTOS DE CAPTURA-RECAPTURA \\ ATRAVÉS DE MODELOS LOG-LINEARES
}

\section{JOSÉ ERIVALDO PEREIRA \\ Engenheiro Agrônomo}

\author{
Orientadora: Prof ${ }^{\mathrm{a}}$. Dr . Clarice G. B. Demétrio
}

Dissertação apresentada à Escola Superior de Agricultura "Luiz de Queiroz", da Universidade de São Paulo, para obtenção do título de mestre em Agronomia, Área de Concentração: Estatística e Experimentação Agronômica.

\section{Piracicaba}

Estado de São Paulo - Brasil

Janeiro / 1995 
Ficha catalográfica preparada pela Seção de Livros da Divisão de Biblioteca e Documentação - PCLQ/USP

Pereira, José Erivaldo

P436a Análise de experimentos de captura-recaptura através de modelos Log-lineares. Piracicaba, 1995.

106p. ilus.

Diss.(Mestre) - ESALQ

Bibliografia.

1. Bioestatística 2. Jacaré - Experimento 3. Modelo matemático I. Escola Superior de Agricultura Luiz de Queiroz, Piracicaba

CDD 519.5. 639.394 


\section{ANÁLISE DE EXPERIMENTOS DE CAPTURA-RECAPTURA ATRAVÉS DE MODELOS LOG-LINEARES}

\section{JOSÉ ERIVALDO PEREIRA}

Aprovado em: 31/03/95

Comissão julgadora:

Prof ${ }^{\mathrm{a}}$. Dr ${ }^{\mathrm{a}}$. Clarice G. B. Demétrio

Prof. Dr. Hilton Thadeu Zarate do Couto

$\operatorname{Prof}^{\mathrm{a}}$. Dr ${ }^{\mathrm{a}}$. Sheila Zambello de Pinho
ESALQ/USP

ESALQ/USP

UNESP

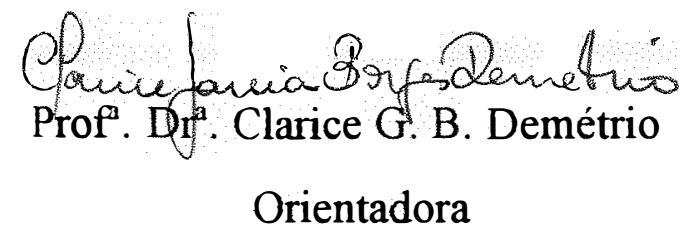


Aos meus pais

Edgar Martins Pereira

e

Maria do Amparo Canuto

OFEREÇO

Aos meus irmãos

Fátima, Edvaldo, Lúcia, Ednaldo, Edgar, Erinaldo e Edberto

DEDICO. 


\section{AGRADECIMENTOS}

À Deus pela força que produz pensamento positivo em mim.

À Empresa Brasileira de Pesquisa Agropecuária - Centro de Pesquisa Agropecuária do Pantanal nas pessoas de Dr. Mário Dantas, Chefe Geral, Dr. João Batista Catto, Chefe Adjunto Técnico e Dr. José Anibal Comastri Filho, Chefe Adjunto de Apoio pela oportunidade para realização do Curso.

À Prof ${ }^{\mathrm{a}} \mathrm{Dr}^{\mathrm{a}}$ Clarice Garcia Borges Demétrio pelos ensinamentos, orientação, incentivo, amizade e valiosas sugestões para a realização deste trabalho.

Ao Prof. Dr. Décio Barbin e ao colega Waldomiro Barioni, pela amizade e apoio em momentos difíceis da minha estada em Piracicaba.

Ao Prof. Dr. Hilton Thadeu Zarate do Couto pela amizade e sugestões apresentadas na elaboração do plano de dissertação.

Aos Professores do Departamento de Matemática e Estatística pelos ensinamentos, convivência e amizade.

Aos demais funcionários do Departamento de Matemática e Estatística pela convivência e amizade. 
À todos os colegas da Pós-Graduação da ESALQ/USP, especialmente a Ana, Márcia, Vera, Bia, Waldomiro, Marcos e Joaquim, peía convivência e amizade.

Aos Pesquisadores do Laboratório de Vida Selvagem da EMBRAPA-CPAP por cederem os dados de recapturas de jacaré.

Ao Pesquisador Guilherme Mourão pelas críticas e sugestões apresentadas.

À todos os colegas e funcionários da EMBRAPA-CPAP, especialmente aos amigos Evaldo e Henrique pela convivência e companheirismo durante minha estada em Corumbá.

Ao amigo Dr. Epitácio Mendes Silva pelos constantes incentivos e apoio em minha vida profissional.

À Edson Higashi e Luis Eduardo Facco pelo auxílio na editoração eletrônica.

A todos que, direta ou inderetamente, colaboraram para a realização deste trabalho. 


\section{SUMÁRIO}

LISTA DE FIGURAS ........................................................... viii

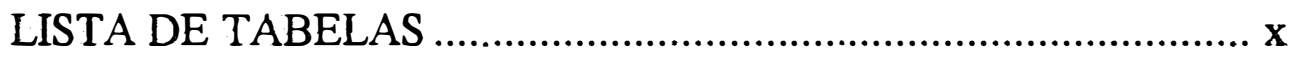

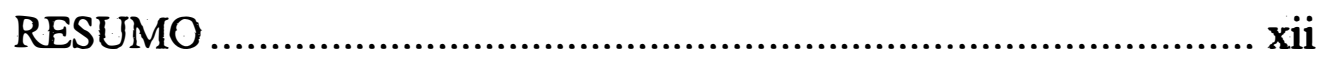

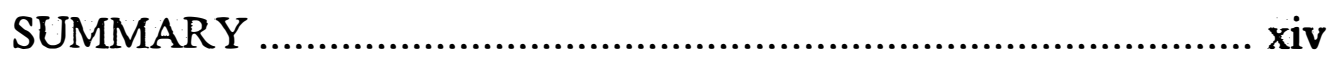

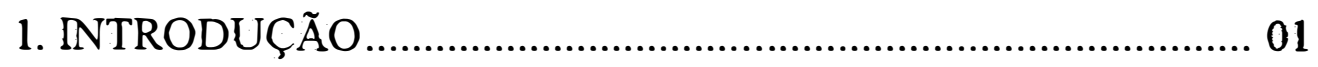

2. REVISÃO DE LITERATURA................................................. 04

2.1. Amostragem simples......................................................... 04

2.1.1. População fechada........................................................ 04

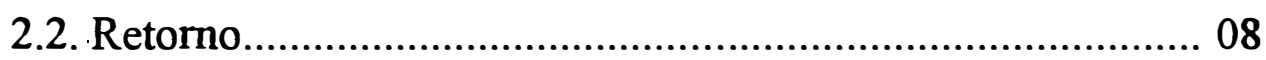

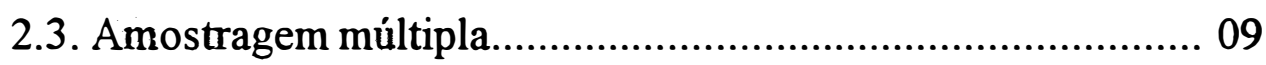

2.3.1. População fechada...................................................... 09

2.3.2. População aberta ..................................................... 15

2.3.3. Combinação de modelos de população fechada e aberta..18

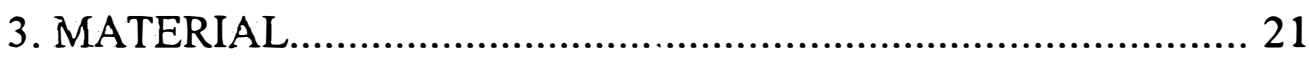

3.1. Caracterização da área de estudo ........................................ 21

3.2. Descrição do experimento...................................................... 24

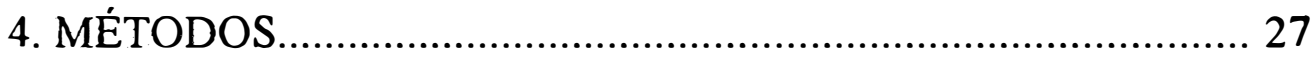

4.1. Descrição do método ......................................................... 27

4.2. Caracterização através de modelos lineares generalizados .... 33

4.3. Aplicação no modelo $\mathrm{M}_{\mathrm{tb}}$ de OTIS et al. (1978) .................. 37 
4.4. Aplicação no modelo Jolly-Seber para população aberta....... 39

4.5. Modelo Poisson ................................................................... 43

4.6. Implementação no GLIM..................................................... 44

4.7. Um exemplo com dados reais ............................................. 46

5. RESULTADOS E DISCUSSÃO …............................................ 50

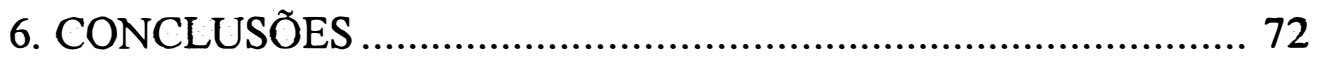

7. REFERÊNCIAS BIBLIOGRÁFICAS ...................................... 73

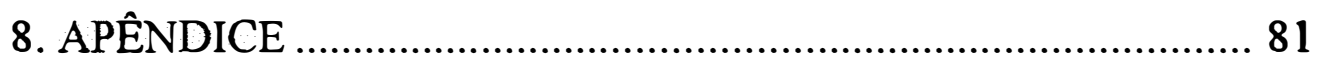

8.1. Apêndice 1 - Histórias de captura e programa do SAS .......... 81

8.2. Apêndice 2 - Programa do GLIM para análise dos dados ..... 85 


\section{LISTA DE FIGURAS}

Figura 1 - Relação entre os modelos de OTIS et al. (1978)............... 11

Figura 2 - Esquema para amostragem através do delineamento

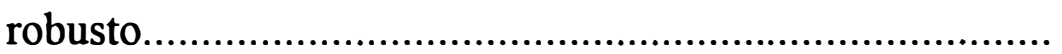

Figura 3 - Área de estudo na Fazenda Nhuminin localizada no Pantanal da Nhecolândia, Mato Grosso do Sul................ 23

Figura 4 - Esforço de captura do experimento .................................. 24

Figura 5 - Captura manual de animais .............................................. 25

Figura 6 - Captura de animais através de laço .................................. 25

Figura 7 - Resíduos de Pearson padronizados da freaquência de cada história de captura plotados contra a frequência de captura naquela história, $S=5$

Figura 8 - Desenho esquemático dos resíduos de Pearson padronizados para as frequências de cada história de captura plotados contra a frequência de captura naquela história, $\mathrm{S}=5$

Figura 9 - Resíduos de Pearson padronizados plotados contra os quantis de probabilidade da distribuição normal, $S=5 \ldots$.

Figura 10 - Resíduos de Pearson padronizados plotados contra os quantis de probabilidade da distribuição normal, $S=4 \ldots$.

Figura 11 - Resíduos de Pearson padronizados da freaquência de cada história de captura plotados contra a frequência de captura naquela história, $S=4$ 
Figura 12 - Desenho esquemático dos resíduos de Pearson padronizados para as frequências de cada história de captura plotados contra a frequência de captura naquela história, $S=5$

Figura 13 - Resíduos de Pearson padronizados da freaquência de cada história de captura plotados contra a frequência de captura naquela história, $S=5$

Figura 14 - Resíduos de Pearson padronizados plotados contra os quantis de probabilidade da distribuição normal, $S=5 \ldots$.

Figura 15 - Desenho esquemático dos resíduos de Pearson padronizados para as frequências de cada história de captura plotados contra a frequência de captura naquela história, $S=5$ 


\section{LISTA DE TABELAS}

Tabela 1. Modelos de captura-recaptura obtidos em amostragem simples

Tabela 2. Estimadores propostos para o tamanho da população (N), para experimentos em amostragem simples

Tabela 3. Modelos de captura-recaptura para população fechadas que permitem probabilidades de captura desiguais

Tabela 4. Representação de um experimento de captura-recaptura com três amostras através de uma tabela de contingência completa

Tabela 5. Correspondência entre parâmetros do GLIM e parâmetros biológicos para o modelo $\mathrm{M}_{\mathrm{tb}}$ de OTIS et al. (1978), com $\mathrm{S}=3$

Tabela 6. Correspordência entre parâmetros do GLIM e parâmetros biológicos para o modelo com três amostras

Tabela 7. Correspondência entre parâmetros do GLIM e parâmetros biológicos para o modelo Jolly-Seber com S-amostras ........

Tabela 8. Dados e análise de recaptura de jacaré (Caiman crocodilus yacare) na fazenda Nhuminim, Pantanal da Nhecolândia, Mato Grosso do Sul, $S=5$.

Tabela 9. Dados com a correção e análise de recaptura de jacaré (Caiman crocodilus yacare) na fazenda Nhumirim, Pantanal da Nhecolândia, Mato Grosso do Sul, $\mathrm{S}=5 \ldots \ldots \ldots$. 
Tabela 10. Dados com a correção e análises de recaptura de jacaré (Caiman crocodilus yacare) na fazenda Nhuminim, Pantanal da Nhecolândia, Mato Grosso do Sul, $S=4 \ldots \ldots \ldots$.

Tabela 11. Análise do modelo com nascimento e morte mais

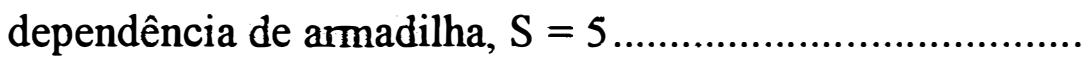

Tabela 12. Análise de heterogeneidade para a população de jacarés (Caiman crocodilus yacare) no Pantanal da Nhecolândia, Mato Grosso do Sul 


\title{
ANÁLISE DE EXPERIMENTOS DE CAPTURA-RECAPTURA ATRAVÉS DE MODELOS LOG-LINEARES
}

\author{
Autor: José Erivaldo Pereira \\ Orientador: Prof ${ }^{\mathrm{A}} \mathrm{Dr}^{\mathrm{a}}$ Clarice G. B. Demétrio
}

\section{RESUMO}

Neste trabalho abordamos a análise de experimento de captura-recaptura usando modelos log-lineares. Para muitos modelos uma equivalência exata pode ser demonstrada entre os parâmetros do modelo loglinear e os parâmetros biológicos usuais tal que as estimativas destes são também estimativas de máxima verossimilhança.

Os modelos para populações fechadas onde uma equivalência exata pode ser estabelecida são $M_{o}, M_{t}, M_{b}$ e $M_{t b}$ de OTIS et al. (1978). Para população aberta exata equivalência é disponível com o modelo Jolly-Seber, ou qualquer submodelo obtido pela omissão de nascimento ou morte, ou ainda, especificando probabilidade de captura constante sobre todas, ou qualquer subconjunto de amostras.

Um programa no SAS que produz as histórias de captura com respectivas contagens observadas e outro no GLIM que possibilita uma completa análise dos dados sob o modelo Jolly-Seber ou qualquer derivação deste, são apresentados.

É discutida a aplicação desta metodologia num conjunto de dados reais de recaptura de jacaré (Caiman crocodilus yacare) obtidos no Pantanal da Nhecolândia, Mato Grosso do Sul, com os resultados mostrando 
que parâmetros de heterogeneidade nas probabilidades de captura dos animais e parâmetros de dependência de armadilha estão em operação na população estudada. Além disso, verificou-se que a densidade estimada para o ano de 1990 é de 50 animais $/ \mathrm{km}^{2}$ valor igual ao encontrado por MOURÃO et al. (1994) utilizando o método de levantamento aéreo. 


\title{
ANALYSIS OF CAPTURE-RECAPTURE EXPERIMENTS THROUGH LOG-LINEAR MODELS
}

\author{
Author: José Erivaldo Pereira \\ Adviser: Prof ${ }^{2} \mathrm{Dr}^{\mathrm{A}}$ Clarice G. B. Demétrio
}

\section{SUMMARY}

In this research we approached the analysis of capturerecapture experiments using log-linear models. For many models an exact equivalence can be shown between the parameters of the log-linear model and the usual biological parameters, in such a way that estimatives of them are also maximum likelihood estimatives.

Models for closed populations in which an exact equivalence can be established are $M_{o}, M_{t}, M_{b}$ e $M_{b b}$ from OTIS et al. (1978). For open populations, exact equivalence is available with the Jolly-Seber model, or submodels obtained by omission of birth, death, or even specifying constant probability of capture over all or any subset of samples.

A SAS program, which generates the histories of capture with their respective observed countings and another with GLIM which makes possible a complete analysis of the data based on Jolly-Seber model or any derivation of this, are shown.

Aplication of this methodology is discussed on a set of real data on recapture of alligator (Caiman crocodilus yacare) observed at Pantanal de Nhecolândia (Nhecolândia swamp), in the state of Mato Grosso do Sul, Brazil, with results showing that heterogeneity parameters on the probabilities 
of animal capture and parameters of trap-hapiness were in operation in the target population. On the other hand it was estimated the animal density for the year of 1990 that was 50 animal per squared kilometer the same value as the one found by MOURÃO et al. (1994) utilizing aerial survey. 


\section{INTRODUÇÃO}

Estimar o tamanho de uma população animal é um problema relevante em estudos ecológicos pois, por exemplo, auxilia a tomada de decisões sobre o manejo e a explotação de uma espécie selvagem. Vários métodos foram introduzidos com este propósito, como pode ser visto, principalmente, em CAUGHLEY (1977), SEBER (1982, 1986, 1992) e POLLOCK (1991). O método de captura-recaptura além de vir recebendo considerável atenção na literatura sobre estimação de abundância animal, tem sido bastante utilizado para estimar parâmetros de populações de vida selvagem. Uma descrição geral deste método é dada por CASAJÚS (1990) como: duas ou mais amostras são selecionadas da população em estudo. Todos os animais capturados na primeira amostra são marcados (ex.: em estudos com aves um anel é colocado em uma das patas; em jacaré é feito uma marcação codificada de acordo com as escamas caudais retiradas, etc.). Em seguida todos os animais marcados (ou parte deles) são devolvidos à população. Para cada uma das amostras subseqüentes são registradas as capturas dos animais marcados e não-marcados; todos os animais nãomarcados na amostra recebem uma marca e, em alguns casos, os animais anteriormente capturados (da amostra) também recebem uma nova marca, indicando a época de sua captura e, em seguida, todos os animais (ou uma parte deles) são devolvidos à população. Desta forma, uma estimativa do tamanho da 
população pode ser obtida através do número de animais marcados, recapturados em cada amostra.

A depender da situação, pode-se considerar que o tempo necessário para completar o experimento de captura-recaptura seja suficientemente pequeno para não ocorrerem perdas (mortes ou emigração) ou ganhos (nascimento ou imigração). Neste caso, diz-se que a população é fechada. Alternativamente, se durante a realização do experimento a população se altera pela ocorrência de nascimento, imigração, morte e/ou emigração, denominamos de população aberta. Além disso, este tipo de experimento pode envolver o processo de amostragem simples que consiste na seleção de duas amostras, ou amostragem múltipla, onde um número, maior que dois, de amostras é obtido. Em ambos os casos, pode-se ou fixar os tamanhos das amostras, ou o número de indivíduos marcados a serem capturados, caracterizando assim os métodos de amostragem direta e inversa, respectivamente.

PETERSEN (1896), foi o primeiro pesquisador a aplicar o método de captura-recaptura para estudar o fluxo migratório de peixes no Mar Báltico. Entretanto, citações históricas do uso deste procedimento são feitas por SEBER (1982). Segundo o autor, Laplacel (1786) já tinha feito uso prático dessa técnica para estimar o tamanho da população francesa, e $\operatorname{Lincoln}^{2}$ (1930) foi um dos primeiros pesquisadores, neste século, a utilizar o método de capturarecaptura para estimar o tamanho da população de patos da América do Norte. Somente a partir dos anos 50 o interesse e a contribuição de estatísticos e probabilistas sobre o tema se deu de forma expressiva, tendo continuidade até os

\footnotetext{
${ }^{1}$ LAPLACE, P.S. Sur les naissances. les mariages et ales morts. Histore de l'Académie Royale des Sciences, Année 1783, Paris, p.693. [104]. 1786.

${ }^{2}$ LINCOLN, F.C. Calculating waterfowl abundance on the basis of banding returns. U.S. Dept. Agric.

Circ. No. 118, 1-4. [1, 104]. 1930.
} 
dias atuais, e resultando numa signficativa quantidade de informações disponíveis.

Neste trabalho será feito um estudo sistemático sobre a análise de experimentos de captura-recaptura, através da abordagem alternativa usando modelos log-lineares. Grande ênfase será dada na situação de maior interesse prático, ou seja, amostragem múltipla em população aberta, onde dados de recaptura de jacaré (Caiman crocodilus yacare) obtidos no pantanal da Nhecolândia, são utilizados como exemplos. 


\section{REVISÃO DE LITERATURA}

\subsection{Amostragem simples}

\subsubsection{População fechada}

PETERSEN (1896) introduziu um estimador do tamanho da população, para o caso de amostragem simples, ao assumir que, intuitivamente, a taxa esperada de animais marcados para não marcados na segunda amostra reflete a mesma taxa na população. Assim tem-se,

$$
\frac{\mathrm{n}_{1}}{\mathrm{~N}}=\frac{\mathrm{m}}{\mathrm{n}_{2}} \Rightarrow \hat{\mathrm{N}}=\frac{\mathrm{n}_{1} \mathrm{n}_{2}}{\mathrm{~m}}
$$

onde

$$
\begin{aligned}
& \mathrm{n}_{1} \text { - tamanho da } 1^{\mathrm{a}} \text { amostra selecionada; } \\
& \mathrm{n}_{2} \text { - tamanho da } 2^{\mathrm{a}} \text { amostra selecionada; } \\
& \mathrm{m} \text { - número de animais marcados observados na } 2^{\mathrm{a}} \text { amostra; } \\
& \mathrm{N} \text { - tamanho da população. }
\end{aligned}
$$

A dificuldade encontrada em utilizar este estimador é que o mesmo apresenta esperança infinita, pois $\mathrm{m}$ tem uma probabilidade positiva de assumir o valor zero, e sua variância não existe. Além disso, apresenta viés significativo quando $\mathrm{m}$ tem valor esperado pequeno. 
As suposições do modelo de Petersen são:

i) a população é fechada (não há nascimento, morte, imigração ou emigração);

ii) todos os animais são igualmente prováveis de serem capturados em cada amostra (independente da condição de marcação ou outro fator como tamanho, sexo, idade, comportamento social ou qualquer outra fonte de variação);

iii) as marcas são claramente visíveis e não são perdidas.

É pertinente comentar que a primeira suposição de população fechada é freqüentemente inválida pelo fato que populações silvestres não são estáticas sobre o tempo. Além disso, a possibilidade de remoção (mortalidade, emigração) ou recrutamento (nascimento, imigração) esta quase sempre presente. A segunda suposição que é conhecida como suposição de igual retorno é também muito violada em populações naturais. Alternativas para esta podem ser de dois tipos:

a) Dependência de armadilha - a probabilidade de captura em qualquer amostra depende da história de captura a priori do animal;

b) Heterogeneidade - a probabilidade de captura em qualquer amostra é uma propriedade do animal e pode variar na população.

A Tabela $l$ apresenta as distribuições de probabilidades apropriadas para todas as situações em amostragem simples. 
Tabela 1 - Modelos de captura-recaptura obtidos em amostragem simples.

\begin{tabular}{c|c|c|c|c}
\hline \multirow{2}{*}{} & \multicolumn{3}{|c}{ AMOSTRAGEM SIMPLES } \\
\cline { 2 - 5 } & \multicolumn{2}{|c|}{ DIRETA } & \multicolumn{2}{c}{ INVERSA } \\
\cline { 2 - 5 } & Com reposição & $\frac{\text { Sem reposição }}{\mathrm{m}}$ & $\frac{\text { Com reposição }}{\mathrm{n}_{2}}$ & $\frac{\text { Sem reposição }}{\mathrm{n}_{2}}$ \\
\hline $\begin{array}{c}\text { Variável } \\
\text { aleatória }\end{array}$ & Binomial & Hipergeométrica & $\begin{array}{c}\text { Binomial } \\
\text { negativa }\end{array}$ & $\begin{array}{c}\text { Hipergeométrica } \\
\text { negativa }\end{array}$ \\
\hline Modelo teórico & (1) & (3) & (4) \\
\hline $\begin{array}{c}\text { Função de } \\
\text { distribuição de } \\
\text { probabilidade }\end{array}$ & (1) & (2) & (3) \\
\hline
\end{tabular}

onde:

(1): $P\left(m / n_{1}, n_{2}, N\right)=\left(\begin{array}{c}n_{2} \\ m\end{array}\right)\left(\frac{n_{1}}{N}\right)^{m}\left(1-\frac{n_{1}}{N}\right)^{n_{2}-m} ; m=0,1, \ldots, n_{2}$ $\operatorname{com} \quad E(m)=n_{2} \frac{n_{1}}{N} \quad$ e $\quad V(m)=n_{2} \frac{n_{1}}{N}\left(1-\frac{n_{1}}{N}\right)$

(2): $P\left(m / n_{1}, n_{2}, N\right)=\frac{\left(\begin{array}{l}n_{1} \\ m\end{array}\right)\left(\begin{array}{l}N-n_{1} \\ n_{2}-m\end{array}\right)}{\left(\begin{array}{l}N \\ n_{2}\end{array}\right)}$, máx. $\left\{0, n_{1}+n_{2}-N\right\} \leq m \leq$ min. $\left\{n_{1}, n_{2}\right\}$ $\operatorname{com} \quad E(m)=\frac{n_{1} n_{2}}{N} \quad$ e $\quad V(m)=\frac{n_{1} n_{2}}{N}\left(1-\frac{n_{1}}{N}\right)\left(\frac{N-n_{2}}{N-1}\right)$

(3): $\mathrm{P}\left(\mathrm{n}_{2} / \mathrm{n}_{1}, \mathrm{~m}, \mathrm{~N}\right)=\left(\begin{array}{c}\mathrm{n}_{2}-1 \\ \mathrm{~m}-1\end{array}\right)\left(\frac{\mathrm{n}_{1}}{\mathrm{~N}}\right)^{\mathrm{m}}\left(1-\frac{\mathrm{n}_{1}}{\mathrm{~N}}\right)^{\mathrm{n}_{2}-\mathrm{m}} ; \mathrm{n}_{2} \geq \mathrm{m}$ $\operatorname{com} \quad E\left(n_{2}\right)=\frac{m}{p}$ e $V\left(n_{2}\right)=\frac{m(1-p)}{p^{2}}$ 


$$
\begin{aligned}
& \text { para } p=\frac{n_{1}}{N} \\
& \text { (4): } P\left(n_{2} / n_{1}, m, N\right)=\frac{n_{1}}{N} \frac{\left(\begin{array}{l}
n_{1}-1 \\
m-1
\end{array}\right)\left(\begin{array}{l}
N-n_{1} \\
n_{2}-m
\end{array}\right)}{\left(\begin{array}{l}
N-1 \\
n_{2}-1
\end{array}\right)}, m \leq n_{2} \leq\left(N-n_{1}\right)+m \\
& \text { com } E\left(n_{2}\right)=\frac{m(N+1)}{\left(n_{1}+1\right)} \text { e } V\left(n_{2}\right)=\frac{m(N+1)\left(N-n_{1}\right)\left(n_{1}-m+1\right)}{\left(n_{1}+1\right)^{2}\left(n_{1}+2\right)}
\end{aligned}
$$

Os estimadores de máxima verossimilhança para $\mathrm{N}$, nos modelos 1, 2, 3 e 4 são todos aproximadamente iguais ao estimador intuitivo de Petersen (CASAJÚS, 1990). E como este tem esperança infinita e sua variância não existe BAILEY (1951), CHAPMAN (1951) e CHAPMAN (1952); independentemente, propuseram estimadores (Tabela 2) para os modelos 1, 2 e 4, respectivamente, sendo que os dois primeiros apresentam viés menor do que o do estimador de Petersen e o último é não-viciado.

Tabela 2 - Estimadores propostos para o tamanho da população $(\mathrm{N})$, para experimentos em amostragem simples.

\begin{tabular}{l|c|c}
\hline & $\hat{\mathrm{N}}$ & $\mathrm{V}(\hat{\mathrm{N}})$ \\
\hline BAILEY (1951) & $\frac{n_{1}\left(n_{2}+1\right)}{(m+1)}$ & $V(\hat{N}) \leq\left(\frac{n_{1} n_{2}}{2}\right)^{2}$ \\
\hline CHAPMAN (1951) & $\frac{\left(n_{1}+1\right)\left(n_{2}+1\right)}{(m+1)}-1$ & $\frac{\left(n_{1}+1\right)\left(n_{2}+1\right)\left(n_{1}-m\right)\left(n_{2}-m\right)}{(m+1)^{2}+(m+2)}$ \\
\hline CHAPMAN (1952) & $\frac{n_{2}\left(n_{1}+1\right)}{m}-1$ & $\frac{(N+1)\left(N-m_{1}\right)\left(n_{1}-m+1\right)}{m\left(n_{1}+2\right)}$ \\
\hline
\end{tabular}


Outra distribuição de probabilidade muito importante na estimação do $\mathrm{N}$, é a multinomial, aqui caracterizada por

$$
P\left(\left\{r_{a}\right\} / N\right)=\frac{N !}{\Pi r_{a} !(N-r) !}\left(p_{1} q_{2}\right)^{r_{10}}\left(q_{1} p_{2}\right)^{r_{01}}\left(p_{1} p_{2}\right)^{r_{11}}\left(q_{1} q_{2}\right)^{N-r},
$$

onde

$\mathrm{r}_{\mathrm{a}}$-é o número de animais com história de captura a.

$\mathrm{p}_{\mathrm{i}}$ - é probabilidade de captura na $\mathrm{i}$-ésima amostra $(\mathrm{i}=1,2)$.

$\mathrm{q}_{\mathrm{i}}$-é probabilidade de não captura na i-ésima amostra $(\mathrm{i}=1,2)$.

$\mathrm{r}$ - é o número de diferentes animais capturados no experimento.

$\left\{r_{a}\right\}$ - é o conjunto das possíveis histórias de captura.

\subsection{Retorno}

A suposição de igual retorno é muito restritiva e causa problema na maioria das aplicações do método de captura-recaptura, pois, a exigência de que todos os animais, marcados e não-marcados, tenham a mesma probabilidade de captura é crucial para a acuracidade dos resultados. A ausência desta é considerada a maior fonte de erro nos experimentos de captura-recaptura.

Eberhardt $^{1}$ (1969), citado por CAUGHLEY (1977), classifica as principais causas de desigual retorno como:

1. uma propriedade inerente ao animal (expressa em seu comportamento na imediata vizinhança da armadilha); 
2. o resultado da aprendizagem (animais podem tornar-se "trap-happy" ou trap-shy") e

3. a propriedade dependente da oportunidade relativa de captura (um animal não pode ser capturado se nenhuma armadilha é colocada dentro do seu "habitat").

O efeito relativo a (1) é difícil de ser detectado a partir dos registros de captura, já que é possível para alguns indivíduos terem probabilidade de captura infinitamente pequena, portanto, nunhuma evidência da presença destes animais estará disponível nos resultados do experimento. O efeito relativo a (2) pode ser detectado se os animais são recapturados em mais de uma ocasião, naturalmente seria uma exigência tomar mais que 2 (duas) ocasiões de amostragem. Certamente, alternativas para este problema seria mudar o método de captura para um no qual as chances de captura são menos dependentes da decisão feita pelo animal, ou usar um modelo que considere o "trap-happy" e "trap-shy", ou ainda reduzir o número de ocasiões de recapturas de tal forma que nenhum animal tenha tempo suficiente de aprender como pode ou não, ser capturado. A terceira causa de desigual probabilidade de captura pode ser parcialmente controlada no planejamento do experimento pela aleatorização das estações de captura a cada ocasião de amostragem.

\subsection{Amostragem múltipla}

\subsubsection{População fechada}

SCHNABEL (1938) introduziu o primeiro modelo de capturarecaptura com um número maior do que 2 (dois) de ocasiões de amostragens, ao 
assumir que os $M_{j}$, o número total de animais marcados na população imediatamente antes da j-ésima amostra ser tomada, são parâmetros populacionais conhecidos. Desta forma, considerando a distribuição binomial em cada ocasião de amostragem propôs um estimador para $\mathrm{N}$ dado por

$$
\hat{N}=\frac{\sum n_{j} M_{j}}{\sum m_{j}}
$$

onde $n_{j}$ é o número de animais capturados na j-ésima amostra e $m_{j}$ é o númerc de animais marcados capturados na j-ésima amostra. Esse estimador equivale a uma extensão do estimador de Petersen para j ocasiões de amostragens.

CORMACK (1968) afirma que se $M_{j} / N$ é pequeno, e $m_{j}$ pode ser tomado como uma variável Poisson, então $\hat{\mathrm{N}}$ é uma estimativa exata de máxima verossimilhança para $\mathrm{N}$.

O modelo de SCHNABEL (1938) é tido como o modelo que dá origem ao estimador clássico do tamanho populacional em experimentos de captura-recaptura envolvendo múltiplas ocasiões de amostragem. Entretanto, atualmente este é indicado na literatura como o modelo $M_{t}$ que é um caso particular do conjunto de modelos introduzidos por OTIS et al. (1978), para o qual se assume que cada animal na população tem a mesma probabilidade de captura em cada ocasião de amostragem, ou seja, igual ao retorno em cada amostra.

Modelos que levam em consideração a probabilidade de captura variando com a heterogeneidade (h), resposta comportamental à armadilha (b), variação temporal (t) e todas as possíveis combinações entre estes fatores estão disponíveis para análise de dados de experimentos de captura-recaptura, com 
múltiplas ocasiões de amostragem em populações fechadas. Os oito modelos que são obtidos através das considerações citadas $\left(\mathbf{M}_{\mathbf{o}}, \mathbf{M}_{\mathrm{h}}, \mathbf{M}_{\mathrm{b}}, \mathbf{M}_{\mathrm{bh}}, \mathbf{M}_{\mathrm{t}}, \mathbf{M}_{\mathrm{tb}}, \mathbf{M}_{\mathrm{th}}\right.$, $\mathbf{M}_{\text {tbh }}$ ) foram completamente desenvolvidos por OTIS et al. (1978), WHITE et al. (1982) e POLLOCK \& OTTO (1983).

OTIS et al. (1978) observaram através de estudos de simulação que, embora, os estimadores do tamanho populacional nestes modelos sejam viesados, dentro de certas condições como probabilidade de captura de ao menos 0,1 em cada ocasião de amostragem e número de ocasiões de amostragens entre 5 a 10, os resultados obtidos são razoáveis. EVANS \& BONETT (1994) apresentaram uma correção do viés para estimadores do tamanho da população nesta situação introduzindo um estimador modificado construído com auxílio de modelos log-lineares para tabelas de contingência. A Figura 1 apresenta a relação entre os modelos apresentados.

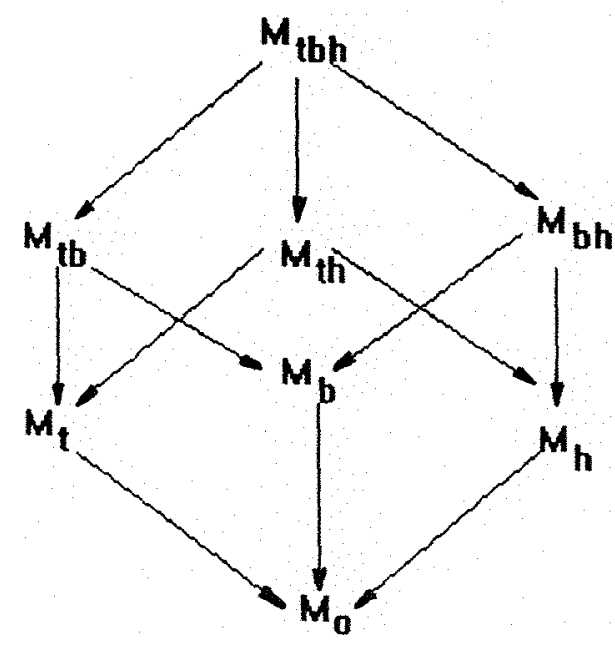

Figura 1. Relações entre os modelos de OTIS et al. (1978) (a seta indica que o modelo é um caso especial imediato do outro). 
Estes modelos diferem na forma pela qual a probabilidade de captura é modelada. Assim considerando-se,

$\mathrm{P}_{\mathrm{ij}}$ - a probabilidade de captura do i-ésimo animal na população na j-ésima ocasião de amostragem, com, $\mathrm{i}=1,2, \ldots, \mathrm{N}$ e $\mathrm{j}=1,2, \ldots, \mathrm{t}$; têm-se, em termos das suposições e correspondentes probabilidades de capturas os seguintes modelos:

1. MODELO $\mathbf{M}_{\mathbf{0}}: \mathbf{P}_{\mathrm{ij}}=\mathbf{P}$

Este é o modelo mais restritivo pois assume que as probabilidades de captura são constantes.

O estimador de máxima verossimilhança não existe em forma fechada exceto para $t=2$, e pode ser encontrado no apêndice de OTIS et al.(1978).

2. MODELO $\mathbf{M}_{\mathbf{t}}: \mathbf{P}_{\mathbf{i j}}=\mathbf{P}_{\mathbf{j}}, \mathbf{j}=1, \ldots, \mathrm{t}$.

Probabilidades de captura variam somente com o tempo, ou seja, ao longo das ocasiões de amostragens.

O estimador de máxima verossimilhança não existe em forma fechada, exceto para $t=2$ (quando este coincide com o estimador de Petersen). $\mathrm{O}$ estimador de Schnabel é frequentemente utilizado com este modelo, mas é apenas uma aproximação do estimador de máxima verossimilhança introduzido por DARROCH (1958) e pode ser visto no apêndice de OTIS et al. (1978). 
CHAO (1989) desenvolveu um novo estimador para este modelo cujas estatísticas suficientes são o número de indivíduos capturados ivezes $\operatorname{com} \mathrm{i}=1,2, \ldots, \mathrm{t}$.

3. MODELO $\mathbf{M}_{\mathbf{b}}: \mathbf{P}_{\mathrm{ij}}=\left\{\begin{array}{l}\mathbf{P} \text { para primeira captura } \\ \text { C para recaptura. }\end{array}\right.$

Este é o modelo mais simples que permite resposta comportamental à armadilha. Uma característica importante deste modelo é que os animais não contribuem com qualquer informação para estimação do tamanho da população após a primeira captura. Assim este modelo é equivalente ao modelo de remoção introduzido por ZIPPIN (1956).

O estimador de máxima verossimilhança é um caso particular do estimador de remoção generalizado, o qual pode ser encontrado no apêndice de OTIS et al.(1978).

Este modelo permite heterogeneidade de probabilidades de captura entre os animais, mas não permite variação nas probabilidades de captura no tempo.

Segundo POLLOCK (1991) este modelo foi primeiramente desenvolvido por Burnham ${ }^{2}$ (1972) e Burnham \& Owerton ${ }^{34}(1978,1979)$. O

\footnotetext{
${ }^{2}$ BURNHAM. K.P. Estimation of population size in multiple capture studies when capture probabilities vary among animals. Oregon State University, Dept. of Statistics. 1972. (Ph. D. dissertation). 3BURNHAM. K.P. \& OVERTON, W.S. Estimation of the size of a closed population when capture probabilities vary among animals. Biometrika, 65: 625-33, 1978.

${ }^{4}$ BURNHAM, K.P. \& OVERTON. W.S. Robust estimation of population size when capture probabilities vary among animals. Ecology, 60: 927-36, 1979.
} 
estimador é baseado no método "jackknife" introduzido por QUENOUILLE (1956), e consiste numa combinação linear de freqüências de captura conforme apresenta o apêndice de OTIS et al. (1978). CHAO (1988) introduziu um estimador dos momentos que é menos viesado quando a probabilidade de captura média é pequena, tal que a maioria dos animais são capturados apenas 1 ou 2 vezes nas amostras. Ainda CHAO (1989) introduziu um novo estimador para o modelo $\mathrm{Mh}$, cujas estatísticas suficientes são o número de indivíduos capturados i-vezes, onde $\mathrm{i}=1,2, \ldots, \mathrm{t}$.

5. MODELO $\mathbf{M}_{t b}: \mathbf{P}_{\mathrm{ij}}=\left\{\begin{array}{l}\mathbf{P}_{\mathrm{j}} \text { para qualquer primeira captura, } \mathbf{j}=1, \ldots, \mathrm{t} \text {. } \\ \mathbf{C}_{\mathrm{J}} \text { para qualquer recaptura, } \mathbf{j}=\mathbf{2 , \ldots , t} .\end{array}\right.$

Este modelo permite variação nas probabilidades de captura devido a ambos tempo e comportamento (dependência de armadilha).

BURNHAM et al. (1987) desenvolveram um estimador do tamanho da população sob este modelo cujas estatísticas suficientes são o número de animais capturados em cada ocasião $\left(n_{\mathrm{i}}\right)$, e o número de animais marcados na população imediatamente antes da i-ésima amostra $\left(\mathrm{M}_{\mathrm{i}-1}\right)$.

6. MODELO $\mathbf{M}_{\mathrm{th}}: \mathbf{P}_{\mathrm{ij}}=\mathbf{P}_{\mathrm{i}} \mathbf{P}_{\mathbf{j}}, \mathrm{j}=1, \ldots$, t. e $\mathrm{i}=1, \ldots, \mathrm{N}$.

Este modelo assume heterogeneidade com variação nas probabilidades de captura no tempo.

CHAO et al. (1992) desenvolveram um estimador para o tamanho da população. Neste caso não existe estatística suficiente. 
7. MODELO $\mathbf{M}_{b h}: \mathbf{P}_{i j}=\left\{\begin{array}{l}P_{i} \text { para primeira captura, } \\ C_{i} \text { para todas as recapturas, } i=1, \ldots, N .\end{array}\right.$

Este modelo assume heterogeneidade com dependência de armadilha, mas não variação temporal nas probabilidades de captura.

O estimador de remoção generalizado apresentado no apêndice de OTIS et al. (1978) é utilizado neste caso.

8. MODELO $\mathbf{M}_{t \mathrm{bh}}: P_{i j}=\left\{\begin{array}{l}P_{i j} \text { para primeira captura } \\ C_{i j} \text { para todas as recapturas } j=1, \ldots, t \text { e } i=1, \ldots, N \text {. }\end{array}\right.$

Este modelo é importante sob o aspecto conceitual, entretanto apresenta problemas de estimabilidade e identificabilidade de parâmetros. Neste caso o tamanho da população não é estimável.

A Tabela 3 , mostra as fontes de variação na probabilidade de captura incorporada nos modelos. Percebe-se que apenas o modelo $M_{\text {tbh }}$ não apresenta estimador disponivel para o tamanho da população. 
Tabela 3 - Modelos de captura-recaptura para populações fechadas que permitem probabilidades de captura desiguais.

\begin{tabular}{|c|c|c|c|c|}
\hline \multirow[t]{2}{*}{ Modelo } & \multicolumn{3}{|c|}{ Fonte de variação na probabilidade de captura } & \multirow{2}{*}{$\begin{array}{l}\text { Estimador } \\
\text { disponivel }\end{array}$} \\
\hline & Heterogeneidade & $\begin{array}{l}\text { Resposta à } \\
\text { armadilha }\end{array}$ & Tempo & \\
\hline $\begin{array}{l}\mathrm{M}_{\mathrm{o}} \\
\mathrm{M}_{\mathrm{h}}\end{array}$ & $\mathrm{X}^{2}$ & & & $\begin{array}{c}\text { Nulo } \\
\text { "Jackknife" } \\
\text { Mh-Chao }\end{array}$ \\
\hline $\mathrm{M}_{\mathrm{b}}$ & & $\mathrm{X}$ & & Zippin \\
\hline $\mathrm{M}_{\mathrm{bh}}$ & $\mathrm{X}$ & $\mathrm{X}$ & & Remoção \\
\hline $\mathrm{M}_{\mathrm{t}}$ & & & $\mathrm{X}$ & $\begin{array}{l}\text { Darroch } \\
\text { Mt-Chao }\end{array}$ \\
\hline $\mathrm{M}_{\mathrm{th}}$ & $\mathrm{X}$ & & $\mathrm{X}$ & Mth-Chao \\
\hline $\mathrm{M}_{\mathrm{tb}}$ & & $\mathrm{x}$ & $\mathrm{X}$ & Mtb-Bumham \\
\hline $\mathrm{M}_{\mathrm{tbh}}$ & $\mathrm{X}$ & $\mathrm{X}$ & $\mathrm{X}$ & - \\
\hline
\end{tabular}

1. Conjunto de 8 modelos de OTIS et al. (1978).

2. Denotam as fontes de variação na probabilidade de captura incorporada nos modelos.

\subsubsection{População aberta}

Em muitos estudos de captura-recaptura, notadamente aqueles a longo prazo, não é possível assumir que a população é fechada a adições e permanente deleções. O modelo básico que aborda esta situação foi introduzido independentemente por JOLLY (1965) e SEBER (1965), ambos desenvolvendo o modelo produto de multinomiais. CORMACK (1972) mostra uma breve descrição intuitiva do modelo e seus estimadores enquanto POLLOCK et al. (1990) o fizeram com maior detalhe, e SEBER (1982) dá uma melhor descrição bastante detalhada.

O modelo J-S, como é conhecido, permite a estimação do tamanho da população a cada ocasião de amostragem bem como estimação da 
probabilidade de sobrevivência e do número de nascimentos entre ocasiões de amostragem.

Este modelo faz as seguintes suposições:

1. Cada animal presente na população no momento da i-ésima amostra $(i=1,2, \ldots$, S) tem a mesma probabilidade de captura $\left(P_{i}\right)$.

2. Cada animal marcado, presente na população imediatamente após a i-ésima amostra, tem a mesma probabilidade de sobrevivência $\left(\phi_{i}\right)$ até a (i+1)-ésima ocasião de amostragem $(i=1,2, \ldots, S-1)$.

3. As marcas não são perdidas ou "overlooked".

4. Todas as amostras são instantâneas e cada soltura é feita imediatamente após a captura.

Embora este modelo seja considerado o mais importante, tanto no aspecto prático como teórico, tem sido criticado em dois níveis. Um conjunto de críticas questiona os resultados:

i) por apresentarem altos erros padrões, e serem correlacionados com os valores estimados;

ii) por permitir estimativas fora do intervalo paramétrico, como, probabilidade maior que a unidade ou taxa de nascimento negativa.

Outro conjunto de críticas aborda a natureza restritiva das suposições, como:

i) todos os animais são independentes com a mesma probabilidade de captura;

ii) comportamento dos animais não é afetado pela história de captura e iii) não pode existir emigração temporária da população em estudo. 


\subsubsection{Combinação de modelos de população fechada e aberta}

POLLOCK (1982) introduziu um delineamento para estudos de longa duração que é robusto à heterogeneidade e/ou resposta à amadilha. Este permite uma análise que usa metodologia de modelos para população fechada e aberta conjuntamente. Considere a representação de um experimento de amostragem de captura-recaptura dada pela Figura 2 , onde se têm $\mathrm{S}$ períodos de amostragem primários (por exemplo, anos) e dentro de cada um desses, I periodos de amostragem secundários que são fechados no tempo (por exemplo 1 dias consecutivos de capturas).

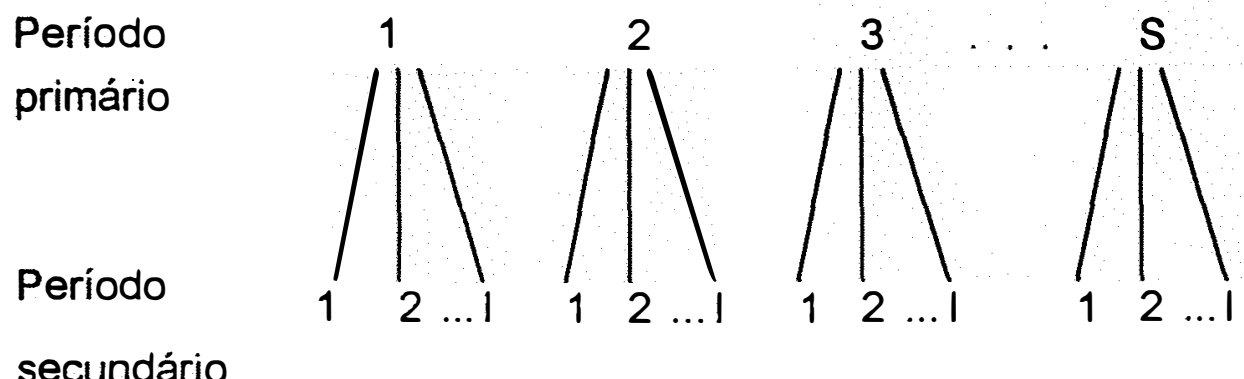

Figura 2 - Esquema para amostragem através do delineamento robusto.

Nesta situação o interesse é estimar o tamanho da população para cada período de amostragem primário $\left(\mathrm{N}_{1}, \mathrm{~N}_{2}, \ldots, \mathrm{N}_{\mathrm{S}}\right)$ assumindo que a população é constante sobre os períodos de amostragem secundários dentro de cada período de amostragem primário. Além disso, é de interesse estimar as taxas de nascimento e sobrevivência entre os períodos de amostragem primários indicadas por $\mathrm{B}_{1}, \mathrm{~B}_{2}, \ldots, \mathrm{B}_{\mathrm{S}-1}$ e $\phi_{1}, \phi_{2}, \ldots, \phi_{\mathrm{S}-1}$, respectivamente. 
Desta forma, dois procedimentos de estimação são possíveis de serem utilizados:

1. Através do modelo J-S: sob este procedimento, todos os períodos de amostragem secundários dentro do período de amostragem primário seriam agrupados, ou seja, os registros de captura indicarão se um animal é capturado ao menos uma vez ou não capturado em cada período de amostragem secundário. Amason \& Baniuk5 (1978) citados por POLLOCK (1982) sugerem o agrupamento com o propósito de aumentar a precisão quando as probabilidades de captura são baixas.

2. Delineamento robusto: este procedimento tenta minimizar a influência da desigual "catchability" nos estimadores através da exploração dos dois níveis de amostragem. Como os estimadores da taxa de sobrevivência são menos afetados pela desigual "catchability" do que os estimadores do tamanho da população, eles são estimados por meio do modelo J-S que assume igual "catchability", exatamente como descrito anteriormente. Alternativamente, estimadores do tamanho da população para cada período de amostragem primário $\left(\mathrm{N}_{1}, \ldots, \mathrm{N}_{\mathrm{S}}\right)$ serão obtidos utilizando modelos para população fechada permitindo desigual "catchability" e baseados apenas nas capturas e recapturas dentro do período de amostragem primário. Neste caso, os estimadores são disponiveis para todos os períodos primários $(i=1, \ldots, S)$, enquanto sob $o$ modelo J-S estão disponíveis somente para $\mathrm{i}=2, \ldots, \mathrm{S}-1$.

Os estimadores da taxa de nascimento são obtidos agora utilizando estes estimadores do tamanho da população, sendo, portanto, possível

${ }^{5}$ ARNASON, A.N. \& BANIUK, L. POPAN-2, a data maintenance and analysis system for recapture data. Charles Babbage Res. Cent. St. Pierre, Manitoba, 1978. 269pp. 
obter estimativas para $\mathrm{B}_{1}, \ldots, \mathrm{B}_{\mathrm{S}-2}$ enquanto sob o modelo J-S é possível apenas estimar $B_{2}, \ldots, B_{s-2}$.

Um exemplo apresentado por POLLOCK (1982) mostra que as estimativas produzidas pelo estimador "jacklnife" é o dobro das estimativas obtidas pelo estimador de Jolly-Seber, numa população com forte grau de heterogeneidade. Isso, certamente, destaca a importância prática do delineamento robusto. Entretanto, a maior dificuldade em usar este delineamento é decorrente do estudo de OTIS et al. (1978), os quais sugeriram que os modelos para população fechada exigem de 5 a 10 ocasiões de amostragem com probabilidade de captura média de ao menos 0,1 por período para que se obtenham resultados razoáveis. Assim, o caso mais simples seria formado por 3 períodos primários cada um contendo 5 períodos de amostragem secundários. 


\section{MATERIAL}

\subsection{Caracterização da área de estudo}

O Pantanal é uma área inundavél, com cerca de $140.000 \mathrm{~km}^{2}$, localizada próxima do centro da América do Sul. Além do grande número de espécies animais e vegetais, é constituído por depósitos sedimentares de origem relativamente recente, e é caracterizado pelo mosaico de áreas inundáveis e nãoinundáveis (locais de solos mais altos). A região é drenada pelos tributários do rio Paraguai que fluem em direção ao sul da borda oeste do Pantanal. A declividade do solo é cerca de $6-12 \mathrm{~cm} / \mathrm{km}$ no sentido leste-oeste e $1-2 \mathrm{~cm} / \mathrm{km}$ no sentido norte-sul (BRASIL, 1982). O clima é caracterizado por verão quente e úmido e inverno morno e seco, os quais são interrompidos por ocasionais frentes frias oriundas do sul.

Embora o Pantanal possa ser considerado um simples macrosistema, os nativos da região o reconhecem como um habitat de grande diversidade. ADAMOLI (1981) formalmente dividiu a área em dez sub-regiões. No centro meridional do Pantanal foi reconhecida a sub-região chamada Nhecolândia, que é limitada ao norte pelo Rio Taquari e ao sul pelo Rio Negro. A sub-região da Nhecolândia é caracterizada por solos arenosos e é classificada como uma área moderadamente inundável, com níveis de inundação variando de poucos centímetros a cerca de 3 metros. Os dados utilizados neste trabalho foram 
obtidos na fazenda Nhumirim (4300 ha, $18^{\circ} 59^{\prime} \mathrm{S}$ e $56^{\circ} 39^{\prime} \mathrm{W}$; Figura 3.), uma área representativa da parte mais alta do Pantanal da Nhecolândia. A fazenda é constituída por cerca de 100 pequenas lagoas sendo que a maioria apresenta profundidade de 0,5-2,0 metros.

Estas lagoas variam grandemente em suas características limnológicas, mas podem ser grosseiramente classificadas por águas mineralizadas, alcalínas $(\mathrm{pH}=9,5)$; sua vegetação aquática é donominada por algas verde-azuis e as vezes por macroalgas submersas do gênero Chara e Nitella. As "Baias", por outro lado, contêm uma rica quantidade de macrofitas aquáticas, com ampla variação na composição florística e biomassa. Seu pH está no intervalo de aproximadamente 5,1 a 8,5 (MOURÃO, 1989). 


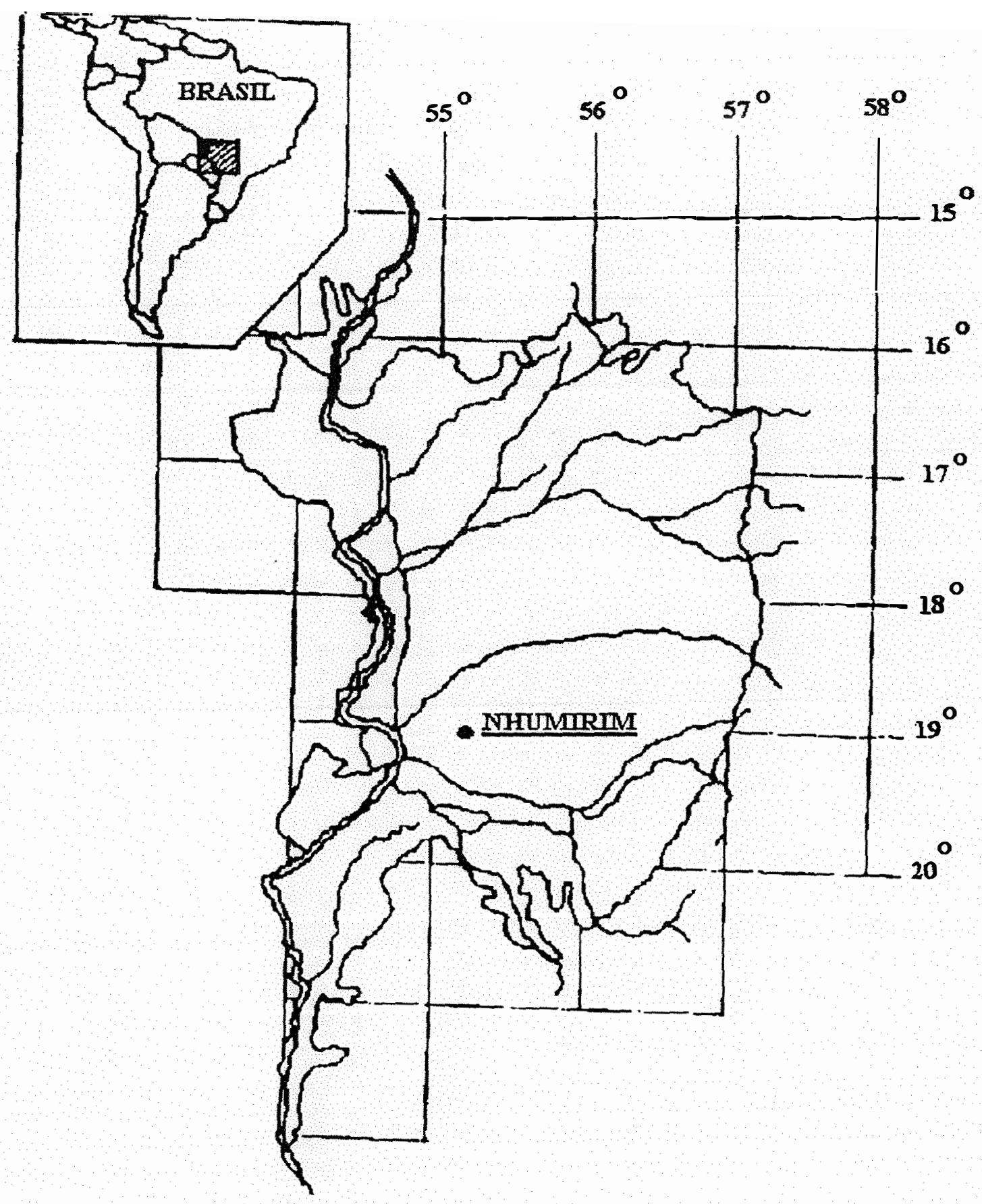

Figura 3 - Área de estudo na fazenda Nhumirim localizada no Pantanal da Nhecolândia, Mato Grosso do Sul. O Rio Paraguai é marcado com linhas duplas, e os tributários com linhas simples. 


\subsection{Descrição do experimento}

Os dados que foram utilizados neste trabalho são resultados de um experimento desenvolvido por MOURÃO et al. (no prelo), na Fazenda Nhuminim. Os animais foram capturados ou recapturados durante os anos de 1987 a 1991 em quase todas as lagoas da fazenda. Como pode ser observado na Figura 4, o esforço de captura se concentrou principalmente nos anos de 1987 e 1989.

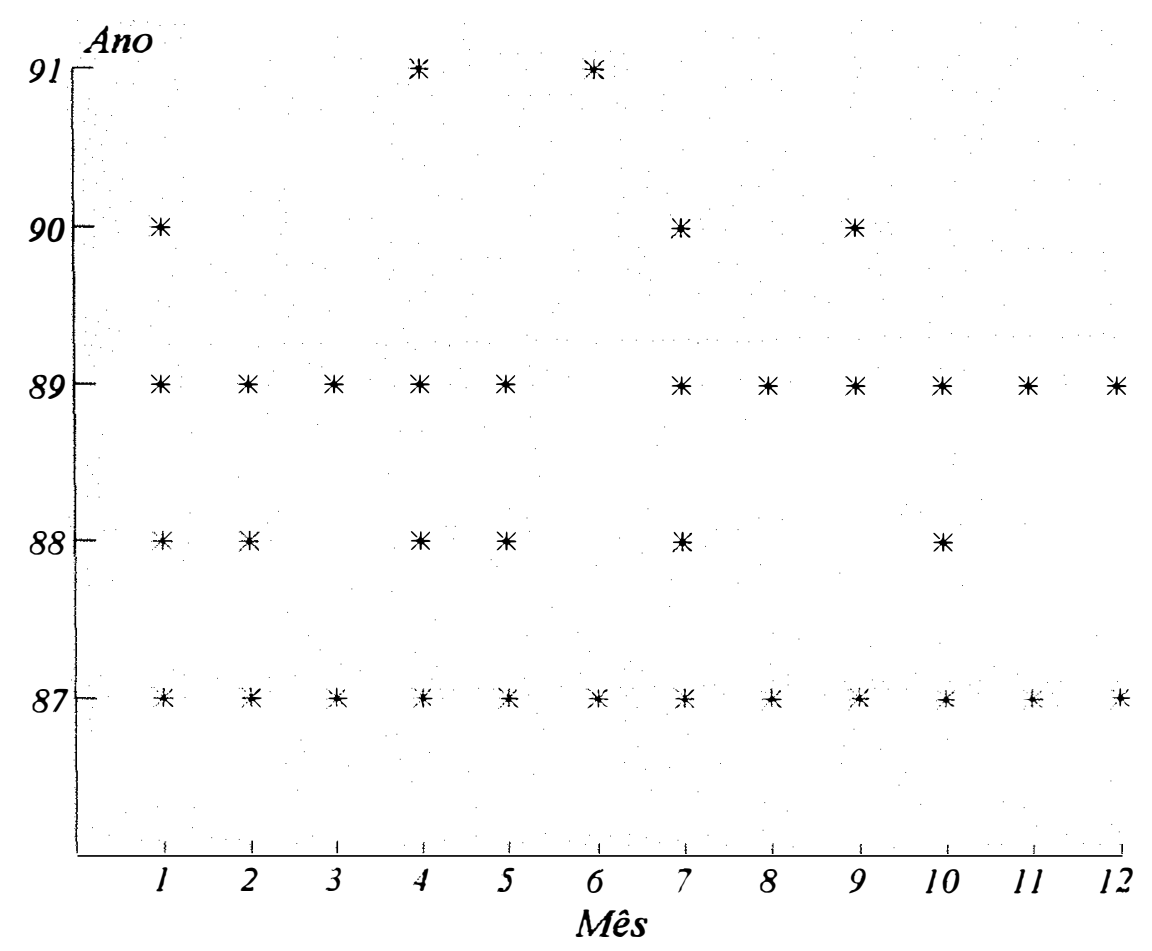

Figura 4 - Esforço de captura do experimento.

A captura foi realizada à noite tendo sido os animais focalizados com refletor e capturados manualmente ou através de um dispositivo de laço, conforme ilustrado nas Figuras 5 e 6. 

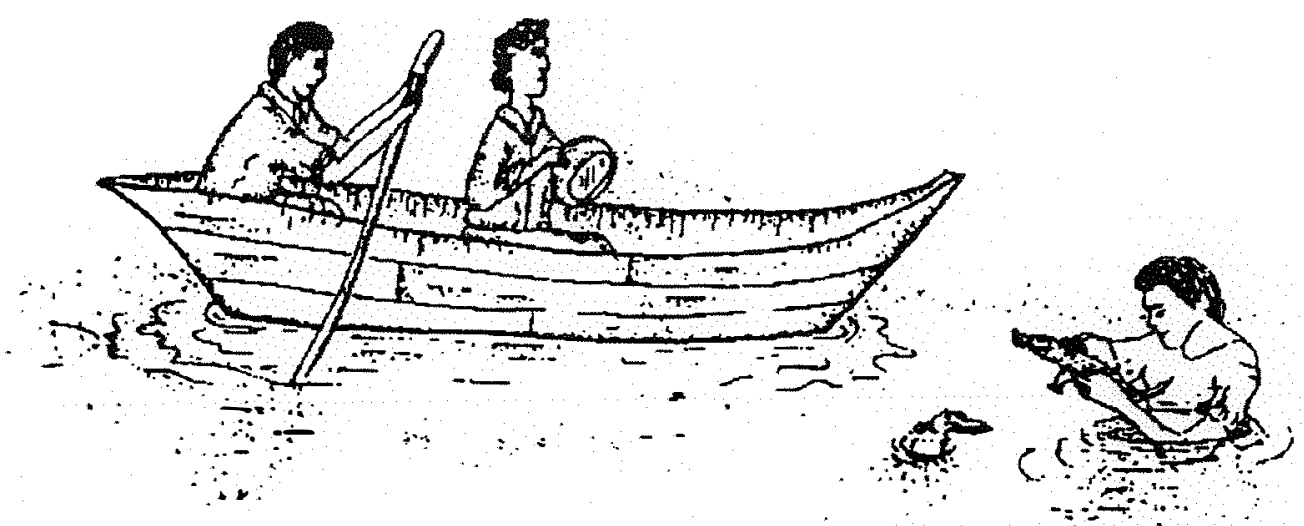

$-1=$

Figura 5 - Captura manual de animais.

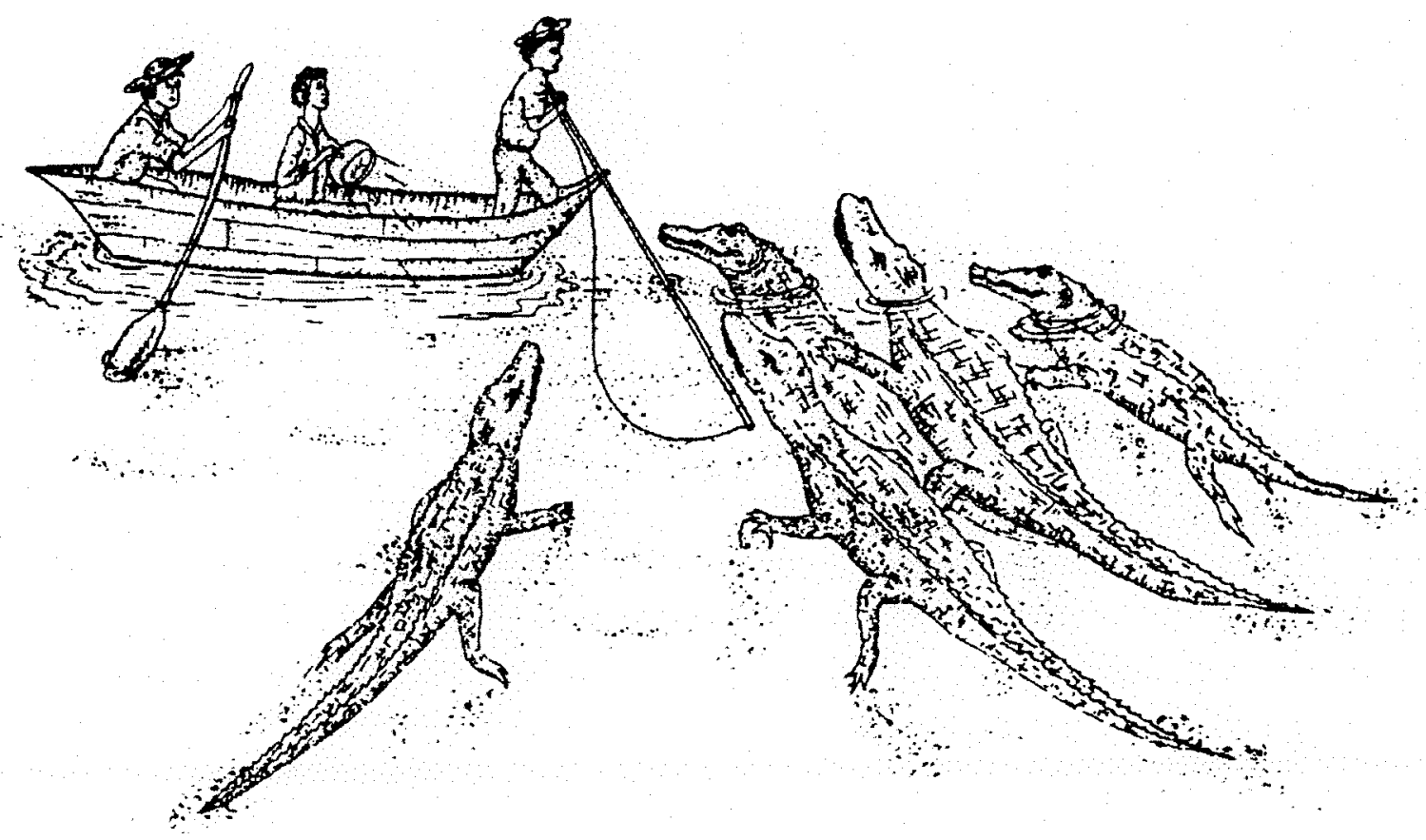

Figura 6 - Captura de animais através de laço. 
Cada animal capturado foi individualmente marcado pela remoção de uma única combinação de escamas caudais, de tal forma que todo animal capturado possuía uma marca diferente. Além disso, foram tomadas medidas biométricas e determinado o sexo. Todos os animais eram devolvidos à população na noite de captura, e no local onde foram encontrados. 


\section{MÉTODOS}

\subsection{Descrição do método}

Uma abordagem alternativa ao enfoque multinomial clássico, usando modelos log-lineares, para análise de experimentos de captura-recaptura em populações fechadas foi proposta por FIENBERG (1972) e posteriormente aplicada em populações abertas por CORMACK (1979). BISHOP et al. (1975) apresentaram modelos log-lineares para população fechada em múltiplas ocasiões de amostragens.

EVANS et al. (1994) apresentaram uma teoria geral para modelagem em populações fechadas utilizando modelos log-lineares, tratando melhor o problema de heterogeneidade e resposta à armadilha através da estratificação da população subjacente às amostras, entretanto, citam a dificuldade em usar o método, no presente, pela falta de software.

CORMACK (1989) desenvolveu modelos log-lineares para os modelos $M_{o}, M_{t}, M_{b}$ e $M_{t b}$ e para o modelo Jolly-Seber, onde apresenta vantagens e desvantagens do uso deste método.

Um experimento de captura-recaptura com $\mathrm{S}$ ocasiões de amostragem apresenta $t=\left(2^{s}-1\right)$ diferentes padrões de observação dos animais. Naturalmente as freqüências de cada padrão podem ser consideradas como contagens observadas $r_{a}$ de um número de classes mutuamente exclusivas 
$(a=1, \ldots, t)$ como realizações da variável aleatória $R_{\mathfrak{a}}$ com esperança $m_{a}$, podendo $l_{a}=\log m_{a}$ ser escrita como uma função linear conhecida de um conjunto de parâmetros desconhecidos $k_{a b} \theta_{b}$, ou matricialmente por $\mathbf{l}=\mathbf{K} \theta$, onde $\mathbf{K}$ é a matriz do modelo.

Inferência sobre $\theta_{b}$ é baseada no estimador de máxima verossimilhança, assumindo-se que $\mathrm{R}_{\mathrm{a}}$ é uma variável aleatória com distribuição de Poisson ou multinomial.

Assim o modelo geral é dado por,

$$
l_{a}=\log m_{i_{1} i_{2} \ldots i_{s}}=u+u_{1\left(i_{1}\right)}+\ldots+u_{s\left(i_{s}\right)}+\sum u_{\alpha \beta\left(i_{\alpha} i_{\beta}\right)}+\ldots+u_{1 \ldots s\left(i_{1} i_{2} \ldots i_{s}\right)}
$$

onde

u corresponde à média geral (intensidade de amostragem média);

$\mathrm{u}_{\alpha\left(\mathrm{i}_{\alpha}\right)}$ corresponde aos efeitos principais de cada ocasião de amostragem (intensidade de amostragem), $\operatorname{com} \alpha=1, \ldots, \mathrm{s}$.

$\mathrm{u}_{\alpha \beta\left(\mathrm{i}_{\alpha} \mathrm{i}_{\beta}\right)}$ corresponde às interações de primeira ordem ou dependências de ocasiões de amostragem, $\operatorname{com} \alpha=1, \ldots, \mathrm{s}-1$ e $\beta=2, \ldots, \mathrm{s}$

$\mathrm{u}_{1 \ldots s\left(\mathrm{i}_{1} \mathrm{i}_{2} \ldots \mathrm{i}_{\mathrm{s}}\right)}$ corresponde à interação de mais alta ordem.

Com $2^{\mathrm{s}}$ categorias existe somente um parâmetro independente para cada efeito principal e um para cada interação, exatamente como no modelo para um experimento fatorial $2^{n}$, enquanto que a interação de mais alta ordem é assumida ser zero já que $r_{22 \ldots .}$ não é observável.

Desta forma, esta representação equivaie a uma reparametrização do modelo multinomial com $\left(2^{\mathrm{s}}-1\right)$ parâmetros em ambos os 
lados da equação (1), e modelos exibindo diferentes graus de dependência podem ser formulados hierarquicamente.

Assim, por exemplo, definindo o efeito principal de uma amostra particular como o contraste entre o número de animais não vistos naquela amostra, mas vistos em todas as outras com aqueles vistos em todas as amostras, tem-se o modelo geral apresentado para a Tabela 4.

Tabela 4 - Representação de um experimento de captura-recaptura três ocasiões através de uma tabela de contingência completa.

\begin{tabular}{c|c|c|c|c}
\hline \multirow{2}{*}{$3^{\mathrm{a}}$} & \multicolumn{3}{|c}{$1^{\mathrm{a}}$ Amostra } \\
\cline { 2 - 5 } Amostra & \multicolumn{2}{|c|}{ Presente } & \multicolumn{2}{c}{ Ausente } \\
\cline { 2 - 5 } & \multicolumn{2}{|c|}{$2^{\mathrm{a}}$ Amostra } & \multicolumn{2}{c}{$2^{\mathrm{a}}$ Amostra } \\
\cline { 2 - 5 } & Presente & Ausente & Presente & Ausente \\
\hline Presente & $\mathrm{m}_{111}$ & $\mathrm{~m}_{121}$ & $\mathrm{~m}_{211}$ & $\mathrm{~m}_{221}$ \\
\hline Ausente & $\mathrm{m}_{112}$ & $\mathrm{~m}_{122}$ & $\mathrm{~m}_{212}$ & $\mathrm{~m}_{222}$ \\
\hline
\end{tabular}

Neste caso, o modelo geral é dado por

$$
1_{i_{1} i_{2} i_{3}}=\log m_{i_{1} i_{2} i_{3}}=u+u_{1\left(i_{1}\right)}+u_{2\left(i_{2}\right)}+u_{3\left(i_{3}\right)}+u_{12\left(i_{1} i_{2}\right)}+u_{23\left(i_{2} i_{3}\right)}+u_{13\left(i_{1} i_{3}\right)}+u_{123\left(i_{1} i_{2} i_{3}\right)}
$$

onde, para a parametrização proposta, tem-se:

$\mathrm{i}_{1}=0$, se o animal é visto na primeira ocasião;

$\mathrm{i}_{1}=1$, se o animal não é visto na primeira ocasião;

$\mathrm{i}_{2}=0$, se o animal é visto na segunda ocasião;

$\mathrm{i}_{2}=1$, se o animal não é visto na segunda ocasião; 
$\mathrm{i}_{3}=0$, se o animal é visto na terceira ocasião;

$\mathrm{i}_{3}=1$, se o animal não é visto na terceira ocasião;

obtendo-se, assim, as seguintes combinações lineares de parâmetros u's, associadas a cada história de captura.

$$
\begin{aligned}
& l_{111}=u \text {; } \\
& l_{211}=u+u_{1} \\
& 1_{121}=\mathrm{u}+\mathrm{u}_{2} \text {; } \\
& l_{221}=u+u_{1}+u_{2}+u_{12} ; \\
& \mathrm{l}_{112}=\mathrm{u}+\mathrm{u}_{3} ; \\
& \mathrm{l}_{212}=\mathrm{u}+\mathrm{u}_{1}+\mathrm{u}_{3}+\mathrm{u}_{13} \\
& \mathrm{l}_{122}=\mathrm{u}+\mathrm{u}_{2}+\mathrm{u}_{3}+\mathrm{u}_{23} \text {; } \\
& \mathrm{l}_{222}=\mathrm{u}+\mathrm{u}_{1}+\mathrm{u}_{2}+\mathrm{u}_{12}+\mathrm{u}_{3}+\mathrm{u}_{13}+\mathrm{u}_{23}+\mathrm{u}_{123} \text {. }
\end{aligned}
$$

Como $r_{222}$ é não observável, o modelo $l_{222}$ não é definido, de tal forma que existem 7 observações modeladas por 7 parâmetros, pois $u_{123}$ não aparece. Assim, se o modelo sem interação entre a primeira e terceira amostras é selecionado, então,

$$
\mathbf{u}_{13}=0
$$

e esta restrição é refletida na relação,

$$
1_{212}+1_{111}=1_{211}+1_{112}
$$

mas

$$
\ln \mathrm{m}_{212}+\ln \mathrm{m}_{111}=\ln \mathrm{m}_{211}+\ln \mathrm{m}_{112}
$$




$$
\ln \left(\mathrm{m}_{212} \mathrm{~m}_{111}\right)=\ln \left(\mathrm{m}_{211} \mathrm{~m}_{112}\right)
$$

ou

$$
\frac{\mathrm{m}_{211}}{\mathrm{~m}_{111}}=\frac{\mathrm{m}_{212}}{\mathrm{~m}_{112}}
$$

que é preferivel à relação mais usual entre totais marginais dada por:

$$
\frac{m_{2+1}}{m_{1+1}}=\frac{m_{2+2}}{m_{1+2}}
$$

onde

$$
\begin{aligned}
& \mathrm{m}_{1+2}=\mathrm{m}_{112}+\mathrm{m}_{122} \\
& \mathrm{~m}_{2+1}=\mathrm{m}_{211}+\mathrm{m}_{221} \\
& \mathrm{~m}_{2+2}=\mathrm{m}_{212}+\mathrm{m}_{222} \\
& \mathrm{~m}_{1+1}=\mathrm{m}_{111}+\mathrm{m}_{121}
\end{aligned}
$$

A relação marginal é menos fácil de ser manuseada pelo fato que $r_{222}$ não sendo observável implica que os $r_{2+2}, r_{22+}, r_{+22}, r_{++2}, r_{+2+}$, e $r_{2++}$ não o são também.

Desde que são $t=\left(2^{s}-1\right)$ observações, qualquer modelo pode conter no máximo ( $\left.2^{s-1}\right)$ parâmetros, e tem-se interesse em escolher aqueles que tenham uma interpretação biológica natural, representando, na medida do possível, diferentes aspectos da dinâmica da população em estudo e do processo de amostragem empregado.

Esta parametrização é a mesma utilizada pelo pacote estatístico GLIM (PAYNE, 1986), conforme pode ser visto em AGRESTI (1990), e a correspondência um a um entre parâmetros do GLIM e funções de parâmetros biológicos para alguns modelos foi estabelecida por CORMACK (1989), de tal 
forma que inferências sobre parâmetros do GLIM podem ser convertidas em inferências sobre parâmetros biológicos.

Por exemplo, num estudo consistindo de três ocasiões de amostragens para estimar o tamanho de uma população fechada na qual as probabilidades de um animal ser observado nas três amostras são $\mathrm{p}_{1}, \mathrm{p}_{2}$ e $\mathrm{p}_{3}$ independentemente de ele ter sido avistado em qualquer outra amostra, os valores esperados são,

$$
\begin{aligned}
& \mathrm{m}_{111}=\mathrm{Np} \mathrm{p}_{1} \mathrm{p}_{3}, \\
& \mathrm{~m}_{211}=\mathrm{N}\left(1-\mathrm{p}_{1}\right) \mathrm{p}_{2} \mathrm{p}_{3}, \\
& \mathrm{~m}_{121}=\mathrm{Np_{1 }}\left(1-\mathrm{p}_{2}\right) \mathrm{p}_{3}, \\
& \mathrm{~m}_{221}=\mathrm{N}\left(1-\mathrm{p}_{1}\right)\left(1-\mathrm{p}_{2}\right) \mathrm{p}_{3}, \\
& \mathrm{~m}_{112}=\mathrm{Np} \mathrm{p}_{1} \mathrm{p}_{2}\left(1-\mathrm{p}_{3}\right), \\
& \mathrm{m}_{212}=\mathrm{N}\left(1-\mathrm{p}_{1}\right) \mathrm{p}_{2}\left(1-\mathrm{p}_{3}\right), \\
& \mathrm{m}_{122}=\mathrm{N} \mathrm{p}_{1}\left(1-\mathrm{p}_{2}\right)\left(1-\mathrm{p}_{3}\right),
\end{aligned}
$$

então,

$$
\mathrm{u}=\mathrm{l}_{111}=\log \left(\mathrm{Np}_{1} \mathrm{p}_{2} \mathrm{p}_{3}\right)
$$

e,

tomando taxas de outros termos em relação a $m_{111}$, tem-se, $u_{i}=\log \left(1-p_{i}\right) / p_{i} \quad$ e $\quad u_{i j}=0$ 
Assim, estimativas de $p_{i}$ são encontradas por

$$
p_{i}=\frac{1}{1+e^{u_{i}}}
$$

e estas então substituídas em (2) para obter a estimativa de $\mathrm{N}$ em termos das estimativas dos parâmetros do GLIM.

\subsection{Caracterização através de modelos lineares generalizados}

Esta classe de modelos é uma extensão de modelos lineares clássicos e foi desenvolvida por NELDER \& WEDDERBURN (1972). Na realidade, eles mostraram que uma série de técnicas comumente estudadas separadamente podem ser reunidas sob o nome de modelos lineares generalizados. Assim os modelos log-lineares são casos especiais de MLG (CORDEIRO, 1986 e DEMÉTRIO, 1993).

Para um experimento de captura-recaptura as freqüências observadas dos padrões de captura $R_{1}, R_{2}, \ldots, R_{t}$ são variáveis aleatórias independentes com médias $\mathrm{m}_{1}, \mathrm{~m}_{2}, \ldots, \mathrm{m}_{\mathrm{t}}$, isto é,

$$
E\left(R_{a}\right)=m_{a}, a=1,2, \ldots, t
$$

e tais que $R_{\mathrm{a}}$ tem distribuição pertencente à família exponencial com as seguintes propriedades:

1) a distribuição de cada $R_{a}$ é da forma canônica e depende de um único parâmetro $\theta_{\mathrm{a}}$, isto é,

$$
f\left(r_{a} ; \theta_{a} ; \phi\right)=\exp \left\{\frac{1}{a(\phi)}\left[r a \theta_{a}-b\left(\theta_{a}\right)+c\left(r_{a} ; \phi\right)\right]\right\},
$$


onde

b(.) e c(.) são funções conhecidas;

$\theta_{\mathrm{a}}$ é chamado parâmetro natural da família exponencial e, em geral, $\mathrm{a}(\phi)=\frac{\phi}{\mathrm{W}}$, sendo $\phi$ chamado parâmetro de dispersão. Além disso, tem-se que,

$$
E\left(R_{a}\right)=m_{a}=b^{\prime}\left(\theta_{a}\right)
$$

e

$\operatorname{Var}\left(R_{a}\right)=a(\phi) b "(\theta a)=a(\phi) V\left(m_{a}\right)=a(\phi) V_{a}$,

onde $V_{a}=d_{a} / d_{a}$ é chamada função de variância, e como depende unicamente da média tem-se que o parâmetro natural pode ser expresso como:

$$
\theta_{\mathrm{a}}=\int \mathrm{V}_{\mathrm{a}}^{-1} \mathrm{dm} \mathrm{m}_{\mathrm{a}}=\mathrm{q}\left(\mathrm{m}_{\mathrm{a}}\right),
$$

onde $\mathrm{q}\left(\mathrm{m}_{\mathrm{a}}\right)$ é uma função de $\mathrm{m}_{\mathrm{a}}$, conhecida.

Assim, assumindo que cada $\mathrm{R}_{\mathrm{a}}$ tem distribuição de Poisson com parâmetro $\mathrm{ma}_{\mathrm{a}}$, tem-se,

$$
f\left(r_{a} ; m_{a}\right)=\frac{m_{a} e^{-m_{a}}}{r_{a} !} I_{A}^{\left(r_{a}\right)}, m_{a}>0
$$

onde $A=\{0,1,2, \ldots\}$

ou na forma canônica

$$
f\left(r a ; m_{a}\right)=\exp \left\{r_{a} \ln m_{a}-m_{a}-\ln r_{a} !\right\}
$$

Assim,
$\mathrm{a}(\phi)=1$
$\mathrm{b}(\theta)=\mathrm{ma}_{\mathrm{a}}=\mathrm{e}^{\theta_{\mathrm{a}}}$
$\theta_{\mathrm{a}}=\ln \mathrm{m}_{\mathrm{a}}$
$c\left(r_{a} ; \phi\right)=-\ln r_{a}$

ii) As distribuições de todos ra's são da mesma forma. 
Para a especificação do modelo, os parâmetros $\theta_{\mathrm{a}}$ não são de interesse direto (desde que há um para cada observação) e sim um conjunto menor de parâmetros $\beta_{1}, \beta_{2}, \ldots, \beta_{\mathrm{p}}(\mathrm{p}<\mathrm{t})$ tais que uma combinação linear de parâmetros $\beta$ ‘s é igual a alguma função do valor esperado de $r_{a}$, isto é,

$$
g\left(m_{a}\right)=\sum_{b=1}^{p} X_{a b} \beta_{b}=\underset{\sim}{X} \underset{\sim}{\beta},
$$

onde

(i) $g($.$) é uma função monótona, derivável chamada função de ligação;$

(ii) $X a^{\prime}$ é um vetor ( $\mathrm{px} 1$ ) que define aspectos da dinâmica da população e procedimento de amostragem no número esperado de animais com histórias de captura a (iii) $\beta$ é o vetor ( $\mathrm{px} 1)$ de parâmetros, isto é,

$$
\underline{\beta}^{\prime}=\left(\beta_{1}, \beta_{2}, \ldots, \beta_{p}\right)
$$

O modelo linear generalizado é, neste caso, então definido por:

a) Um componente aleatório representado pelas variáveis aleatórias independentes $R_{1}, R_{2}, \ldots, R_{t}$ provenientes da distribuição de Poisson que faz parte da família exponencial.

b) Um componente sistemático linear nos parâmetros, chamado preditor linear

$$
\underline{\eta}=X \cdot \underline{\beta}
$$

onde

$\underline{\eta^{\prime}}=\left(\eta_{1}, \eta_{2}, \ldots, \eta_{\mathrm{t}}\right)$, conjunto dos preditores lineares para cada $\mathrm{r}_{\mathrm{a}}$.

$\underline{\beta}^{\prime}=\left(\beta_{1}, \beta 2, \ldots, \beta p\right)$, parâmetros associados à matriz $X$.

$X^{\prime}=\left(X_{1}, X_{2}, \ldots, X_{1}\right)$, matriz do modelo especificando aspectos da dinâmica

da população e do processo de amostragem. 
c) Uma função de ligação g(.) tal que,

$$
\eta_{\mathrm{a}}=\mathrm{g}\left(\mathrm{m}_{\mathrm{a}}\right)
$$

onde

$$
\mathrm{m}_{\mathrm{a}}=\mathrm{E}\left(\mathrm{R}_{\mathrm{a}}\right)
$$

e como,

$$
\begin{gathered}
\eta_{\mathrm{a}}=\ln \mathrm{m}_{\mathrm{a}} \\
\eta_{\mathrm{a}}=\mathrm{g}\left(\mathrm{m}_{\mathrm{a}}\right)=\ln \left(\mathrm{m}_{\mathrm{a}}\right)
\end{gathered}
$$

ou seja, a função logarítmica lineariza $\mathrm{m}_{\mathbf{a}}$.

Logo, este modelo, é baseado na família exponencial com um parâmetro desconhecido, cujas médias são não lineares num conjunto de parâmetros lineares, isto é,

$$
\mathrm{m}_{\mathrm{a}}=\mathrm{e}^{\eta_{\mathrm{a}}}=\exp (\underset{\sim \mathrm{a}}{\mathrm{X}} \underset{\sim}{\beta})
$$

Logo, considerando o modelo log-linear dado por,

$$
\eta_{\mathrm{a}}=\ln \mathrm{E}\left(\mathrm{r}_{\mathrm{a}}\right)=\underset{\sim \mathrm{a}}{\mathrm{X}} \underset{\sim}{\beta}
$$

um meio para estimar as freqüências esperadas é estimando primeiro $\beta$ e então pela propriedade de invariância dos estimadores de máxima verossimilhança estimar os $n_{a}$ 's e os $m_{a}{ }^{\prime} s=\exp \left(n_{a}{ }^{\prime} s\right)$.

O algoritmo de estimação para esse modelo fica,

$$
X \cdot W^{(m)} X \beta^{(m+1)}=X \cdot W^{(m)} r^{*(m)}
$$


onde

$$
\begin{gathered}
\mathrm{W}=\operatorname{diag}\left(\mathrm{m}_{1}, \mathrm{~m}_{2}, \ldots, \mathrm{m}_{\mathrm{t}}\right) \mathrm{e} \\
\stackrel{\sim}{\mathrm{r}}^{*}=\underset{\sim}{\mathrm{n}}+\mathrm{W}^{-1}(\underset{\sim}{\mathrm{r}}-\underset{\sim}{\mathrm{m}})
\end{gathered}
$$

ou ainda, escrevendo-se o logaritmo da função de verossimilhança em função de $\underset{\sim}{\mathrm{m}}$ e fazendo-se

$$
\frac{\partial l(m)}{\partial m}=0,
$$

obtém-se

$$
X^{\prime} \underset{\sim}{\mathrm{m}}=\mathrm{X}^{\prime} \underset{\sim}{\mathrm{r}}
$$

O resíduo de Pearson é obtido por

$$
p_{a}=\frac{r_{a}-\hat{m_{a}}}{\sqrt{\hat{m_{a}}}}
$$

4.3. Aplicação no modelo Mtb de OTIS et al. (1978)

Seja,

$\mathrm{p}_{\mathrm{i}}$, a probabilidade de um animal ser capturado pela primeira vez na i-ésima amostra;

$\mathrm{c}_{\mathrm{i}}$, a probabilidade de um animal ser capturado na i-ésima amostra dado que ele foi capturado previamente. 
Com $S=3$, tem-se

$$
\begin{aligned}
& \mathrm{m}_{11}=\mathrm{Np} \mathrm{p}_{1} \mathrm{c}_{2} \mathrm{c}_{3} \\
& \mathrm{~m}_{211}=\mathrm{N}\left(1-\mathrm{p}_{1}\right) \mathrm{p}_{2} \mathrm{c}_{3} \\
& \mathrm{~m}_{121}=\mathrm{Np} \mathrm{p}_{1}\left(1-\mathrm{c}_{2}\right) \mathrm{c}_{3} \\
& \mathrm{~m}_{221}=\mathrm{N}\left(1-\mathrm{p}_{1}\right)\left(1-\mathrm{p}_{2}\right) \mathrm{p}_{3} \\
& \mathrm{~m}_{112}=\mathrm{Np} \mathrm{p}_{1}\left(1-\mathrm{c}_{3}\right) \\
& \mathrm{m}_{212}=\mathrm{N}\left(1-\mathrm{p}_{1}\right) \mathrm{p}_{2}\left(1-\mathrm{c}_{3}\right) \\
& \mathrm{m}_{122}=\mathrm{Np} \mathrm{p}_{1}\left(1-\mathrm{c}_{2}\right)\left(1-\mathrm{c}_{3}\right)
\end{aligned}
$$

Assim,

$$
\begin{gathered}
\frac{m_{211}}{m_{111}}=\frac{\left(1-p_{1}\right) p_{2}}{p_{1} c_{2}}, \frac{m_{121}}{m_{11}}=\frac{\left(1-c_{2}\right)}{c_{2}}, \frac{m_{112}}{m_{11}}=\frac{\left(1-c_{3}\right)}{c_{3}}, \\
\frac{m_{221}}{m_{121}}=\frac{\left(1-p_{1}\right)\left(1-p_{2}\right) p_{3}}{p_{1}\left(1-c_{2}\right) c_{3}}, \frac{m_{212}}{m_{112}}=\frac{\left(1-p_{1}\right) p_{2}}{p_{1} c_{2}}=\frac{m_{211}}{m_{111}}, \frac{m_{122}}{m_{112}}=\frac{\left(1-c_{2}\right)}{c_{2}}=\frac{m_{121}}{m_{11}},
\end{gathered}
$$

de tal forma que a correspondência entre os parâmetros do GLIM e parâmetros biológicos são mostrados na Tabela 5 . 
Tabela 5 - Correspondência entre parâmetros do GLIM e parâmetros biológicos para o modelo $\mathrm{M}_{\mathrm{tb}}$ de OTIS et al. (1978), com $\mathrm{S}=3$.

\begin{tabular}{lll} 
Nome do GLIM & Parâmetros do GLIM & Parâmetros biológicos \\
\hline Média Geral & $\mathrm{u}$ & $\log \left(N \mathrm{p}_{1} \mathrm{c}_{2} \mathrm{c}_{3}\right)$ \\
Efeitos Principais & $\mathrm{u}_{1}, \mathrm{u}_{2}, \mathrm{u}_{3}$ & $\begin{array}{l}\log \left[\left(1-\mathrm{p}_{1}\right) \mathrm{p}_{2} /\left(\mathrm{p}_{1} \mathrm{c}_{2}\right)\right], \log \left[\left(1-\mathrm{c}_{2}\right) / \mathrm{c}_{2}\right], \\
\end{array}$ \\
$\begin{array}{lll}\log \left[\left(1-\mathrm{c}_{3}\right) / \mathrm{c}_{3}\right] \\
\text { Interações }\end{array}$ & $\mathrm{u}_{12}$ & $\log \left\{\left(1-\mathrm{p}_{2}\right) \mathrm{c}_{2} \mathrm{p}_{3} /\left[\mathrm{p}_{2}\left(1-\mathrm{c}_{2}\right) \mathrm{c}_{3}\right]\right\}$ \\
& $\mathrm{u}_{13}, \mathrm{u}_{23}$ & 0 \\
\hline
\end{tabular}

Fonte: CORMACK (1989).

\subsection{Aplicação no modelo Jolly-Seber para população aberta}

Seja,

$\mathrm{p}_{\mathrm{i}}$, a probabilidade de captura de um animal não marcado na i-ésima amostra;

$\phi_{\mathrm{i}}$, a probabilidade de um animal sobreviver da i-ésima para (i+1)-ésima amostra;

$\chi_{\mathrm{i}}$, a probabilidade que um animal não seja visto após a i-ésima amostra;

$\mathrm{B}_{\mathrm{i}}$, número de novos animais para a população entre a i-ésima e a (i+1)-ésima amostras, definido por,

$\mathrm{B}_{\mathrm{i}}=\mathrm{N}_{\mathrm{i}}\left(1-\mathrm{P}_{\mathrm{i}}\right) \phi_{\mathrm{i}} \psi_{\mathrm{i}}$ 
onde

$1 / \psi_{\mathrm{i}}$, é a probabilidade que um animal vivo e não marcado na população no momento da (i+1)-ésima amostra estava na população no momento da i-ésima amostra;

e fazendo,

$$
\lambda_{i}=\chi_{i} /\left[\phi_{i}\left(1-P_{i+1}\right) \chi_{i+1}\right]
$$

$1 / \lambda_{\mathrm{i}}$, é a probabilidade que um animal vivo na população no momento da i-ésima amostra mas não observado em ocasiões subsequentes, ainda esteja vivo na população no momento da (i+1)-ésima amostra.

Desta forma, para um experimento com três amostras, $S=3$, o número esperado de animais para cada história de captura é parametrizado por:

$$
\begin{aligned}
& \mathrm{m}_{111}=N p_{1} \phi_{1} \mathrm{p}_{2}\left(1-\chi_{2}\right) \\
& \mathrm{m}_{211}=\mathrm{N}\left(1-\mathrm{p}_{1}\right) \phi_{1} \psi_{1} \mathrm{p}_{2}\left(1-\chi_{2}\right) \\
& \mathrm{m}_{121}=\mathrm{N} \mathrm{p}_{1} \phi_{1}\left(1-\mathrm{p}_{2}\right)\left(1-\chi_{2}\right) \\
& \mathrm{m}_{221}=\mathrm{N}\left(1-\mathrm{p}_{1}\right) \phi_{1} \psi_{1}\left(1-\mathrm{p}_{2}\right) \psi_{2}\left(1-\chi_{2}\right), \\
& \mathrm{m}_{112}=\mathrm{Np} \phi_{1} \phi_{2} \chi_{2} \\
& \mathrm{~m}_{212}=\mathrm{N}\left(1-\mathrm{p}_{1}\right) \phi_{1} \psi_{1} \mathrm{p}_{2} \chi_{2}
\end{aligned}
$$

Obtendo-se razões dos $\mathrm{m}_{\mathrm{a}}$, que representam na medida do possível cada parâmetro biológico considerado, tem-se 


$$
\begin{gathered}
\frac{m_{211}}{m_{111}}=\frac{\left(1-p_{1}\right) \psi_{1}}{p_{1}}, \frac{m_{121}}{m_{111}}=\frac{\left(1-p_{2}\right)}{p_{2}}, \frac{m_{112}}{m_{111}}=\frac{\chi_{2}}{1-\chi_{2}}, \\
\frac{m_{211}}{m_{121}}=\frac{\left(1-p_{1}\right) \psi_{1}}{p_{1}} \psi_{2}=\psi_{2} \frac{m_{211}}{m_{111}} \\
\frac{m_{212}}{m_{112}}=\frac{\left(1-p_{1}\right) \psi_{1}}{p_{1}}=\frac{m_{211}}{m_{111}}, \\
\frac{m_{122}}{m_{112}}=\frac{\lambda_{1}\left(1-p_{2}\right)}{p_{2}}=\lambda_{1} \frac{m_{121}}{m_{111}},
\end{gathered}
$$

tal que a correspondência entre parâmetros do GLIM e parâmetros biológicos é dada na Tabela 6.

Tabela 6 - Correspondência entre parâmetros do GLIM e parâmetros biológicos para um experimento com três amostras.

\begin{tabular}{lll} 
Nome do GLIM & \multicolumn{1}{c}{$\begin{array}{c}\text { Parâmetros do } \\
\text { GLIM }\end{array}$} & \multicolumn{1}{c}{ Parâmetros biológicos } \\
\hline Média geral & $\mathrm{u}$ & $\log \left[N \mathrm{p}_{1} \phi_{1} \mathrm{p}_{2}\left(1-\chi_{2}\right)\right]$ \\
Efeitos Principais & $\mathrm{u}_{1}, \mathrm{u}_{2}, \mathrm{u}_{3}$ & $\begin{array}{l}\log \left[\left(1-\mathrm{p}_{1}\right) \psi_{1} / \mathrm{p}_{1}\right], \log \left[\left(1-\mathrm{p}_{2}\right) / \mathrm{p}_{2}\right], \\
\log \left[\chi_{2} /\left(1-\chi_{2}\right)\right]\end{array}$ \\
& & $\log \left(\psi_{2}\right)$ \\
Interações & $\mathrm{u}_{12}$ & $\log \left(\lambda_{1}\right)$ \\
& $\mathrm{u}_{23}$ & Assumido ser zero \\
\hline
\end{tabular}

Fonte: CORMACK (1989). 
A Tabela 7, apresenta o caso geral para o modelo de JollySeber. Pode-se observar que nascimento e morte entre a i-ésima e a (i+1)-ésima amostras são representados, respectivamente, pelas interações $u_{12 \ldots i}$ e $u_{(i+1) \ldots(s-1) s}$.

Tabela 7 - Correspondência entre parâmetros do GLIM e parâmetros biológicos para o modelo de Jolly-Seber com S-amostras.

\begin{tabular}{lcc}
\hline Nome do GLIM & Parâmetros do GLIM & Parâmetros biológicos \\
\hline Media Geral & $\mathrm{u}$ & $\log \left[N p_{1} \phi_{1} \mathrm{p}_{2} \phi_{2} \ldots \mathrm{p}_{\mathrm{S}-1}\left(1-\chi_{\mathrm{S}-1}\right)\right]$ \\
Efeitos Principais & $\mathrm{u}_{1}, \mathrm{u}_{\mathrm{i}}, \mathrm{u}_{\mathrm{S}}$ & $\log \left[\left(1-\mathrm{p}_{1}\right) \Psi_{1} / \mathrm{p}_{1}\right], \log \left[\left(1-\mathrm{p}_{\mathrm{i}}\right) / \mathrm{p}_{\mathrm{i}}\right]$, \\
& & $\log \left[\chi_{\mathrm{s}-1} /\left(1-\chi_{\mathrm{s}-1}\right)\right]$ \\
Interações & $\mathrm{u}_{12}, \mathrm{u}_{123}, \mathrm{u}_{1234}, \ldots$ & $\log \left(\psi_{2}\right), \log \left(\psi_{3}\right), \log \left(\psi_{4}\right), \ldots$ \\
& $\mathrm{u}_{(\mathrm{S}-1) \mathrm{S}}, \mathrm{u}_{(\mathrm{S}-2)(\mathrm{S}-1) \mathrm{S}}, \mathrm{u}_{(\mathrm{S}-3)(\mathrm{S}-2)(\mathrm{S}-1) \mathrm{S}}$ & $\log \left(\lambda_{\mathrm{S}-2}\right), \log \left(\lambda_{\mathrm{S}-3}\right), \log \left(\lambda_{\mathrm{S}-4}\right), \ldots$ \\
& Todas outras interações & 0 \\
\hline
\end{tabular}

Fonte: CORMACK (1989).

Pode-se observar claramente na Tabela 7 que, a menos que alguma restrição seja feita no modelo, os parâmetros $p_{1}, \psi_{1}$, não são estimáveis mas apenas a combinação $\left(1-p_{1}\right) \psi_{1} / p_{1}$, e similarmente $\phi_{S-1}$, $p_{S}$ não são estimáveis mas apenas $\left(1-\chi_{S-1}\right)=\phi_{S-1} p_{S}$. O tamanho da população na primeira ocasião de amostragenm também não é estimável pois a média geral u é igual a $\mathrm{NP}_{1}$ vezes o produto de parâmetros estimáveis, e $\mathrm{p}_{1}$ é não estimável. Entretanto, o tamanho da população em todas as ocasiões de amostragens intermediárias é estimável, pois pode ser expresso como uma função de $u$ e outros parâmetros estimáveis. O modelo tem os mesmos valores esperados como o modelo de JollySeber. As estimativas obtidas pelo modelo de Poisson são idênticas àquelas 
obtidas por JOLLY (1965) e SEBER (1965) utilizando modelos produto de multinomiais. As estimativas dos $p_{i}$ são obtidas diretamente de $u_{i}$ e as outras estimativas pela substituição ("back-substitution") das estimativas $\mathrm{m}_{\mathrm{ijk}}$.. conforme mencionado anteriormente.

Um modelo com probabilidade de captura constante em todas as amostras ("constant sampling effort") pode ser obtido a partir de outro com duas ou mais probabilidades de captura $(1<i<S)$ pela simples substituição dos parâmetros u's intermediários por um único parâmetro que é a soma desses. Se não existir nascimento no primeiro período $\left(\psi_{1}=1\right)$ ou morte no período final $\left(\chi_{\mathrm{s}}\right.$. ${ }_{1}=0$ ) este procedimento pode ser estendido para a primeira e última ocasiões de amostragens. Caso contrário, a estimativa da constante $\mathrm{p}$ nas amostras centrais, a depender da experiência do pesquisador, pode ser estendida para primeira e última amostras, permitindo assim a estimação condicionada de $\psi_{1}$ e $\phi_{s-1}$, separadamente.

Estimativas negativas de parâmetros do GLIM para nascimento e morte são inadimissiveis biologicamente, pois sendo $1 / \psi_{i}$ e $1 / \lambda_{i}$ probabilidades, as estimativas de $\log \psi_{i}$ e $\log \lambda_{i}$ devem ser não negativas. Estimativas desse tipo devem ser desconsideradas, eliminando-se o parâmetro correspondente do modelo e promovendo um novo ajuste.

\subsection{Modelo Poisson}

Na abordagem de modelos log-lineares para experimentos de captura-recaptura tem-se que as observações são variáveis aleatórias $R_{a}$ cujas esperanças são $\mathrm{N}$ vezes algumas funções $\mathrm{P}_{\mathrm{a}}$ de parâmentros biológicos $\theta$ da dinâmica da população e processo de amostragem, assim, 


$$
\begin{gathered}
R^{\prime}=\left(R_{1}, \ldots, R_{t}\right) \\
R_{a} \cap P\left(N P_{a}\right)
\end{gathered}
$$

A função de verossimilhança para a distribuição de Poisson, neste caso é dada por,

$$
L(N, \theta)=\Pi_{a} \exp \left(-N P_{a}\right)\left(N P_{a}\right)^{r_{a}} / r_{a} !
$$

as estimativas do modelo de Poisson são obtidas, maximizando-se simultaneamente em relação a $\theta$ e a $N$, via parâmetros do modelo log-linear considerado.

\subsection{Implementação no GLIM}

O ajuste de modelos log-lineares no GLIM é feito gerando a matriz do modelo $\mathbf{K}$ cujas colunas são os coeficientes dos parâmetros u's que estão sendo considerados, (CORMACK, 1980). As observações serão sempre introduzidas na ordem padrão de um experimento fatorial $2^{\mathrm{s}}$. Dessa forma as colunas da matriz K são facilmente obtidas pelo uso da função \%GL (x,y), a qual gera valores $1 \mathrm{a} x$ em blocos de $\mathrm{y}$.

Para um experimento com $S=3$, o programa completo seria:

\$UNITS 7 \$DATA R \$ READ

$\begin{array}{llllllllllll}r_{1} & r_{2} & r_{3} & r_{4} & r_{5} & r_{6} & r_{7}\end{array}$

\$CAL P $1=\% G L(2,1)-1:$ P2=\%GL(2,2)-1 : P3=\%GL(2,4)-1 \$

\$YVAR R \$ERR P \$FIT P1+P2+P3 \$ 
\$DIS E R \$STOP

A saída compreende a "deviance" residual do modelo ajustado, as estimativas dos parâmetros do GLIM com erros padrões assintóticos, os valores esperados e os resíduos de Pearson padronizados para cada uma das sete histórias de captura.

O modelo com "constant sampling effort" pode ser incorporado por:

$\$ C A L \quad P C=P 1+P 2+P 3 \quad$ \$FIT PC\$

e modelos incluindo diferentes termos de interação por,

\$CAL I12=P1*P2 : I13=P1*P3 : I23=P2*P3 \$

\$FIT $\mathrm{P} 1+\mathrm{P} 2+\mathrm{I} 12+\mathrm{P} 3+\mathrm{I} 13+\mathrm{I} 23$ ou qualquer subconjunto apropriado.

Os vetores $\mathrm{P} 1, \mathrm{P} 2, \mathrm{I} 12, \mathrm{P} 3, \mathrm{I13}, \mathrm{I} 23$, são, respectivamente, os coeficientes de $u_{1}, u_{2}, u_{12}, u_{3}, u_{13}, u_{23}$.

Estimativas dos parâmetros biológicos podem ser obtidos por (3), "back-transformation", conforme já descrito. A obtenção dos erros padrão assintóticos dos parâmetros biológicos é possível pelo uso do método delta e matriz de variância-covariância dos parâmetros do GLIM. CORMACK (1989) sugere a obtenção da distribuição Monte Carlo, da estimativa do tamanho da população, através de simulações do modelo selecionado usando os parâmetros estimados deste.

A seleção do modelo mais adequado deve ser orientada por considerações biológicas, conjuntamente com a consideração da "deviance" residual, a diferença de "deviances" entre modelos encaixados e padrões dos resíduos. Com $\left(2^{\mathrm{S}}-1\right)$ diferentes histórias de captura é comum os dados estarem moderadamente esparsos, e a distribuição $\chi^{2}$ assintótica para várias estatísticas 
pode ser inapropriada, CORMACK (1985) e McCULLAG \& NELDER (1989) apresentam mais detalhes sobre a escolha de qual padronização residual deve ser usada para dados modelados através da distribuição de Poisson.

\subsection{Um exemplo com dados reais}

A partir dos resultados do experimento de captura-recaptura desenvolvido por MOURÃO et al. (no prelo) foram consideradas 5 ocasiões de amostragens referentes aos anos de 1987 a 1991, dando origem, portanto, a 31 padrões diferentes observáveis os quais estão listados no Apêndice 1 junto com um programa obtido no SAS que produz o número de animais observados em cada uma das histórias de captura. O animal foi considerado presente em uma dada ocasião de amostragem se era capturado ao menos uma vez naquela ocasião.

Desde que o estudo foi realizado num período longo é natural enfocar a análise através do modelo para população aberta de JOLLY-SEBER (1965).

Assim conforme a Tabela 7, têm-se quatro conjuntos de parâmetros relacionados diretamente aos parâmetros clássicos de probabilidades de captura, taxa de sobrevivência, taxa de crescimento e tamanho da população, que são respectivamente, $\left(\mathrm{u}_{1}, \mathrm{u}_{2}, \mathrm{u}_{3}, \mathrm{u}_{4}, \mathrm{u}_{5}\right),\left(\mathrm{u}_{45}, \mathrm{u}_{345}, \mathrm{u}_{2345}\right),\left(\mathrm{u}_{12}, \mathrm{u}_{123}, \mathrm{u}_{1234}\right),(\mathrm{u})$, e apenas por conveniência os três primeiros serão chamados de (P1, P2, P3, P4, P5), (D1, D2, D3), (B2, B3, B4). Além disso, as interações simples entre efeitos principais $\left(u_{12}, u_{23}, u_{34}, u_{45}\right)$ representadas por (I1, I2, I3, I4). Dessa forma estes quatro últimos conjuntos de parâmetros ficam caracterizados como: 
1. Probabilidade de captura: P1, P2, P3, P4, P5 para as 5 ocasiões de amostragens na ordem 1987 a 1991, são relacionados às probabilidades $p_{1}, p_{2}$, $\mathrm{p}_{3}, \mathrm{p}_{4}, \mathrm{p}_{5}$ que um animal vivo é observado na i-ésima amostra com $\mathrm{i}=1,2,3$, 4,5 .

Conforme já mencionado $\mathrm{p}_{s}$ não pode ser estimado se está ocorrendo morte, nem $p_{1}$ pode ser estimado na presença de nascimento. No modelo do GLIM, P1 e P5 podem sempre ser estimados, mas estimativas de $p_{1} e$ $\mathrm{p}_{5}$ podem ser deduzidas destas somente na ausência de nascimento e morte, respectivamente.

Um modelo no qual cada jacaré tem a mesma probabilidade de ser capturado em cada ocasião de amostragem é obtido pela substituição de todos os parâmetros equivalentes por apenas um. Assim em população fechada (representada só pelos efeitos principais), todos $\mathrm{P} 1, \ldots, \mathrm{P} 5$ são substituídos por um simples PC; com nascimento P1 deve permanecer separado, enquanto P2 ...P5 são substituídos por PB; com morte P5 permanece separado, enquanto P1...P4 são substituídos por PD; com ambos nascimento e morte P2...P4 são substituídos por PBD enquanto P1 e P5 permanecem separados.

2. Taxas de morte: D1, D2, D3 são relacionados as probabilidades $\phi_{1}, \phi_{2}, \phi_{3}$ que um animal vivo na população numa dada amostra ainda esteja vivo na população na ocasião da próxima amostra. Informação sobre $\phi_{3}$ pode ser obtida do parâmetro de intensidade de amostragem final P5 somente se intensidade constante de amostragem é assumida.

Uma estimativa negativa para qualquer parâmetro de morte do GLIM indica que a probabilidade de sobrevivência estimada será maior do que 1 . Isto pode ocorrer por causa da variabilidade de amostragem. Neste caso a 
probabilidade de sobrevivência pode ser igualada a 1 através da omissão do parâmetro correspondente do modelo.

3. Taxas de nascimento: B2, B3, B4 representam os números de novos animais na população entre uma amostra e a próxima. Informação sobre nascimento entre a primeira e a segunda amostras pode ser obtida do parâmetro P1 somente se intensidade constante de amostragem é assumida.

Assim como as taxas de morte qualquer taxa de nascimento pode ser igualada a zero pela simples omissão do parâmetro correspondente do modelo. Qualquer parâmetro cuja estimativa é negativa deve ser igualado a zero para trazê-lo para dentro do intervalo.

4. Parâmetros de interação: I1, I2, I3, I4 representam o efeito imediato que o processo de captura pode ter no comportamento do animal por ocasião do próximo periodo de amostragem. Esta parametrização representa um modelo limitado para dependência de armadilha pois assume que o efeito da apreensão é o mesmo para cada animal capturado numa dada amostra, além de não considerar toda a história de captura prévia dos animais.

O primeiro e último destes parâmetros não são identificáveis

se nascimento e morte ocorreram, neste caso, I1 é idêntico a B2 e I4 a D3.

Dessa forma estes 4 conjuntos de parâmetros deram origem a modelos encaixados, os quais foram obtidos no GLIM através da diretiva \$FIT, sendo indicada por:

\$FIT $\mathrm{P} 1+\mathrm{P} 2+\mathrm{P} 3+\mathrm{P} 4+\mathrm{P} 5$ \$ para população fechada;

\$FIT $\mathrm{P} 1+\mathrm{P} 2+\mathrm{P} 3+\mathrm{P} 4+\mathrm{P} 5+\mathrm{D} 1+\mathrm{D} 2+\mathrm{D} 3$ \$ para população aberta considerando um caso particular do modelo J-S com somente morte. 
\$FIT $\mathrm{P} 1+\mathrm{P} 2+\mathrm{P} 3+\mathrm{P} 4+\mathrm{P} 5+\mathrm{B} 2+\mathrm{B} 3+\mathrm{B} 4$ \$ para população aberta considerando um caso particular do modelo J-S com somente nascimento.

\$FIT $\mathrm{P} 1+\mathrm{P} 2+\mathrm{P} 3+\mathrm{P} 4+\mathrm{P} 5+\mathrm{D} 1+\mathrm{D} 2+\mathrm{D} 3+\mathrm{B} 2+\mathrm{B} 3+\mathrm{B} 4$ \$ para população aberta com nascimento e morte.

\$FIT $\mathrm{P} 1+\mathrm{P} 2+\mathrm{P} 3+\mathrm{P} 4+\mathrm{P} 5+\mathrm{D} 1+\mathrm{D} 2+\mathrm{D} 3+\mathrm{B} 2+\mathrm{B} 3+\mathrm{B} 4+\mathrm{I} 2+\mathrm{I} 3$ \$ para população aberta com nascimento e morte mais dependência de armadilha.

\$FIT P1+PBD+P5+D1+D2+D3+B2+B3+B4 \$ para população aberta com nascimento e morte com esforço constante de amostragem. O programa listado no Apêndice 2, apresenta todos os passos da análise. 


\section{RESULTADOS E DISCUSSÃO}

Considerando, então, os quatro conjuntos de parâmetros (P1, P2, P3, P4, P5), (D1, D2, D3), (B2, B3, B4), (I1, I2, I3, I4) foram ajustados vários modelos resultantes da combinação destes, estando os mais importantes listados na Tabela 8.

Tomando-se os anos de 87 a 91 como ocasiões de amostragens temos 31 classes observáveis listadas no Apêndice 1, cujas frequências são dadas na Tabela 8 na ordem padrão das histórias de captura, ou seja, 11111, 21111, $12111, \ldots$ por linhas na tabela. 
Tabela 8 - Dados e análises de recapturas de jacaré (Caiman crocodilus yacare) na fazenda Nhumirim, Pantanal da Nhecolândia, Mato Grosso do Sul.

\begin{tabular}{|c|c|c|c|c|c|c|c|}
\hline \multicolumn{8}{|c|}{ Contagens observadas nas histórias de captura } \\
\hline 0 & 0 & 0 & 0 & 0 & 0 & 0 & 0 \\
\hline 0 & 0 & 0 & 0 & 0 & 0 & 0 & 70 \\
\hline 0 & 0 & 3 & 9 & 1 & 0 & 4 & 149 \\
\hline 5 & 0 & 373 & 551 & 178 & 10 & 394 & \\
\hline \multicolumn{5}{|c|}{ Modelos } & G. L. & \multicolumn{2}{|c|}{ "Deviance" } \\
\hline \multicolumn{5}{|c|}{ População fechada } & 25 & \multicolumn{2}{|c|}{836,6} \\
\hline \multicolumn{5}{|c|}{ Somente morte } & 22 & \multicolumn{2}{|c|}{472,6} \\
\hline \multicolumn{5}{|c|}{ Somente nascimento } & 22 & \multicolumn{2}{|c|}{181,9} \\
\hline \multicolumn{5}{|c|}{ Nascimento e morte } & 19 & \multicolumn{2}{|c|}{5,6} \\
\hline \multicolumn{5}{|c|}{ Com dependência de armadilha } & 18 & \multicolumn{2}{|c|}{2,0} \\
\hline \multicolumn{5}{|c|}{ Nascimento e morte com parâmetros no intervalo } & 20 & \multicolumn{2}{|c|}{181,3} \\
\hline \multicolumn{5}{|c|}{ Constante esforco } & 21 & \multicolumn{2}{|c|}{51,5} \\
\hline
\end{tabular}

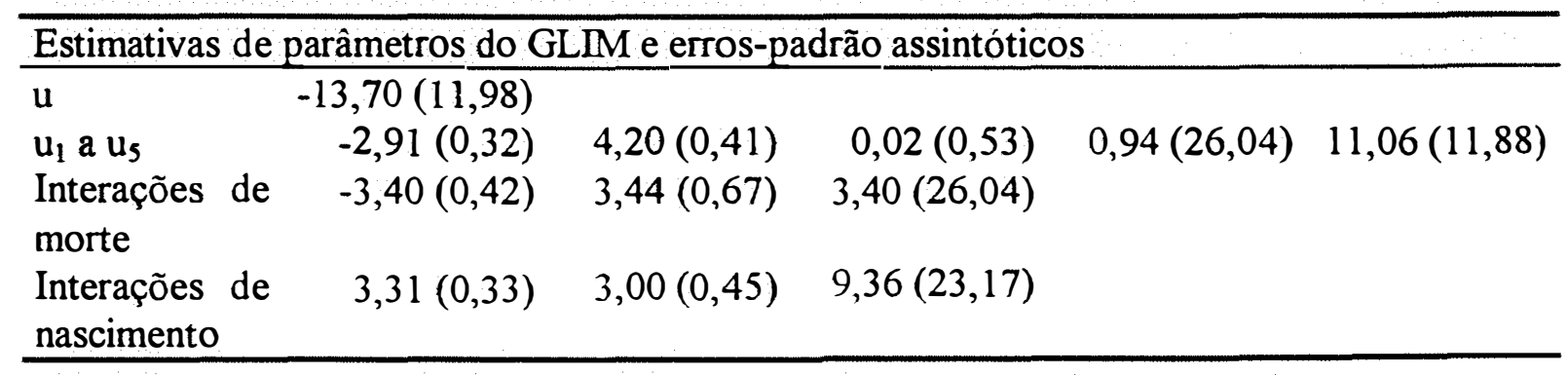

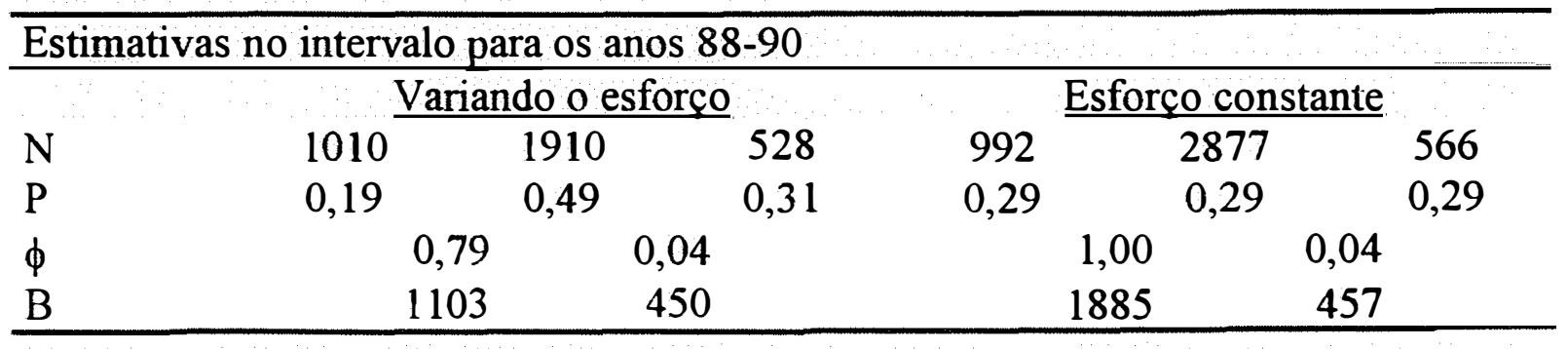

\begin{tabular}{cccccccc}
\hline \multicolumn{7}{l}{ Resíduos padronizados do modelo com nascimento e morte } \\
\hline$-0,0$ & $-0,0$ & $-0,0$ & $-0,0$ & $-0,0$ & $-0,0$ & $-0,0$ & $-0,0$ \\
$-0,0$ & $-0,0$ & $-0,0$ & $-0,0$ & $-0,0$ & $-0,0$ & $-0,0$ & $-0,0$ \\
$-0,3$ & $-0,0$ & $-0,8$ & 0,7 & 3,4 & $-0,0$ & $-0,4$ & 0,0 \\
$-0,2$ & $-0,5$ & 0,1 & $-0,0$ & $-0,0$ & 0,0 & 0,0 & \\
\hline
\end{tabular}


Pode-se observar que dos 31 padrões observáveis 19 apresentaram freqüências iguais a zero. As três maiores contagens 55.1, 394 e 373 referem-se às histórias 22122, 12222 e 12122 e sempre foram bem ajustadas por qualquer modelo com parâmetros de nascimento e morte. A Tabela 8, mostra que a inclusão de parâmetros de nascimento e morte no modelo reduz de forma marcante o valor da "deviance". A diferença de "deviances" entre os modelo com nascimento e morte e o modelo com dependência de armadilha $(3,6)$ é não significativa $\left(\chi_{(1)}^{2}=3,84\right)$. Desta forma, o modelo com nascimento e morte é aceito, embora quando obtidas as estimativas dos parâmentros do GLIM através da diretiva \$DIS E \$, observa-se que foi obtida uma estimativa negativa para o parâmetro D1. Esta produz uma estimativa negativa para taxa de morte. O modelo é então reajustado sem o parâmetro $\mathrm{D} 1$, e todas estimativas agora estão no intervalo paramétrico, entretanto, a "deviance" do modelo cresce acentuadamente sem D1. O modelo com probabilidade de captura variando e com parâmetros de nascimento e morte quando comparado com o modelo equivalente com probabilidade constante, apresenta uma redução na "deviance" significativa $(45,9)$ e $\left(\chi_{(2)}^{2}=5,99\right)$. Assim as estimativas dos parâmetros biológicos são obtidas através deste modelo. Estes resultados podem ser questionados tanto pela grande quantidade de zeros como pela intensa variabilidade no processo de amostragem, (CORMACK 1985, 1989 e McCULLAGH \& NELDER 1989).

EVANS \& BONETT (1994) propuseram adicionar a cada célula de um experimento de captura-recaptura com $S$ amostras, $S>2$, em classificação cruzada, o valor $(0,5)^{\mathrm{S}-1}$ como procedimento para reduzir o viés do estimador para o modelo log-linear. Esta correção foi utilizada e toda a análise foi repetida gerando os resultados da Tabela 9 . 
Tabela 9 - Dados com a correção e análises de recapturas de jacaré (Caiman crocodilus yacare) na fazenda Nhuminim, Pantanal da Nhecolândia, Mato Grosso do Sul.

\begin{tabular}{|c|c|c|c|c|c|c|c|}
\hline \multicolumn{8}{|c|}{ Contagens observadas nas histórias de captura } \\
\hline 0,0625 & 0,0625 & 0,0625 & 0,0625 & 0,0625 & 0,0625 & 0,0625 & 0,0625 \\
\hline 0,0625 & 0,0625 & 0,0625 & 0,0625 & 0,0625 & 0,0625 & 0,0625 & 70,0625 \\
\hline 0,0625 & 0,0625 & 3,0625 & 9,0625 & 1,0625 & 0,0625 & 4,0625 & 149,0625 \\
\hline 5,0625 & 0,0625 & 373,0625 & 551,0625 & 178,0625 & 10,0625 & 394,0625 & \\
\hline \multicolumn{5}{|c|}{ Modelos } & G. L. & \multicolumn{2}{|c|}{ "Deviance" } \\
\hline \multicolumn{5}{|c|}{ População fechada } & 25 & \multicolumn{2}{|c|}{836,6} \\
\hline \multicolumn{5}{|c|}{ Somente morte } & 22 & \multicolumn{2}{|c|}{471,9} \\
\hline \multicolumn{5}{|c|}{ Somente nascimento } & 22 & \multicolumn{2}{|c|}{184,9} \\
\hline \multicolumn{5}{|c|}{ Nascimento e morte } & 19 & \multicolumn{2}{|c|}{11,6} \\
\hline \multicolumn{5}{|c|}{ Com dependência de armadilha } & 17 & \multicolumn{2}{|r|}{6,3} \\
\hline \multicolumn{5}{|c|}{ Nascimento e morte com parâmetros no intervalo } & 20 & \multicolumn{2}{|c|}{183,3} \\
\hline \multicolumn{5}{|c|}{ Constante esforço } & 21 & \multicolumn{2}{|c|}{57,8} \\
\hline
\end{tabular}

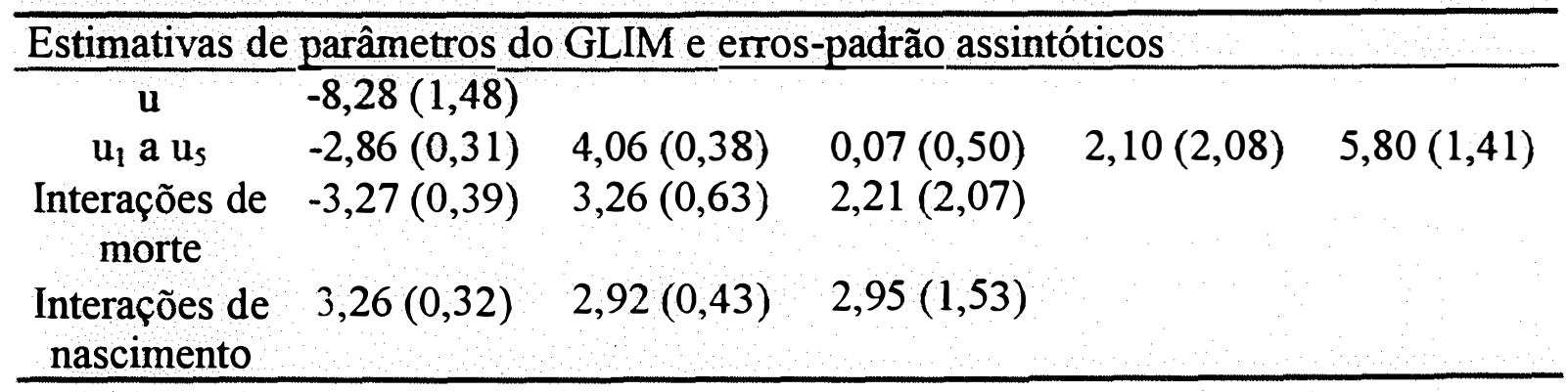

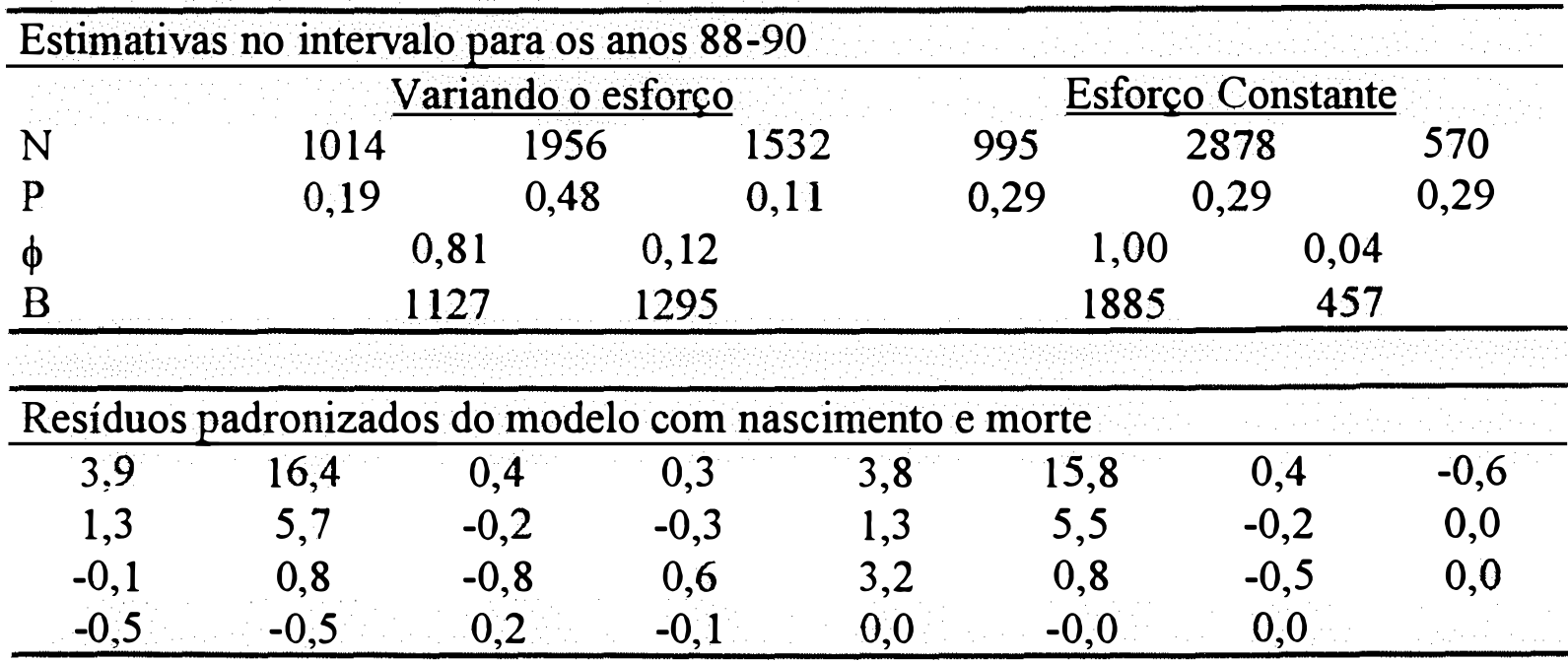


O modelo com nascimento e morte e o modelo com nascimento e morte mais dependência de armadilha não apresentam redução de "deviance" significativa $(5,31)$ e $\left(\chi_{(2)}^{2}=5,99\right)$. Então o primeiro modelo é assumido.

Entretanto, novamente, a estimativa negativa para o parâmetro D1 quando retirada, resulta numa deviance de 183,28 valor muito acima dos 20 graus de liberdade a ela associados. Certamente este fato pode estar relacionado com a dependência das observações, ou seja, o número total de animais observados em qualquer das ocasiões tem uma forte correlação positiva, embora usualmente é assumido que as $\mathbf{S}$ diferentes amostras são independentes. Assim, por exemplo, num experimento com duas ocasiões de amostragem o número de animais vistos na primeira amostra é $\mathrm{r}_{1+}=\mathrm{r}_{11}+\mathrm{r}_{12}$, o número visto na segunda é $r_{+1}=r_{11}+r_{21}$, e o modelo de Poisson assume que as variáveis aleatórias $R_{11}, R_{12} e$ $R_{21}$ são independentes, embora $R_{+1}$ e $R_{1+}$ sejam positivamente correlacionadas porque $\mathrm{R}_{11}$ é comum a ambas.

Além disso, parâmetros de heterogeneidade na probabilidade de captura ou de sobrevivência, conjuntamente, contribuem para inflacionar a "deviance" (ANDERSON et. al., 1994). Assim, como o modelo proposto não é apropriado, pode ser que os dados estejam sobredispersos como conseqüência da dependência e heterogeneidade, neste caso, a "deviance" supera o valor dos graus de liberdade associados.

Por outro lado, comparativamente esta correção não afetou de forma marcante as estimativas dos parâmetros do GLIM, com exceção dos parâmetros P4, D3 e B4 cujas estimativas passaram de 0,94 para 2,10; 3,40 para 2,21 e 9,36 para 2,95, respectivamente. Como consequência as estimativas dos parâmetros biológicos correspondentes foram alteradas de 0,31 para 0,$11 ; 0,04$ 
para 0,12 e 450 para 1295, respectivamente. Naturalmente, o tamanho da população estimado neste período se alterou de 528 para 1532. As estimativas corrigidas são mais razoáveis pois conforme mostrado na Figura 1, o esforço de amostragem nos anos 90 e 91 é pequeno e certamente causa a variabilidade na intensidade de amostragem, assim, a estimativa de probabilidade de captura para este período de 0,11 parece mais razoável que 0,31 quando não utilizamos a correção. O modelo com esforço constante de amostragem praticamente não se alterou. Entretanto, esta restrição não é aceita estatísticamente, o que também corrobora com a variabilidade do processo de amostragem empregado.

Os resíduos de Pearson padronizados para as contagens mostram que a correção tem efeito sobre o sinal negativo das obsevações zero, (Tabelas 8 e 9). Também o efeito da observação discrepante relativa à história 11212 cuja observação é 1 foi removido.

A Figura 7 apresenta os resíduos padronizados contra a frequência de captura, e dá alguma evidência de heterogeneidade na população, conforme CORMACK (1989). Esta é caracterizada pela concavidade da curva voltada para cima além da presença de observações discrepantes com frequências de captura igual a 3 e 4, e as histórias de capturas 21221 e 11111 com resíduos altos e positivos. 


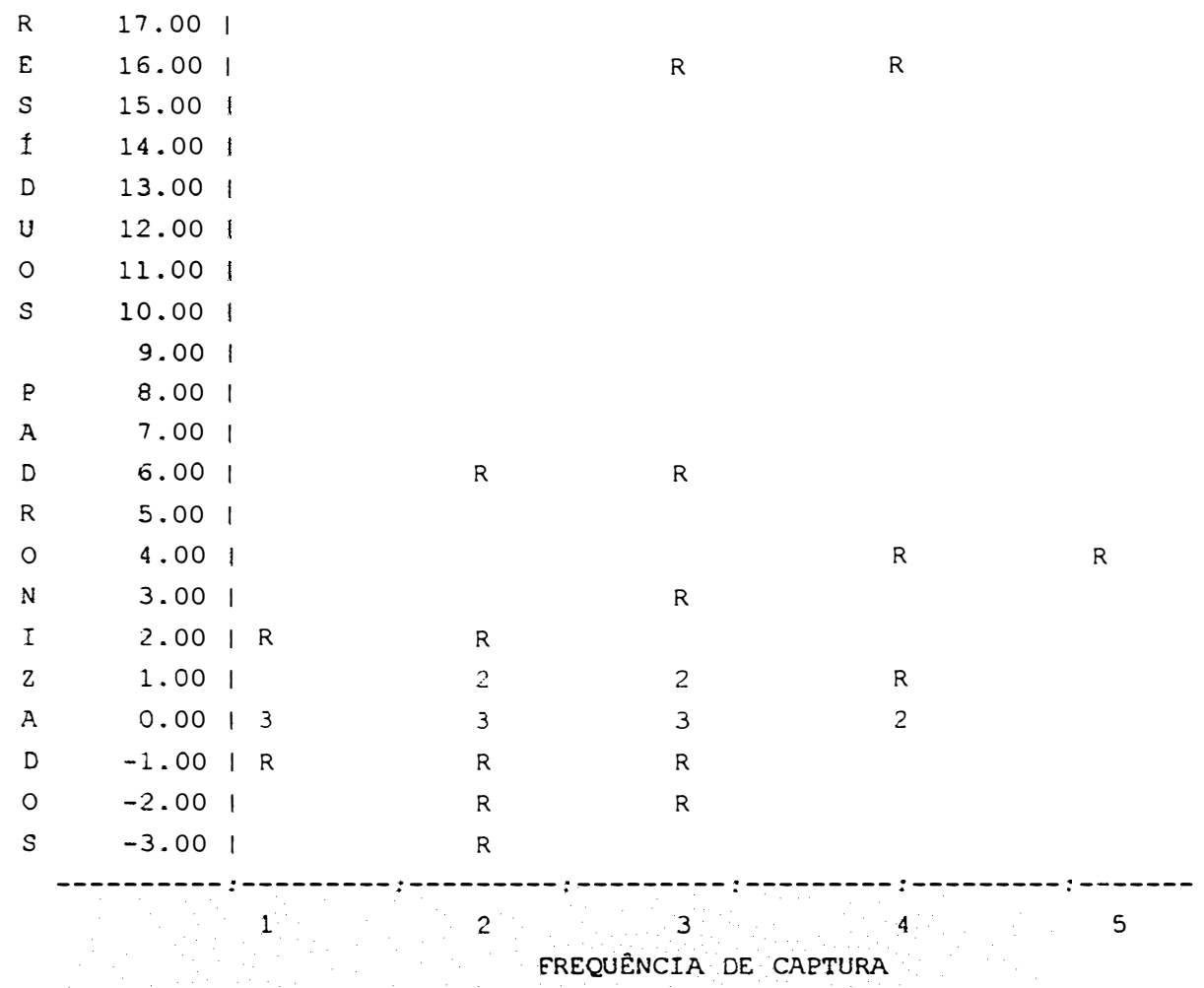

Figura 7 - Resíduos de Pearson padronizados da frequência de cada história de captura plotados contra a frequência de captura naquela história, $S=5$.

Estas evidências, ilustradas no desenho esquemático apresentado na Figura 8, comprometem a validade das estimativas sob o modelo de Jolly-Seber, no sentido que caracterizam sobredispersão dos dados, causada provavelmente pela correlação positiva entre contagens dos diferentes padrões observáveis e heterogeneidade nas probabilidades de captura. 


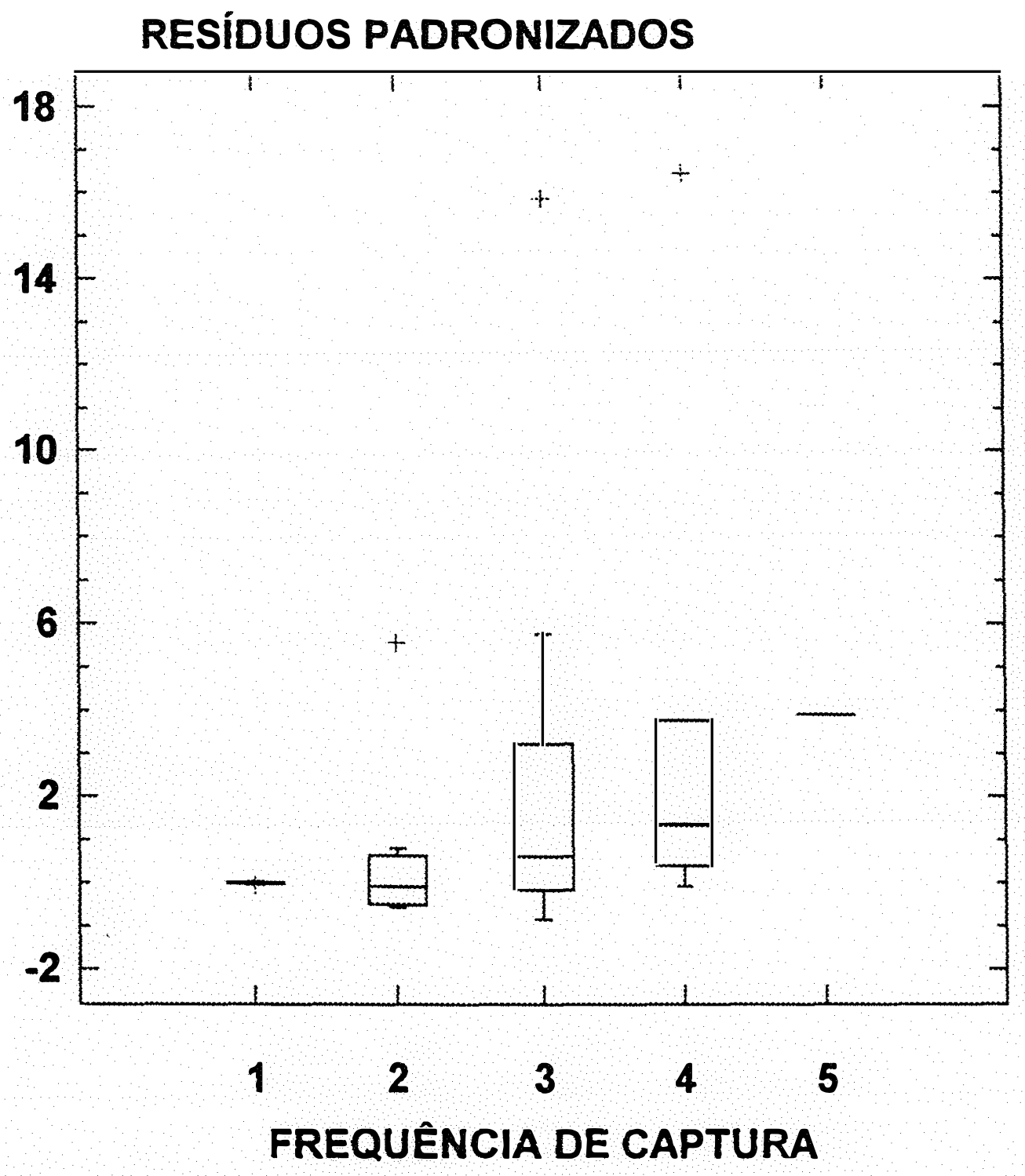

Figura 8 - Desenho esquemático dos resíduos de Pearson padronizados para as frequências de cada história de captura plotados contra a frequência de captura naquela história, $S=5$.

McCULLAGH \& NELDER (1989) frisaram que na presença de sobredispersão os estimadores dos parâmetros do modelo permanecem nãoviesados mas suas variâncias são subestimadas, desta forma, portanto, perdendo em precisão. 
Considerando que a variabilidade no esforço de amostragem, principalmente ocorridas nos anos 90 e 91 , teve uma influência muito forte nas estimativas dos parâmetros dos modelos log-lineares ajustados e consequentemente nas estimativas dos parâmetros biológicos de interesse. Uma análise alternativa agrupando os anos 90 e 91 , dando origem portanto a 4 ocasiões de amostragem, foi realizada, cujas histórias de captura com respectivas contagens observadas constam no Apêndice 1. Também foi considerada a correção indicada por EVANS \& BONETT (1994).

A Tabela 10 apresenta os resultados para esse caso. Percebe-se que as "deviances" dos modelos ajustados foram todas menores do que o caso análogo com 5 ocasiões de amostragens apresentado na Tabela 9. Uma redução marcante nas "deviances" é observada quando se usam parâmentros de nascimento e morte, sendo que neste caso a diferença de "deviances" entre o modelo com nascimento e morte, e o modelo com nascimento e morte mais dependência de armadilha $(4,6)$ é significativa $\left(\chi_{(1)}^{2}=3,84\right)$ e desta forma o último modelo é aceito. A obtenção das estimativas dos parâmetros revela que é necessário o reajuste do modelo sem o parâmetro D1 cuja estimativa é negativa. Quando feito o novo ajuste sem D1 a diferença de deviance $(0,21)$ é não significativa $\left(\chi_{(1)}^{2}=3,84\right)$ indicando que o ajuste não foi fortemente afetado pela remoção como no caso comparativo com 5 ocasiões. Os erros-padrão para as estimativas dos parâmetros do GLIM são menores que os verificados para os modelos com $\mathrm{S}=5$, Tabelas 8,9 e 10 . 
Tabela 10 - Dados e análises de recapturas de jacaré (Caiman crocodilus yacare) na fazenda Nhumurim, Pantanal da Nhecolândia, Mato Grosso do Sul.

\begin{tabular}{|c|c|c|c|}
\hline \multicolumn{4}{|c|}{ Contagens observadas nas histórias de captura } \\
\hline 0,125 & 0,125 & 3,125 & 9,125 \\
\hline 1,125 & 0,125 & 4,125 & 219,125 \\
\hline 5,125 & 0,125 & 373,125 & 551,125 \\
\hline 178,125 & 10,125 & 394,125 & \\
\hline \multicolumn{2}{|c|}{ Modelos } & G. L & "Deviance" \\
\hline \multicolumn{2}{|c|}{ População fechada } & 10 & 808,1 \\
\hline \multicolumn{2}{|l|}{ Somente morte } & 8 & 457,8 \\
\hline \multicolumn{2}{|c|}{ Somente nascimento } & 8 & 179,5 \\
\hline \multicolumn{2}{|c|}{ Nascimento e morte } & 6 & 6,6 \\
\hline \multicolumn{2}{|c|}{ Com dependência de armadilha } & 5 & 2,0 \\
\hline \multirow{2}{*}{\multicolumn{2}{|c|}{$\begin{array}{l}\text { Nascimento e morte mais dependência de } \\
\text { armadilha no intervalo } \\
\text { Constante esforco }\end{array}$}} & 6 & 2,21 \\
\hline & & 7. & 74,095 \\
\hline
\end{tabular}

\begin{tabular}{lllll}
\hline Estimativas de parâmetros do GLIM e erros-padrão assintóticos & & \\
\cline { 1 - 2 } & $-2,67(0,51)$ & & & \\
$\mathrm{u}_{1} \mathrm{a} \mathrm{u}_{4}$ & $-2,86(0,31)$ & $4,28(0,42)$ & $2,84(1,02)$ & $4,30(0,28)$ \\
Interações de morte & $-0,45(1,02)$ & $0,70(0,94)$ & & \\
Interações de nascimento & $3,26(0,32)$ & $3,57(0,50)$ & & \\
Interações de dependência & $-3,03(1,10)$ & & & \\
de armadilha & & & & \\
\hline
\end{tabular}

\begin{tabular}{|c|c|c|c|c|}
\hline \multicolumn{5}{|c|}{ Estimativas no intervalo para os anos $88-89$} \\
\hline & \multicolumn{2}{|c|}{ Variando o esforço } & \multicolumn{2}{|c|}{ Esforco constante } \\
\hline $\mathrm{N}$ & 14294 & 23310 & 15665 & 45014 \\
\hline $\mathrm{P}$ & 0,013 & 0,040 & 0,018 & 0,018 \\
\hline$\phi$ & \multicolumn{2}{|c|}{0,69} & \multicolumn{2}{|c|}{1,00} \\
\hline B & \multicolumn{2}{|c|}{13334} & \multicolumn{2}{|c|}{29349} \\
\hline
\end{tabular}

_Resíduos padronizados do modelo com nascimento e morte mais dependência de armadilha

\begin{tabular}{rrrr}
0,21 & 1,93 & $-0,84$ & 0,62 \\
$-0,40$ & 0,10 & 0,25 & 0,00 \\
$-0,00$ & $-0,30$ & 0,09 & $-0,07$ \\
0,03 & 0,00 & $-0,02$ & \\
\hline
\end{tabular}


As Figuras 9 e 10 quando comparadas mostram que o agrupamento torna os dados menos esparsos pois os resíduos aproximam-se mais da linha reta esperada e a quantidade de resíduos positivos e negativos é mais equilibrada quando $S=4$ (CORMACK, 1985).

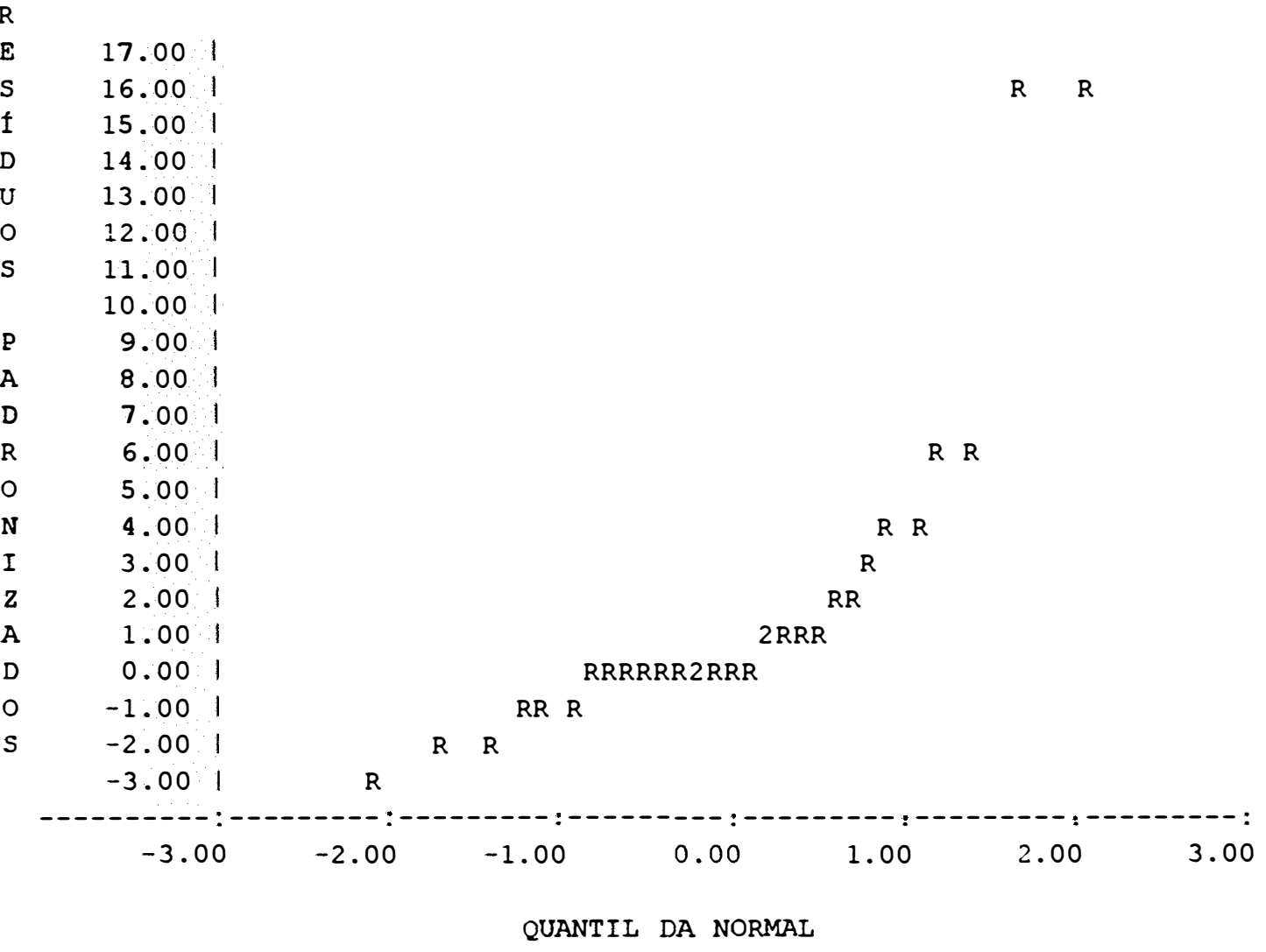

Figura 9 - Resíduos de Pearson padronizados plotados contra os quantis de probabilidade da distribuição normal, $S=5$. 


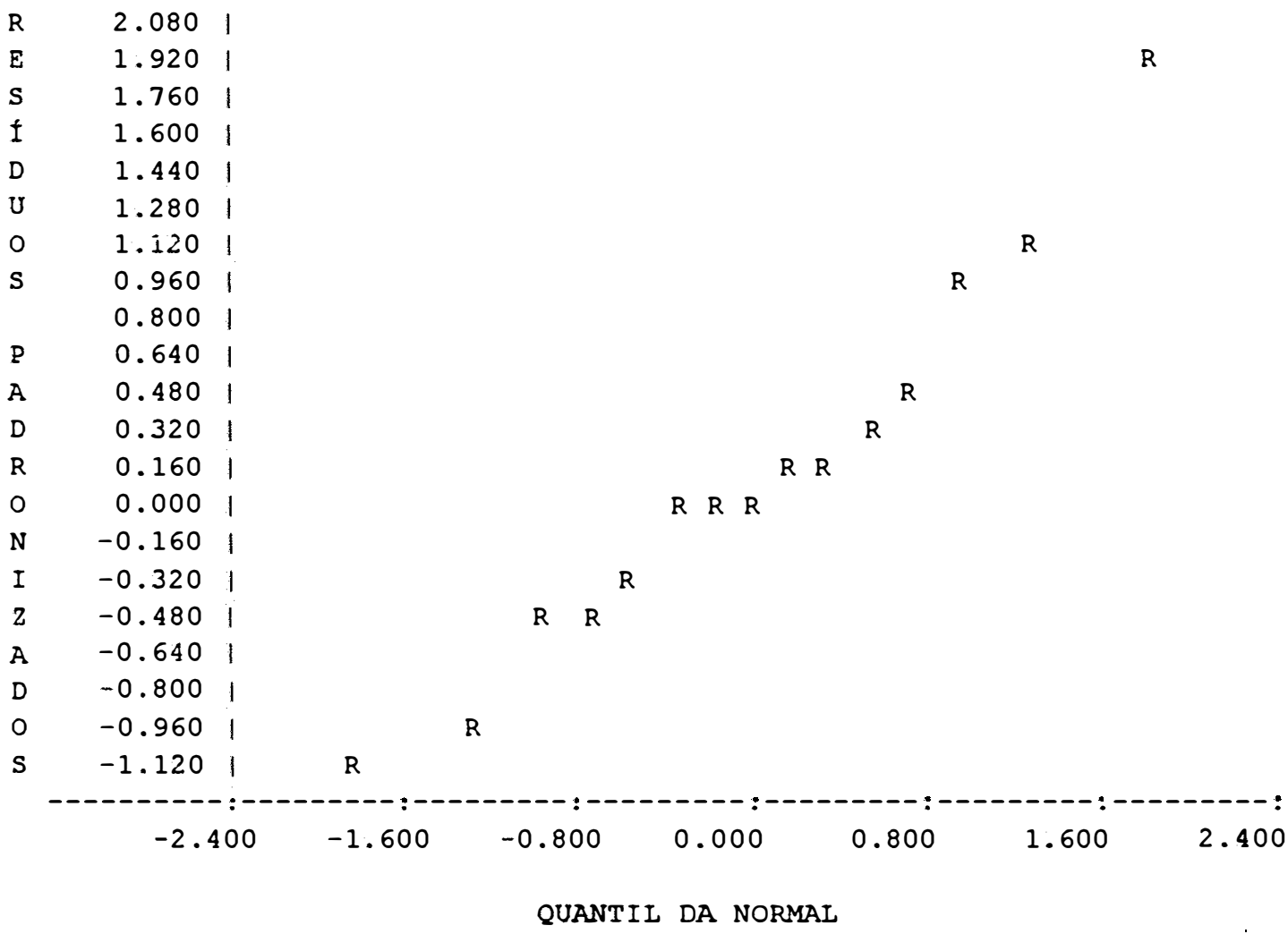

Figura 10 - Resíduos de Pearson padronizados plotados contra os quantis de probabilidade da distribuição normal, $S=4$.

A Figura 11 onde foram plotados os resíduos de Pearson padronizados, para o número de animais observados em cada história de captura e o número esperado pelo modelo com nascimento e morte mais dependência de armadilha, com as frequências de cada história de captura, caracteriza o bom ajuste do modelo por apresentar todos os resíduos no intervalo de $-1,12$ a 2,08. Além disso, não há mais evidência de heterogeneidade forte como na situação anterior. Isto pode ser confirmado pela visualização do correspondente desenho esquemático apresentado na Figura 12, onde verifica-se que os resíduos com frequência de captura 3 estão ligados e a história de captura 1111 tem resíduo próximo de zero. 


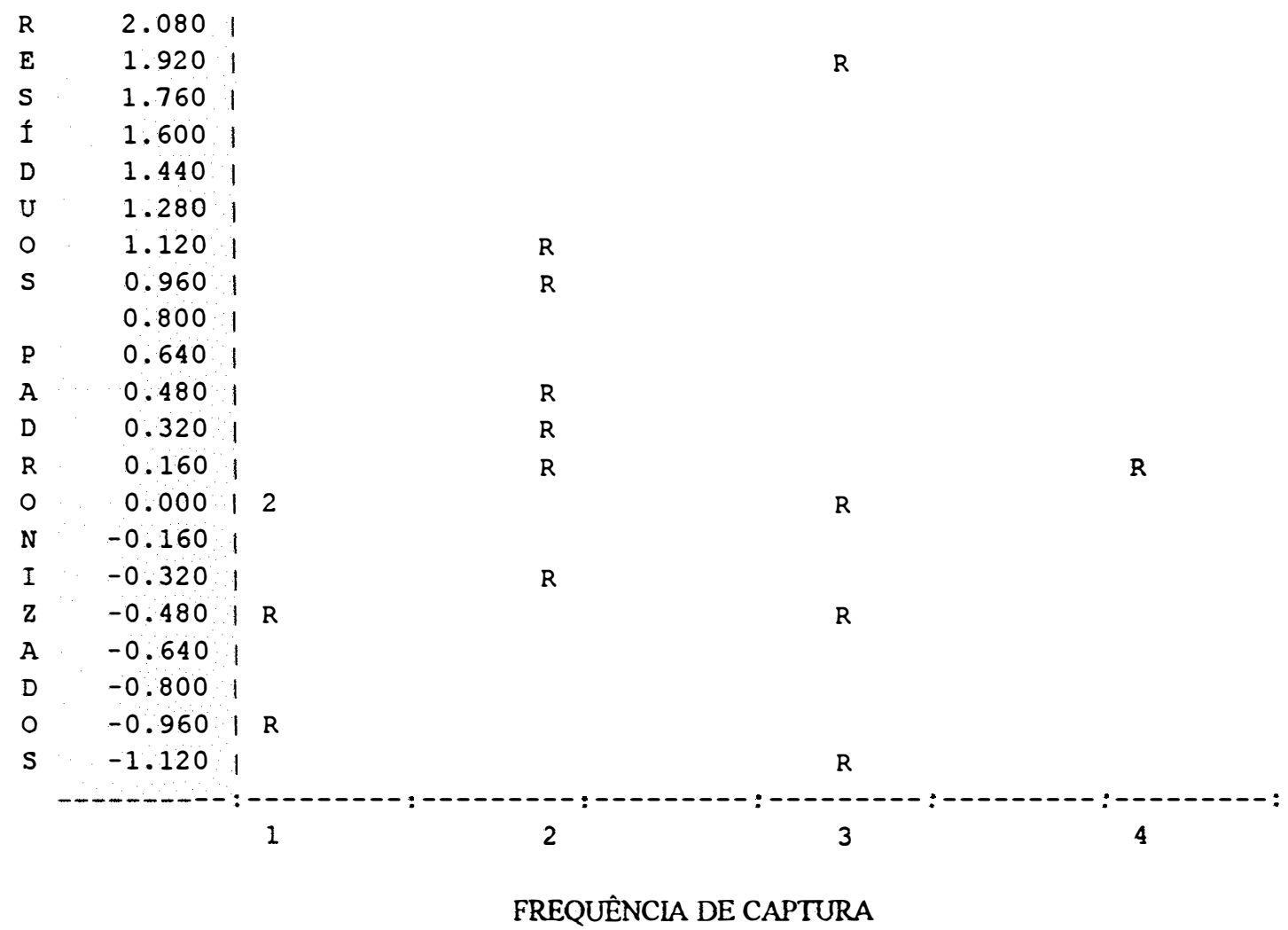

Figura 11 - Resíduos de Pearson padronizados da frequência de cada história de captura plotados contra a frequência de captura naquela história, $\mathrm{S}=$ 4. 


\section{RESÍDUOS PADRONIZADOS}

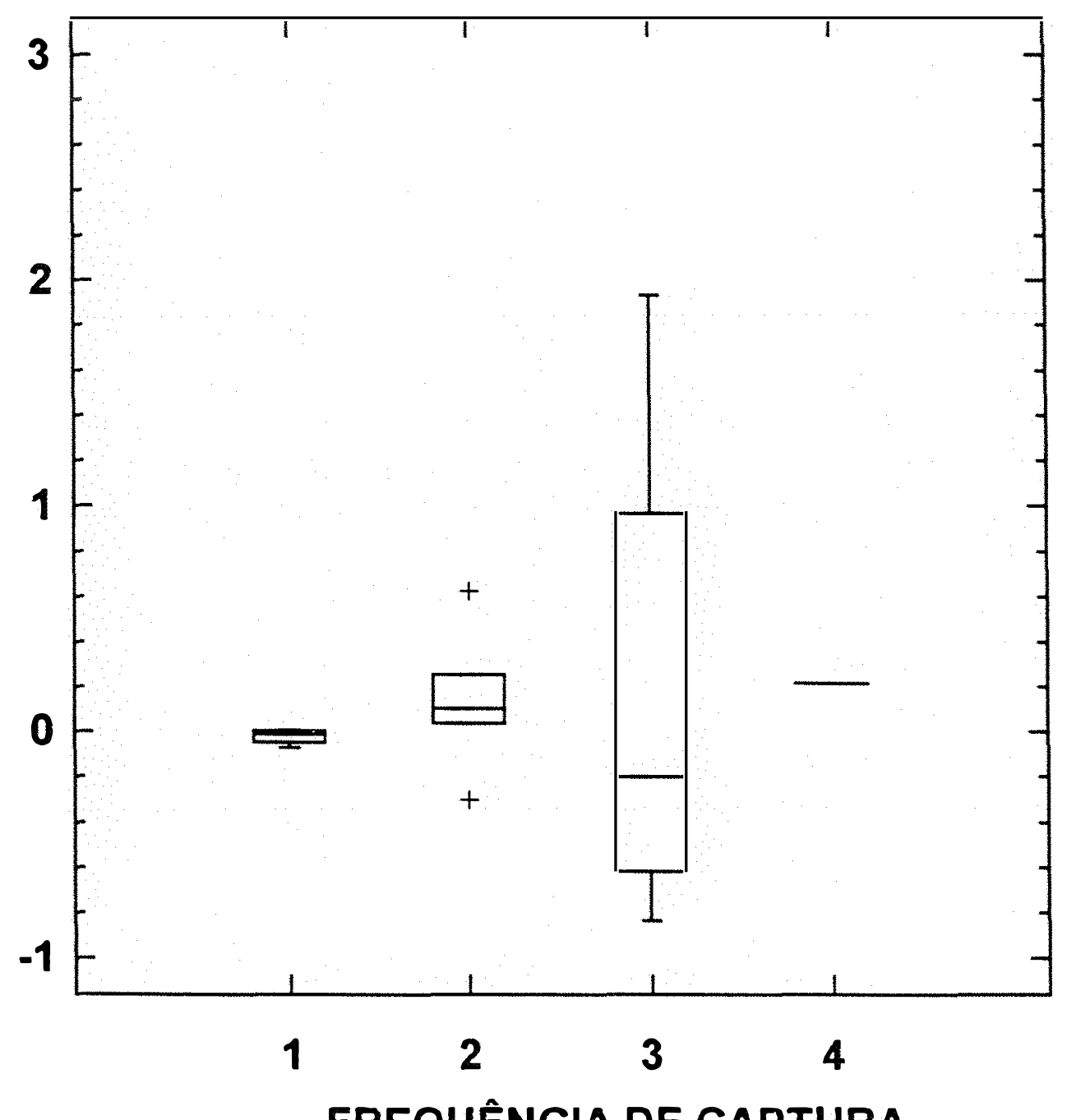

FREQUÊNCIA DE CAPTURA

Figura 12 - Desenho esquemático dos resíduos de Pearson padronizados para as frequências de cada história de captura plotados contra a frequência de captura naquela história, $S=4$.

As diferenças nas estimativas do tamanho da população devese ao forte grau de heterogeneidade observado quando os dados estão muito esparsos. CORMACK (1972) mostrou, utilizando argumentos intuitivos, que a existência de heterogeneidade subestima o tamanho populacional e CAROTHERS 
(1973) documentou este fato através de estudos de simulação para uma população onde ocorria heterogeneidade de probabilidades de captura. POLLOCK et al. (1990) frisam que a heterogeneidade causa um viés negativo e a magnitude deste é determinada pelo grau existente na população.

Já MENKENS \& ANDERSON (1988) observaram através de estudos de simulação que o estimador de Petersen apresenta grande viés na presença de dependência de armadilha ou alto grau de heterogeneidade nas probabilidades de captura individuais numa população de pequenos mamíferos. Para populações fechadas os estudos de POLLOCK et al. (1984) e EVANS et al. (1994) abordam o uso de variáveis auxiliares como um meio para reduzir a heterogeneidade observável. Com estes resultados, provavelmente, o uso do delineamento robusto pode produzir estimativas mais consistentes do tamanho populacional, trazendo uma dificuldade adicional de utilizar modelos log-lineares nas histórias de captura provenenientes do periodo secundário, pois, conforme observado por OTIS et al. (1978) para se terem resultados razoáveis o número de ocasiões deve estar entre 5 a 10.

Embora a diferença de "deviance" entre o modelo com nascimento e morte e modelo com nascimento e morte mais dependência de armadilha observada na Tabela 8 seja igual a 5,3 valor não significativo $\left(\chi_{(2)}^{2}=\right.$ 5,99), as evidências de dependência de armadilha encontradas na análise com agrupamento dos anos 90-91 e o próprio questionamento sobre a validade da distribuição assintótica para dados com grande números de zeros, levou à pesquisa do último.

Os resultados encontram-se na Tabela 11. Observa-se que a "deviance" do modelo com nascimento e morte mais dependência de armadilha com parâmetros no intervalo é igual a 6,503 com 19 graus de liberdade, pois em 
dois passos foram retirados os parâmetros D1 e D2 que produziram estimativas negativas a cada etapa.

Tabela 11. Análise do modelo com nascimento e morte mais dependência de armadilha.

\begin{tabular}{lccc}
\hline & Modelos & G. L. & "Deviance" \\
\hline $\begin{array}{l}\text { Nascimento e morte mais dependência de } \\
\text { armadilha }\end{array}$ & 17 & 6,347 \\
$\begin{array}{l}\text { Nascimento e morte mais dependência de } \\
\text { armadilha com parâmetros no intervalo }\end{array}$ & 19 & 6,503 \\
\hline
\end{tabular}

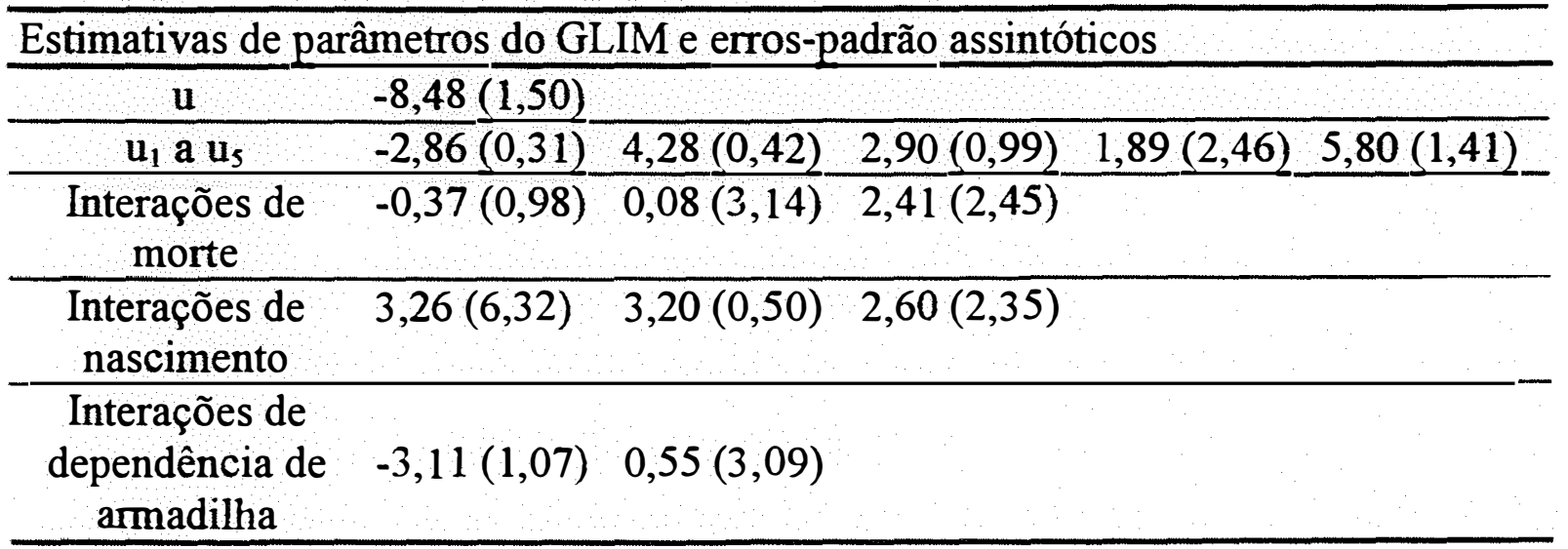

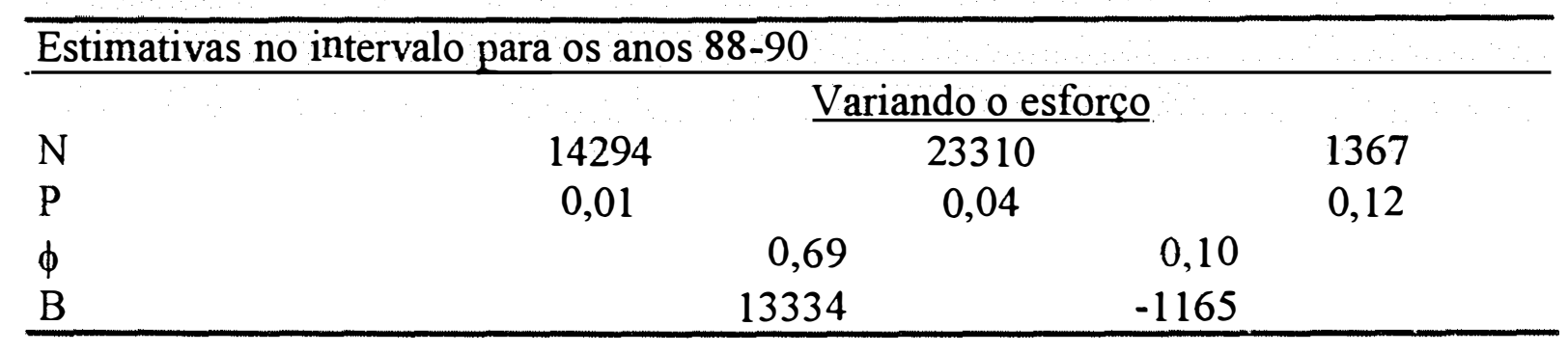

A Figura 13 mostra que a evidência de heterogeneidade permanece, pois pode ser observada uma observação discrepante cuja freqüência de captura é igual a 4, e a característica curvatura, voltada para cima. 


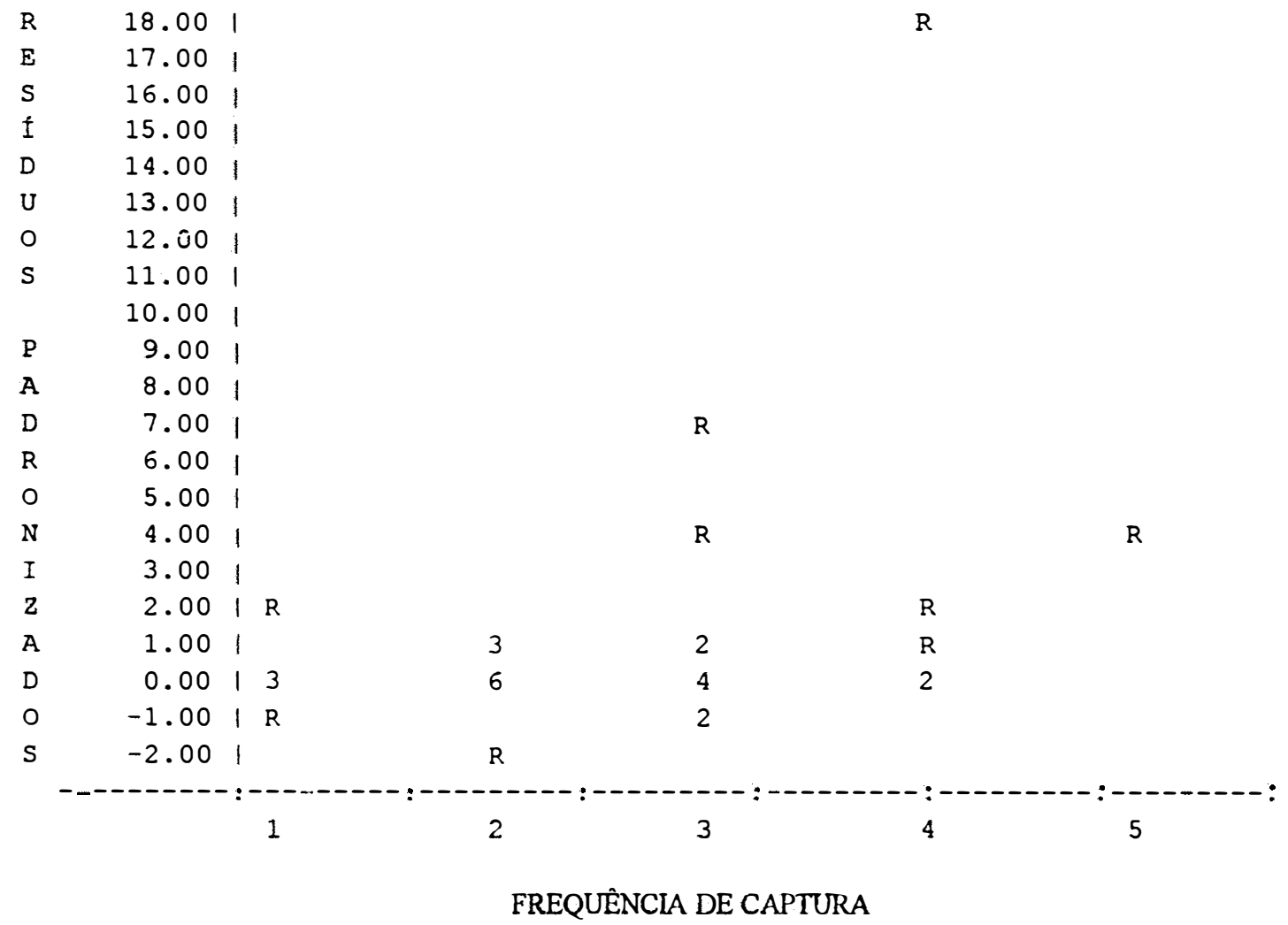

Figura 13 - Resíduos de Pearson padronizados da frequência de cada história de captura plotados contra a frequência de captura naquela história, $S=5$.

A Figura 14 por sua vez apresenta-se longe da reta esperada como já frisado, evidenciando que os dados estão esparsos. 


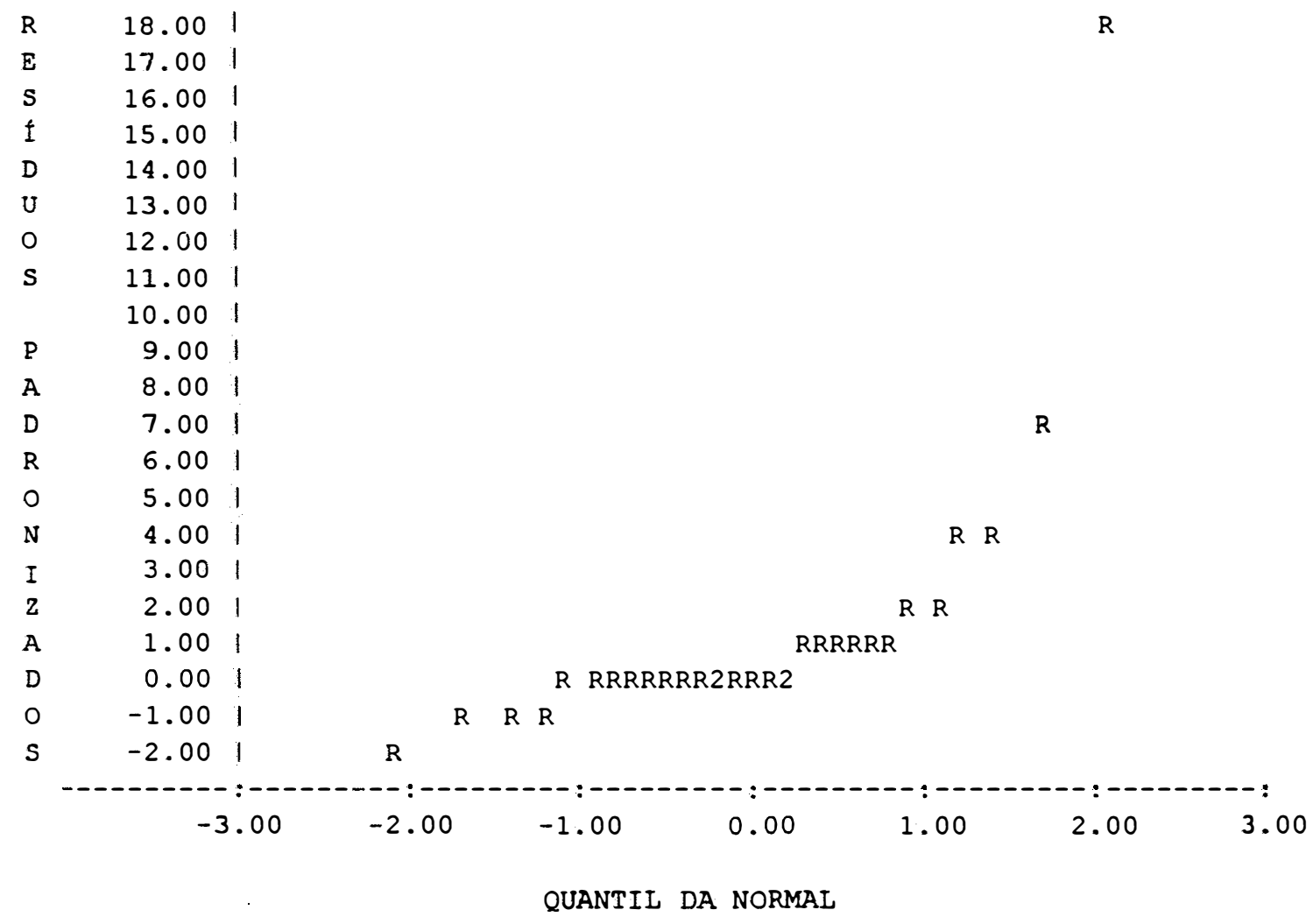

Figura 14 - Resíduos de Pearson padronizados plotados contra os quantis de probabilidade da distribuição normal, $\mathrm{S}=5$.

O desenho esquemático pertinente para este caso é ilustrado na Figura 15. Pode ser observado que os valores residuais não estão ligados nas frequências 3 e 4, e a história 11111 tem um resíduo alto e positivo. 
RESÍDUOS PADRONIZADOS

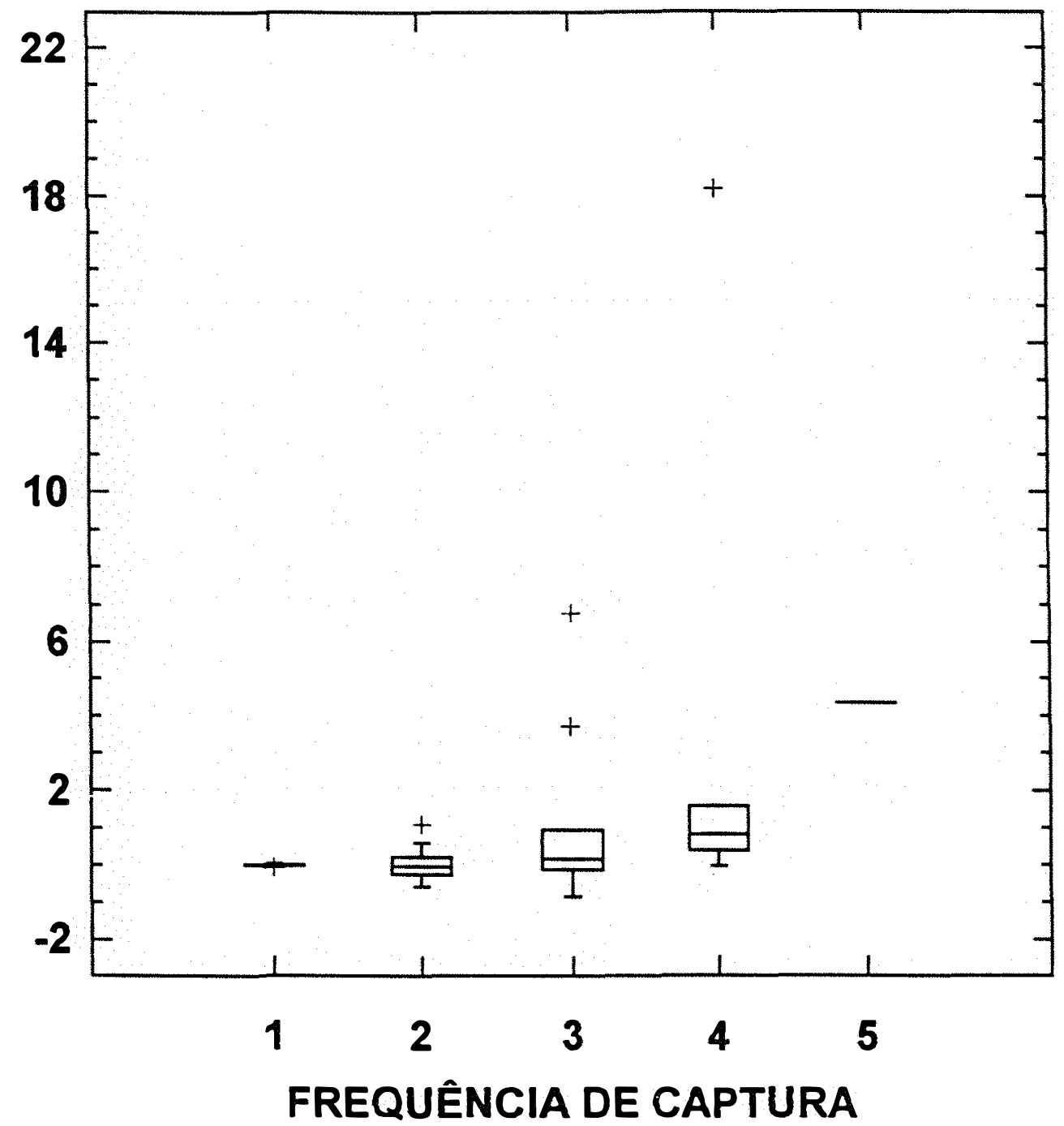

Figura 15 - Desenho esquemático dos resíduos de Pearson padronizados para as frequências de cada história de captura plotados contra a frequência de captura naquela história, $\mathrm{S}=5$.

As estimativas para o tamanho populacional, probabilidade de captura, probabilidade de sobrevivência e número de nascimento para os anos de 88 e 89 coincidem com os valores obtidos sob o modelo equivalente considerando o agrupamento dos anos 90 e 91, apresentados na Tabela 10. Assim, estes 
resultados tendem a confirmar aqueles obtidos na análise com os dados agrupados ("pooled"). Os valores destas estimativas para o ano de 90 são muito próximos aos encontrados com o modelo sem os parâmetros de dependência de armadilha, na Tabela 9, com exceção do valor negativo não esperado para o número de nascimentos, o que pode ser indicativo do deslocamento da população na área de estudo. Outra evidência de perda (por emigração ou predação no ano de 90) na população é que foram observados 394 animais com história de captura 12222, 178 com história de captura 11222, 373 com história de captura 12122, 4 com história de captura 12212 e 149 animais com história de captura 22212. Entretanto este fato confunde-se com o efeito da dependência de armadilha, ou seja, há evidências nas frequências destas histórias de que o "trap-shy" está em operação.

Como o padrão dos resíduos apresentou fortes evidências de heterogeneidade na população, é razoável assim considerar que a probabilidade de captura varia de animal para animal. Então aqueles capturados em todas as amostras terão maior "catchability" média do que os animais que estiveram ausentes em uma das amostras, e assim sucessivamente até aqueles capturados uma vez, e finalmente aqueles que nunca foram capturados. Assim, em termos de probabilidade de captura, os animais do grupo desconhecido não observável, portanto com padrão 22222 , são mais similares àqueles capturados uma vez e menos parecidos com os capturados muitas vezes. Desta forma, uma estratégia para remover heterogeneidade é descartar os animais capturados S-vezes, em seguida os capturados (S-1)-vezes, e assim por diante, examinando a cada estágio a evidência da heterogeneidade remanescente, pela diferença entre os valores observados e esperados. 
A Tabela 12 apresenta os valores observados para as histórias de captura com freqüência maior ou igual a (S-1), e os valores esperados quando diferentes grupos são omitidos do conjunto de dados antes do ajuste do modelo. $\mathrm{O}$ acréscimo na diferença entre os valores observados e esperados à medida que os grupos são removidos mostra que a heterogeneidade ainda permanece, embora a redução na "deviance" quando removemos os animais vistos em 4 ou mais ocasiões não é significativa quando comparada com o valor $\chi_{(s)}^{2}=11,07$.

Tabela 12. Análise de heterogeneidade para a população de jacarés (Caiman crocodilus yacare) no Pantanal da Nhecolândia, Mato Grosso do Sul.

\begin{tabular}{|c|c|c|c|c|}
\hline \multirow[b]{2}{*}{$\begin{array}{l}\text { História de } \\
\text { captura }\end{array}$} & \multirow{2}{*}{$\begin{array}{l}\text { Contagens } \\
\text { observadas } \\
\text { com a } \\
\text { correção }\end{array}$} & \multicolumn{3}{|c|}{$\begin{array}{l}\text { Valores esperados sob modelo com nascimento e } \\
\text { morte mais dependência de armadilha }\end{array}$} \\
\hline & & Todos dados & $\begin{array}{l}\text { omitindo dado } \\
\text { (11111) }\end{array}$ & $\begin{array}{c}\text { omitindo dados } \\
\text { de animais } \\
\text { vistos em } 4 \text { ou } \\
\text { mais ocasiões }\end{array}$ \\
\hline 11111 & 0,0625 & 0,00021 & 0,00018 & 0,00010 \\
\hline 21111 & 0,0625 & 0,00001 & 0,00001 & 0,00001 \\
\hline 12111 & 0,0625 & 0,01495 & 0,01303 & 0,00769 \\
\hline 11211 & 0,0625 & 0,00491 & 0,00430 & 0,00253 \\
\hline 11121 & 0,0625 & 0,00149 & 0,00147 & 0,00124 \\
\hline 11112 & 0,0625 & 0,06885 & 0,06776 & 0,06575 \\
\hline \multicolumn{5}{|c|}{ Parâmetros estimados } \\
\hline & N88 & 14294 & 14451 & 14755 \\
\hline & N89 & 23310 & 23676 & 24132 \\
\hline & N90 & 1367 & 1544 & 2172 \\
\hline "Deviance" & & $\begin{array}{c}6,503 \\
\text { com } 19 \text { g.l. }\end{array}$ & $\begin{array}{c}5,904 \\
\text { com } 18 \text { g. } 1 .\end{array}$ & $\begin{array}{c}4,182 \\
\text { com } 13 \text { g. } 1 .\end{array}$ \\
\hline
\end{tabular}

O efeito dessas manipulações nas estimativas do tamanho da população mostrou que após a remoção de parte da heterogeneidade o tamanho populacional 
estimado para o ano 90 é 2172 produzindo uma densidade de 50,51 animais/ $/ \mathbf{k m}^{2}$, igual ao valor encontrado por MOURÃO et al. (1994) de 50,0 animais $/ \mathrm{km}^{2}$ com $(\mathrm{SE}=15)$ utilizando método de levantamento aéreo. Não foi detectado efeito nas estimativas de sobrevivência, as quais parecem ser robustas à presença de desigual "catchability", como pode ser visualizado no Apêndice 2. 


\section{CONCLUSÕES}

1. A verificação dos resíduos de todos os modelos ajustados sugere que existe um forte grau de heterogeneidade nas probabilidades de captura dos animais na população estudada.

2. A significância dos parâmetros de dependência de armadilha e o baixo número de contagens observadas relativas às recapturas, principalmente nas histórias de captura com freqüência alta, são evidências de que o "trap-shy" esteja em operação, ou seja, o método de apreensão pode estar inibindo os animais a serem capturados.

3. As estimativas para o tamanho da população, após a análise de heterogeneidade, considerando o modelo de Jolly-Seber com parâmetros de nascimento e morte mais dependência de armadilha para os anos de 1988, 1989 e 1990 são 14755, 24132 e 2172, respectivamente.

4. A densidade estimada para a área de estudo é de 50 animais $/ \mathrm{km}^{2}$ para o ano de 1990. 


\section{REFERÊNCIAS BIBLIOGRÁFICAS}

ADAMOLI, J. O Pantanal e suas relações fitogeográficas com os cerrados. Discussão sobre o conceito "Complexo do Pantanal". In: CONGRESSO NACIONAL DE BÔTANICA, 32. , Teresina, 1981. p.109-19.

AGRESTI, A. Categorical data analysis. John Wiley \& Sons, New York, 1990. $561 \mathrm{p}$.

ANDERSON, D. R.; BURNHAM, K. P.; WHITE, G. C. AIC model selection in overdispersed capture-recapture data. Ecology, Tempe, 75(6): 1780-93, 1994.

BAILEY, N.T.J. On estimating the size of mobile populations from recapture data. Biometrika, 38: 293-306, 1951.

BISHOP, Y.M.M.; FIENBERG, S.E.; HOLLAND, P.W. Discrete multivariate analysis: theory and practice. Cambridge, Massachusetts, $1975.557 \mathrm{p}$. 
BRASIL. Projeto RADAMBRASIL - Folha SE-20e SE-21. Departamento Nacional de Produção Mineral. Rio de Janeiro, 1982. v.27.

BURNHAM, K.P.; ANDERSON, D.R.; WHITE, G.C.; BROWNIE, C.; POLLOCK, K.H. Design and analysis of fish survival experiments based on released-recapture data. Bethesda, American Fisheries Society, 1987. 437p. (Monograph, 5).

CAROTHERS, A.D. The effects of unequal catchability on Jolly-Seber estimates. Biometrics, Alexandria, 29: 79-100, 1973.

CASAJÚS, M.I. Estimadores de máxima verossimilhança para os parâmentros de alguns modelos de captura-recaptura em população animal. São Paulo, 1990. 144p. (Mestrado - Instituto de Matemática e Estatística/USP).

CAUGHLEY, G. Analysis of vertebrates populations. London, John Wiley, 1977. $234 \mathrm{p}$.

CHAO, A. Estimating animal abundance with capture frequency data. Journal of Wildlife Managementt, Bethesda, 52: 295-300, 1988.

CHAO, A. Estimating population size for sparse data in capture-recapture experiments. Biometrics, Alexandria, 45: 427-38, 1989. 
CHAO, A.; LEE, S.M.; JENG, S.L. Estimating population size for capturerecapture data when capture probability vary by time and individual animal. Biometrics, Alexandria, 48: 201-16, 1992.

CHAPMAN, D.G. Some properties of the hypergeometric distribution with applications to zoological sample censuses. University of the California Publication Station, 1: 131-60, 1951.

CHAPMAN, D.G. Inverse, multiple and sequential sample censuses. Biometrics, Alexandria, 8: 286-306, 1952.

CORDEIRO, G.M. Modelos lineares generalizados. Campinas, VII SINAPE, 1986. $286 \mathrm{p}$.

CORMACK, R.M. Log-linear models for capture-recapture. Biometrics, Alexandria, 45: 395-413, 1989.

CORMACK, R.M. The statistics of capture-recapture methods. Oceanogr. Mar. Biol. Ann. Rev., 6: 455-506, 1968.

CORMACK, R.M. The logic of capture-recapture estimates. Biometrics, Alexandria, 28: 337-43, 1972. 
CORMACK, R.M. Models for capture-recapture. In: CORMACK, R.M.; PATIL, G.P.; ROBSON, D.S. Sampling biological populations. Fairland, International Cooperative Publ. House, 1979. p.217-55. (Statistical Ecology Ser., 5).

CORMACK, R.M. Model seletion in capture-recapture experiments. GLIM Newsletter, December, 27-9, 1980.

CORMACK, R.M. Examples of the use of GLIM to analyse capture-recapture studies. In:MORGAN, J.T. \& NORTH, P.M., ed. Statistics in ornithology. 1985. p.243-73. (Lecture Notes in Statistics, 29).

DARROCH, J.N. The multiple-recapture census. I. Estimation of a closed population. Biometrika, London, 45: 343-59, 1958.

DEMÉTRIO, C. G. B. Modelos lineares generalizados na experimentação agronômica. Porto Alegre, 1993. 125p.

EVANS, M.A. \& BONETT, D.G. Bias reduction for multiple-recapture estimators of closed population size. Biometrics, Alexandria, 50: 388-95, 1994. 
EVANS, M.A.; BONETT, D.G.; McDONALD, L.L. A general theory for modeling capture-recapture data from a closed population. Biometrics, Alexandria, 50: 396-405, 1994.

FIENBERG, S. The multiple recapture census for closed populations and incomplete $2^{\mathrm{K}}$ contingency tables. Biometrika, London, 59: 591-603, 1972.

JOLLY, G.M. Explicit estimates from capture-recapture data with both death and immigration-stochastic model. Biometrika, London, 52: 225-47, 1965.

McCULLAGH, P. \& NELDER, J.A. Generalized linear models. 2.ed. London, Chapman and Hall, 1989. 511p.

MENKENS, G.E. \& ANDERSON, S.H. Estimation of small-mammal population size. Ecology, Tempe, 69(6): 1952-9, 1988.

MOURÃO, G.M. Limnologia comparativa de Três Lagoas (duas "Baias" e uma "Salina") do Pantanal da Nhecolândia, Mato Grosso do Sul. São Carlos, 1989. (Mestrado - Universidade Federal de São Carlos).

MOURÃO, G.M.; BAYLISS, P.; COUTINHO, M.E.; ABERCROMBIE, C.L.; ARRUDA, A.. Test of an aerial survey for Caiman and other wildlife in the Pantanal, Brazil. Wildlife Society Bulletin, Bethesda, 22: 50-6, 1994. 
MOURÃO, G.M.; COUTINHO, M.E.; CAMPOS, Z.M.S.; ABERCROMBIE, C.L. Growth of the caimam, Caiman crocodilus yacare, in the Pantanal, Brazil. No prelo.

NELDER, J.A. \& WEDDERBURN, W.M. Generalized liner models. Journal of the Royal Statistical Society. Ser. A, London, 135(3): 370-84, 1972.

OTIS, D.L.; BURNHAM, K.P.; WHITE, G.C.; ANDERSON, D.R. Statistical inference for capture data on closed animal populations, Wildlife Monographs, Bethesda, 62: 1-35, 1978.

PAYNE, C.D. The GLIM System Release 3.77 Manual, Oxford, Numerical Algorithms Group, 1986. 3 partes.

PETERSEN, G.G.J. The yearly immigration of young plaice into the Limfjord from the German Sea. Rept. Danish Biol. Sta., 6: 1-48, 1896.

POLLOCK, K.H. A capture-recapture design robust to unequal probability of capture. Journal of Wildlife Management, Bethesda, 46: 752-57, 1982.

POLLOCK, K.H. \& OTTO, M.C. Robust estimation of population size in closed animal populations from capture-recapture experiments. Biometrics, Alexandria, 39: 1035-49, 1983. 
POLLOCK, K.H.; HINES, J.E.; NICHOLAS, J.D. The use of auxiliary variables in capture-recapture experiments. Biometrics, Alexandria, 40: 329-40, 1984.

POLLOCK, K.H. Modeling capture, recapture and removal atatistics for estimation of demographics parameters for fish and wildlife populations: past, present and future. Journal of the American Statistical Association, Alexandria, 86: 225-38, 1991.

POLLOCK, K.H.; NICHOLS, J.D.; BROWNIE, C; HINES, J.E. Statistical inference for capture-recapture experiments. Wildlife Monographs, Bethesda, 107: 1-97, 1990.

QUENOUILLE, M.H. Notes on bias redution. Biometrika, London, 43: 353-60, 1956.

SCHNABEL, Z.E. The estimation of total fish population of a lake. American Mathematical Monthly, Washington, 45: 348-52, 1938.

SEBER, G.A.F. A note on the multiple recapture census. Biometrika, London, 52: 249-59, 1965.

SEBER, G.A.F. The estimation of animal abundance and related parameters. London, Griffin, 1982. 557p. 
SEBER, G.A.F. A review of estimating animal abundance. Biometrics, Alexandria, 42: 267-92, 1986.

SEBER, G.A.F. A review of estimating animal abundance. II. International Statistical Review, Voorburg, 60(2): 129-66, 1992.

WHITE, G.C.; ANDERSON, D.R.; BURNHAM, K.P.; OTIS, D.L. Capturerecapture and removal methods for sampling closed populations. Los Alamos, NM: Los Alamos National Laboratory, 1982. 225p.

ZIPPIN, C. An evaluation of the removal methods of estimating animal populations. Biometrics, Alexandria, 12(2): 163-89, 1956. 


\section{APÊNDICE}

Apêndice 1 - Contagens observadas das histórias de captura e programa do SAS utilizado para a sua obtenção. A área hachurada representa a situação com 4 ocasiões de amostragens.

\begin{tabular}{|c|c|c|c|c|c|c|c|c|c|c|c|c|c|c|c|}
\hline \multicolumn{5}{|c|}{4 OCASIÖES } & & & & & & & \multicolumn{5}{|c|}{5 OCASIŌES } \\
\hline 1 & 2 & 3 & 4 & $r_{n}$ & \multicolumn{5}{|c|}{ NOTAÇÃO } & $r_{a}$ & 1 & 2 & 3 & 4 & 5 \\
\hline $\mathrm{V}$ & $\mathrm{V}$ & $\mathrm{V}$ & $\mathrm{V}$ & 0 & 1 & 1 & 1 & 1 & 1 & 0 & $\mathrm{~V}$ & $\mathrm{~V}$ & $\mathrm{~V}$ & $\mathrm{~V}$ & $\mathrm{~V}$ \\
\hline $\mathbf{N}$ & V & V & $\mathrm{V}$ & 0 & 2 & 1 & 1 & 1 & 1 & 0 & $\mathrm{~N}$ & v & $\mathrm{V}$ & $\mathrm{V}$ & v \\
\hline V & $\mathrm{N}$ & V & V & 3 & 1 & 2 & 1 & 1 & 1 & 0 & V & $\mathrm{N}$ & V & $\mathrm{V}$ & v \\
\hline N & $\mathrm{N}$ & V & V & 9 & 2 & 2 & 1. & 1 & 1 & 0 & $\mathrm{~N}$ & $\mathrm{~N}$ & V & v & V \\
\hline V & V & $\mathrm{N}$ & V & 1 & 1 & 1 & 2 & 1 & 1 & 0 & v & v & $\mathrm{N}$ & v & v \\
\hline $\mathbf{N}$ & $\mathrm{V}$ & $\mathrm{N}$ & $\mathrm{v}$ & 0 & 2. & 1 & 2 & 1 & 1 & 0 & $\mathrm{~N}$ & v & $\mathrm{N}$ & $\mathrm{v}$ & V \\
\hline V & $\mathrm{N}$ & $\mathrm{N}$ & V & 4 & 1 & 2 & 2 & 1 & 1 & 0 & V & $\mathrm{N}$ & $\mathrm{N}$ & $\mathrm{v}$ & $\mathrm{V}$ \\
\hline $\mathbf{N}$ & $\mathrm{N}$ & $\mathrm{N}$ & V & 219 & 2 & 2 & 2 & 1 & 1 & 0 & $\mathrm{~N}$ & $\mathrm{~N}$ & $\mathrm{~N}$ & v & v \\
\hline $\mathrm{V}$ & V & $\mathrm{V}$ & $\mathrm{N}$ & 5 & 1 & 1 & 1 & 2 & 1 & 0 & $\mathrm{v}$ & $\mathrm{v}$ & $\mathrm{V}$ & $\mathrm{N}$ & V \\
\hline $\mathbf{N}$ & V & v & $\mathrm{N}$ & 0 & 2 & 1 & 1 & 2 & 1 & 0 & $\mathrm{~N}$ & v & V & $\mathrm{N}$ & V \\
\hline $\mathrm{V}$ & $\mathrm{N}$ & V & $\mathrm{N}$ & 373 & 1 & 2 & 1 & 2 & 1 & 0 & v & $\mathrm{N}$ & $\mathrm{V}$ & $\mathrm{N}$ & v \\
\hline $\mathrm{N}$ & $\mathrm{N}$ & V & $\mathrm{N}$ & 551 & 2 & 2 & 1 & 2 & 1 & 0 & $\mathrm{~N}$ & $\mathrm{~N}$ & V & $\mathrm{N}$ & v \\
\hline V & V & $\mathrm{N}$ & $\mathrm{N}$ & 178 & 1 & 1 & 2 & 2 & 1 & 0 & v & V & $\mathrm{N}$ & $\mathrm{N}$ & $\mathrm{V}$ \\
\hline $\mathrm{N}$ & V & $\mathrm{N}$ & $\mathrm{N}$ & 10 & 2 & 1 & 2 & 2 & 1 & 0 & $\mathrm{~N}$ & $\mathrm{~V}$ & $\mathrm{~N}$ & $\mathrm{~N}$ & $V$ \\
\hline V & $\mathrm{N}$ & $\mathrm{N}$ & $\mathrm{N}$ & 394 & 1 & 2 & 2 & 2 & 1 & 0 & V & $\mathrm{N}$ & $\mathrm{N}$ & $\mathrm{N}$ & $\mathrm{V}$ \\
\hline $\mathrm{N}$ & $\mathrm{N}$ & $\mathrm{N}$ & $\mathrm{N}$ & - & 2 & 2 & 2 & 2 & 1 & 70 & $\mathrm{~N}$ & $\mathrm{~N}$ & $\mathrm{~N}$ & $\mathrm{~N}$ & $\mathrm{~V}$ \\
\hline & & & & & 1 & 1 & 1 & 1 & 2 & 0 & V & $\mathrm{V}$ & V & V & $\mathrm{N}$ \\
\hline & & & & & 2 & 1 & 1 & 1 & 2 & 0 & $\mathrm{~N}$ & $\mathrm{~V}$ & V & V & $\mathrm{N}$ \\
\hline & & & & & 1 & 2 & 1 & 1 & 2 & 3 & V & $\mathrm{N}$ & V & V & $\mathrm{N}$ \\
\hline & & & & & 2 & 2 & 1 & 1 & 2 & 9 & $\mathrm{~N}$ & $\mathrm{~N}$ & V & V & $\mathrm{N}$ \\
\hline & & & & & 1 & 1 & 2 & 1 & 2 & 1 & V & $\mathrm{V}$ & $\mathrm{N}$ & V & $\mathrm{N}$ \\
\hline & & & & & 2 & 1 & 2 & 1 & 2 & 0 & $\mathrm{~N}$ & $\mathrm{~V}$ & $\mathrm{~N}$ & V & $\mathrm{N}$ \\
\hline & & & & & 1 & 2 & 2 & 1 & 2 & 4 & 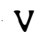 & $\mathrm{N}$ & $\mathrm{N}$ & V & $\mathrm{N}$ \\
\hline & & & & & 2 & 2 & 2 & 1 & 2 & 149 & $\mathrm{~N}$ & $\mathrm{~N}$ & $\mathrm{~N}$ & v & $\mathrm{N}$ \\
\hline & & & & & 1 & 1 & 1 & 2 & 2 & 5 & $\mathrm{~V}$ & $\mathrm{~V}$ & $\mathrm{~V}$ & $\mathrm{~N}$ & $\mathrm{~N}$ \\
\hline & & & & & 2 & 1 & 1 & 2 & 2 & 0 & $\mathrm{~N}$ & V & $\mathrm{V}$ & $\mathrm{N}$ & $\mathrm{N}$ \\
\hline & & & & & 1 & 2 & 1 & 2 & 2 & 373 & V & $\mathrm{N}$ & $\mathrm{V}$ & $\mathrm{N}$ & $\mathrm{N}$ \\
\hline & & & & & 2 & 2 & 1 & 2 & 2 & 551 & $\mathrm{~N}$ & $\mathrm{~N}$ & $\mathrm{~V}$ & $\mathrm{~N}$ & $\mathrm{~N}$ \\
\hline & & & & & 1 & 1 & 2 & 2 & 2 & 178 & $\mathrm{~V}$ & $\mathrm{~V}$ & $\mathrm{~N}$ & $\mathrm{~N}$ & $\mathrm{~N}$ \\
\hline & & & & & 2 & 1 & 2 & 2 & 2 & 10 & $\mathrm{~N}$ & $\mathrm{~V}$ & $\mathrm{~N}$ & $\mathrm{~N}$ & $\mathrm{~N}$ \\
\hline & & & & & 1 & 2 & 2 & 2 & 2 & 394 & $\mathrm{~V}$ & $\mathrm{~N}$ & $\mathrm{~N}$ & $\mathrm{~N}$ & $\mathrm{~N}$ \\
\hline & & & & & 2 & 2 & 2 & 2 & 2 & - & $\mathrm{N}$ & $\mathrm{N}$ & $\mathrm{N}$ & $\mathrm{N}$ & $\mathrm{N}$ \\
\hline
\end{tabular}

$\mathrm{N}$ - não visto

$\mathrm{V}$ - visto 


\section{Programa no SAS para obtenção das frequências nas histórias de captura a partir dos dados brutos.}

\section{Considerando $(S=5)$ ocasiões de amostragens}

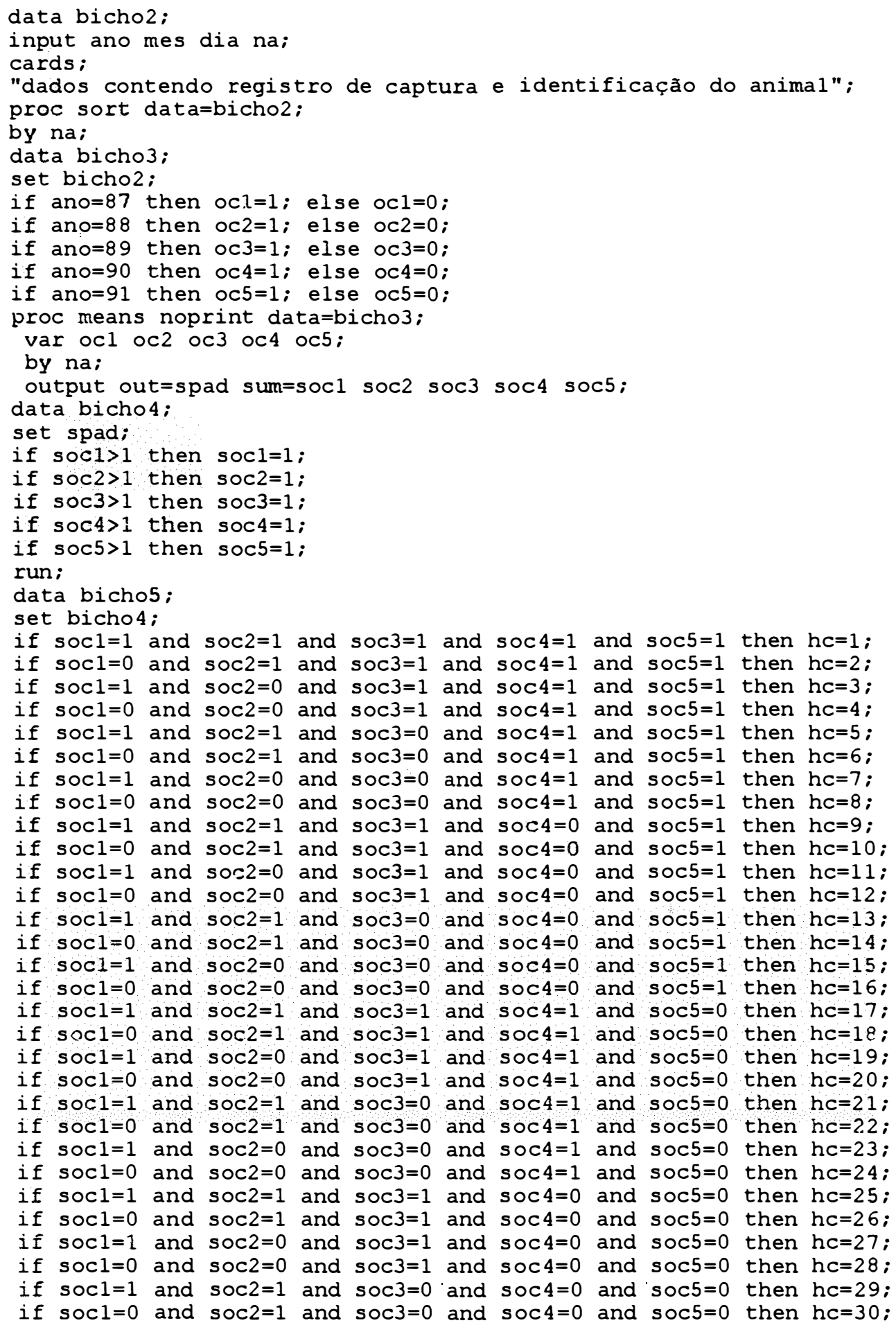


if $\operatorname{soc} 1=1$ and $\operatorname{soc} 2=0$ and $\operatorname{soc} 3=0$ and $\operatorname{soc} 4=0$ and $\operatorname{soc} 5=0$ then $h c=31$;

run;

proc sort data=bicho5;

by he;

proc freq data=bicho5;

tables na;

by hc;

proc means noprint data=bicho5;

var na;

by hc;

output out=npad $\mathrm{n}=\mathrm{hc}$;

run;

proc print data=npad;

run;

\section{Considerando ( $S=4$, agnupamento dos anos 90-91) ocasiões de amostragens}

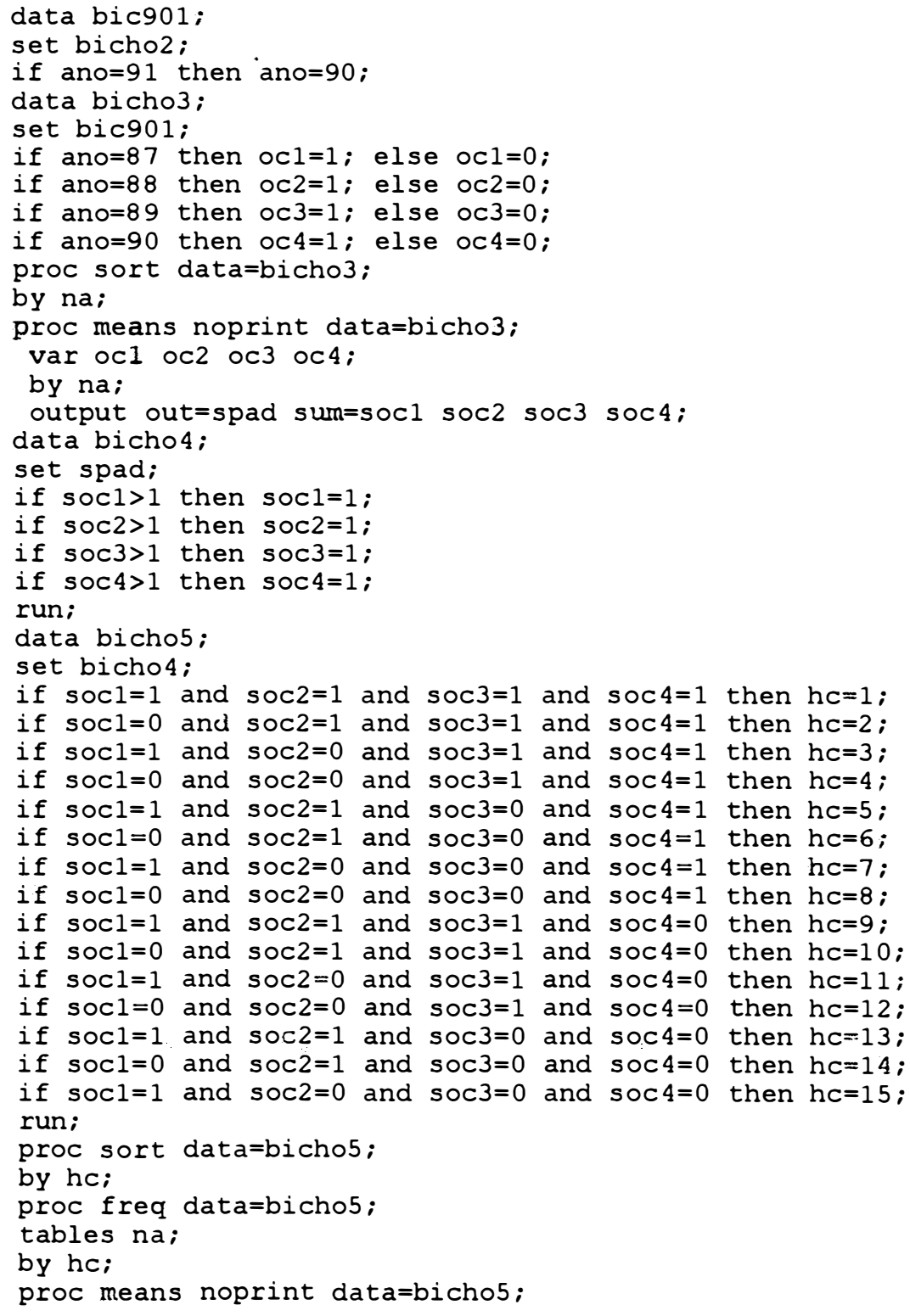


var na;

by hc:

output out=npad $n=n a$; proc print data=npad;

run; 
Apêndice 2 - Programa do GLIM para a análise dos dados, adaptado de CORMACK(1985).

\section{Análise dos dados com $\mathrm{S}=5$ sem correção}

[o] GLIM 3.77 (copyright) 1984 Royal Statistical Society, London

[0]

[i] ? \$UNITS 31 \$DATA R \$READ

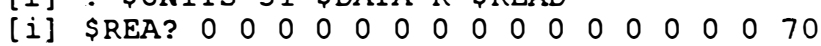

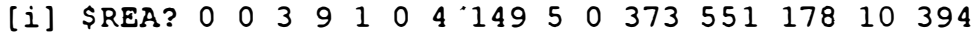

[i] ? \$INPUT 7 CR1 CR5 \$

[i] File name? RECAP. GLM

[i] \$MAC EST

[i] $\$$ CAI $8 E=2 * \star(8 \mathrm{~S}+8 \mathrm{~K}-1): 8 \mathrm{~F}=2 \star \star(-8 \mathrm{~K}): 8 \mathrm{~J}=8 \mathrm{~S}+8 \mathrm{~K}$

[i] $\$ C A L M(8 J)=8 F V(1)+8 F V(8 E+1)$

[i] $\$ C A L A F T=A F T *(2-8 G L(2,8 E))$

[i] $\$ C A L A A(\& J)=8 C U(A F T \star \& F V)$

[i] $\$ C A L B E F=B E B^{\star}(2-8 \mathrm{GL}(2,8 F))$

[i] $\quad \$ C A I B B(1-8 K)=8 C U(B E F \star 8 F V)$

[i] $\$ C A L \quad 8 \mathrm{~K}=8 \mathrm{~K}+1$

[i] \$ENDMAC

[i] \$MAC USE

[i] $\$ C A L A F T=1: B E F=1: 8 \mathrm{~K}=1-8 \mathrm{~S}$

[i] SVAR \&S AA BB M PERM PHIH

[i] $\$ C A L A A=1: M=1$

[i] \$WHILE \& K EST

[i] $\$ C A L$ PERM $=8 G L(8 S, 1)-1:: \operatorname{PERM}(1)=8 \mathrm{~S}: \operatorname{BB}(1)=8 F V(1)$

[i] $\$ C A L A A(\& S)=B B(1): C C=A A(P E R M): M(\& S)=C C(\& S)$

[i] $\$ C A L P H=8 F V(1) / M$

[i] \$CAL TEMP=PH :TEMP (1)=TEMP (2):TEMP $(z S)=\operatorname{TEMP}(z S-1)$

[i] \$SORT TEMP

[i] $\$ C A L \& A=T E M P(\& S)-T E M P(1): 8 C=10 * \star(-4)$

[i] $\$$ CAL NEST $=A A^{\star} M \star B B / \& F V(1) \star \star 2$

[i] $\$ C A L P H I H=A A \star M /(C C \star \& E V(1))$

[i] \$CAL $8 B=8 L E(\& A, 8 C)$

[i] \$SWITCH \&B CONST \$

[i]

[i] \$PRINT 


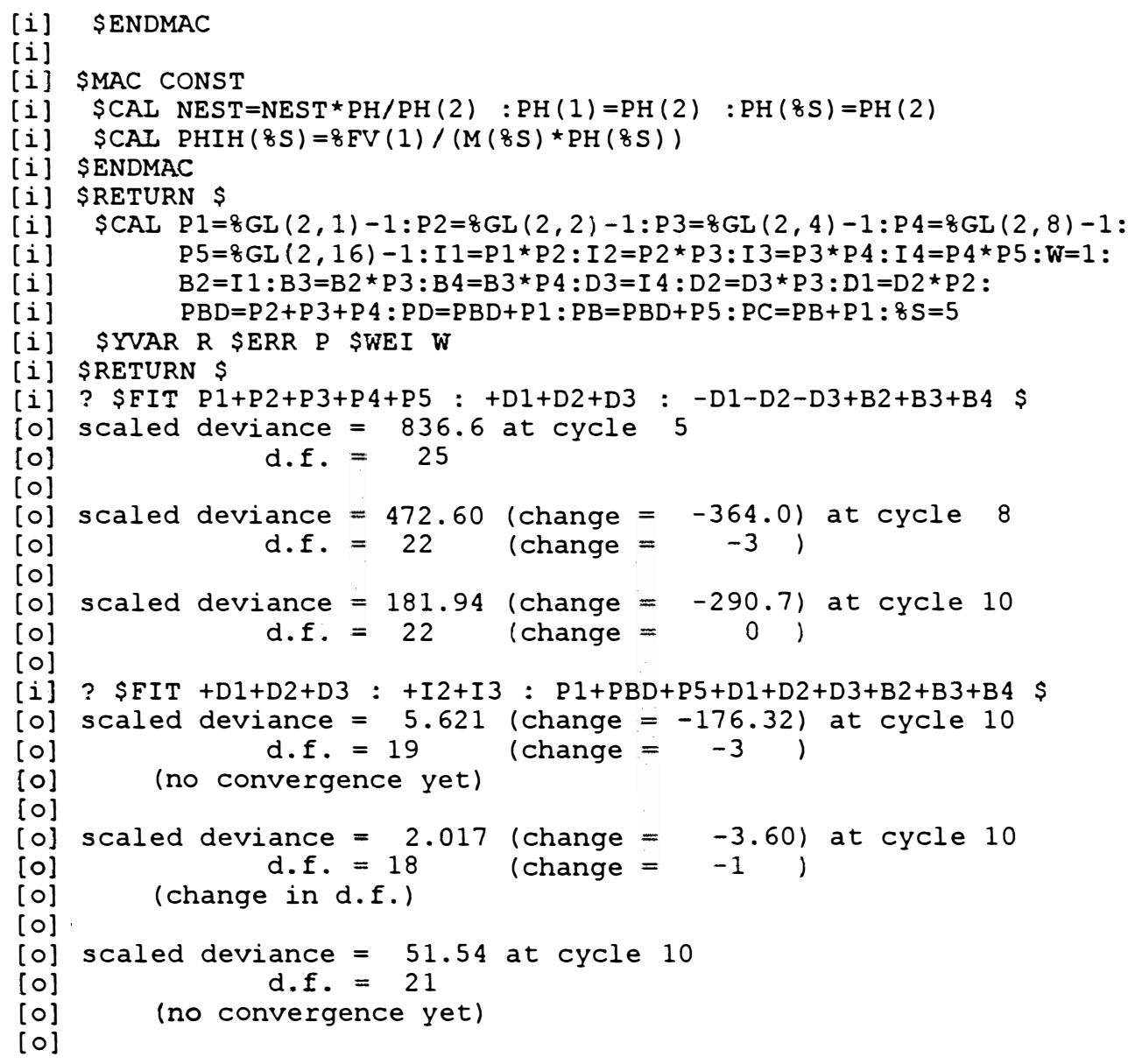

\section{Análise do modelo selecionado com nascimento e morte}

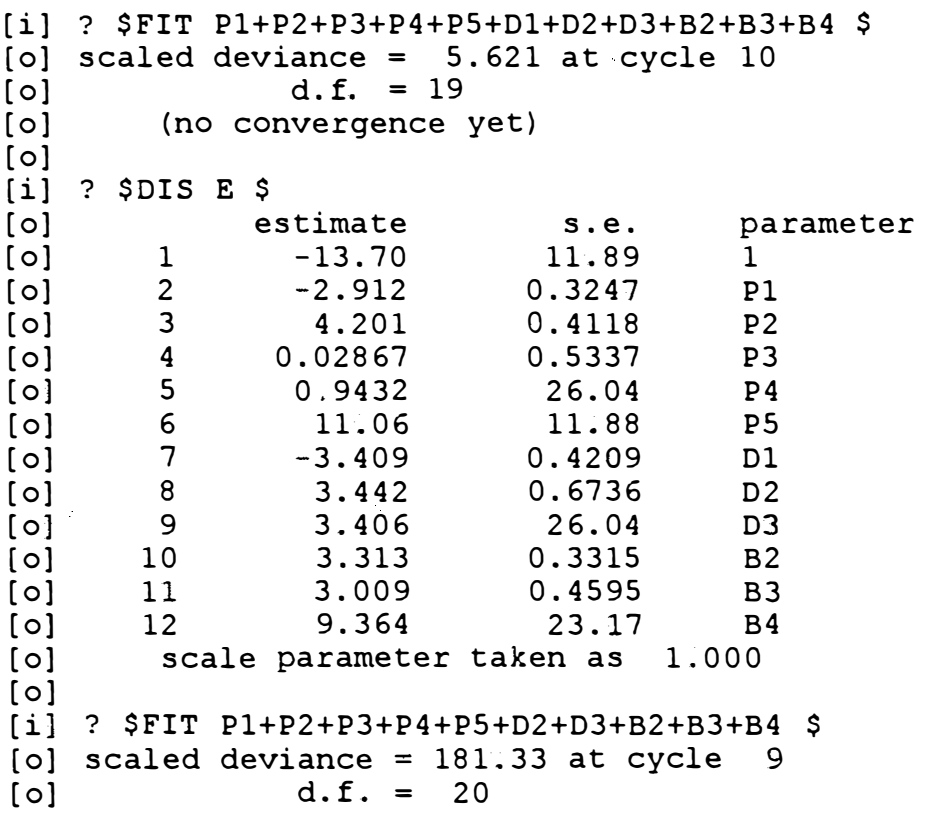




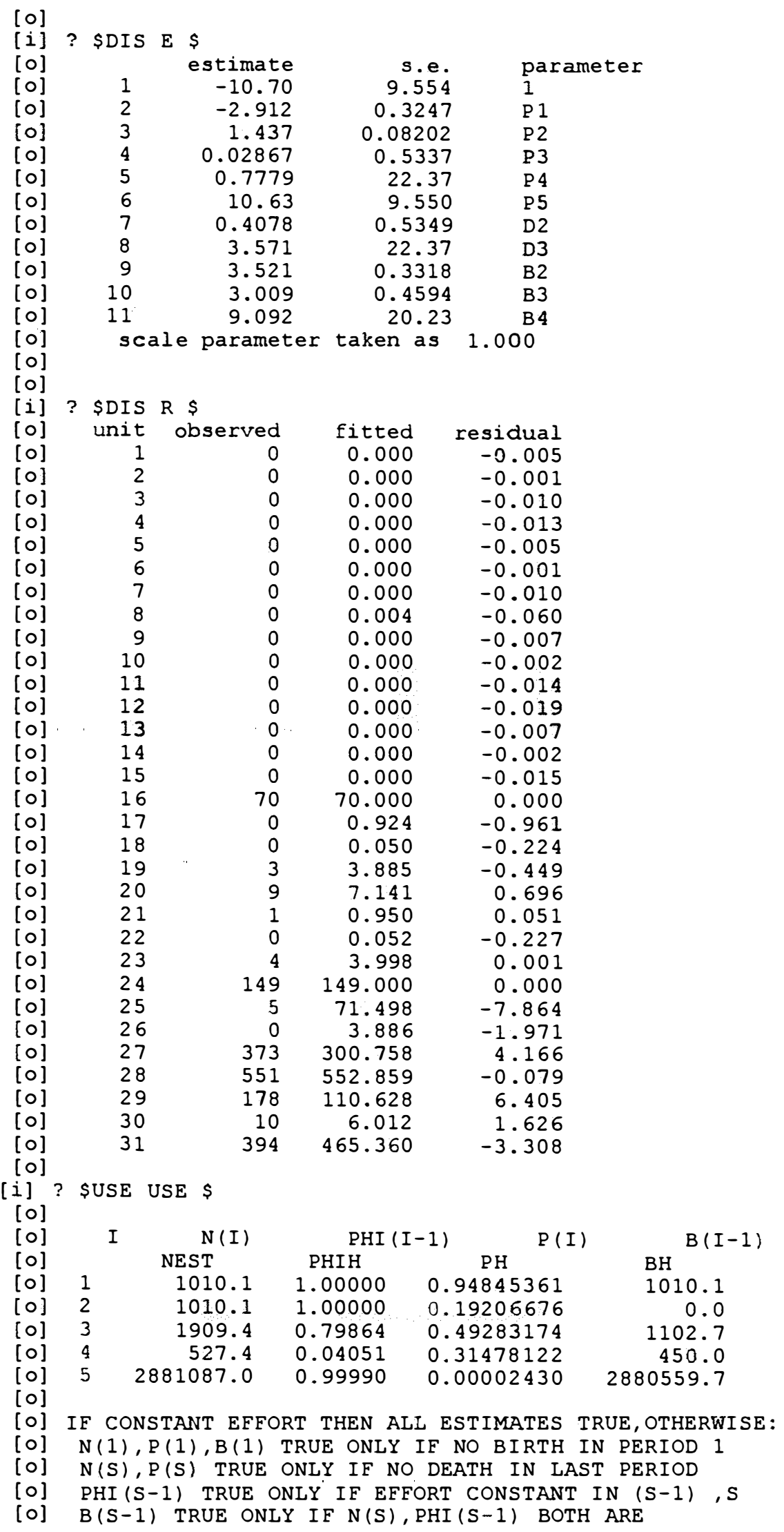


[0]

\section{Análise do modelo com constante esforço de amostragem}

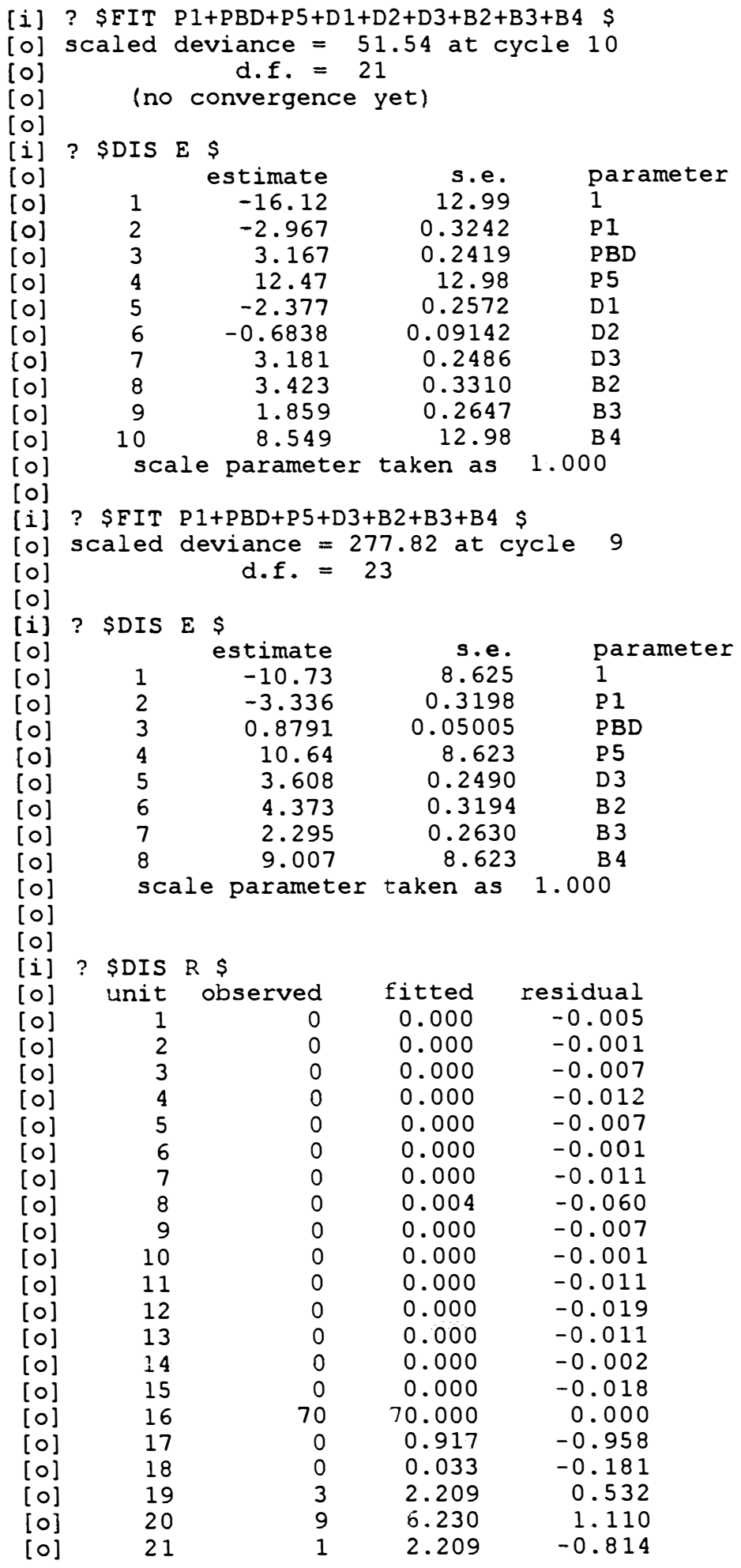




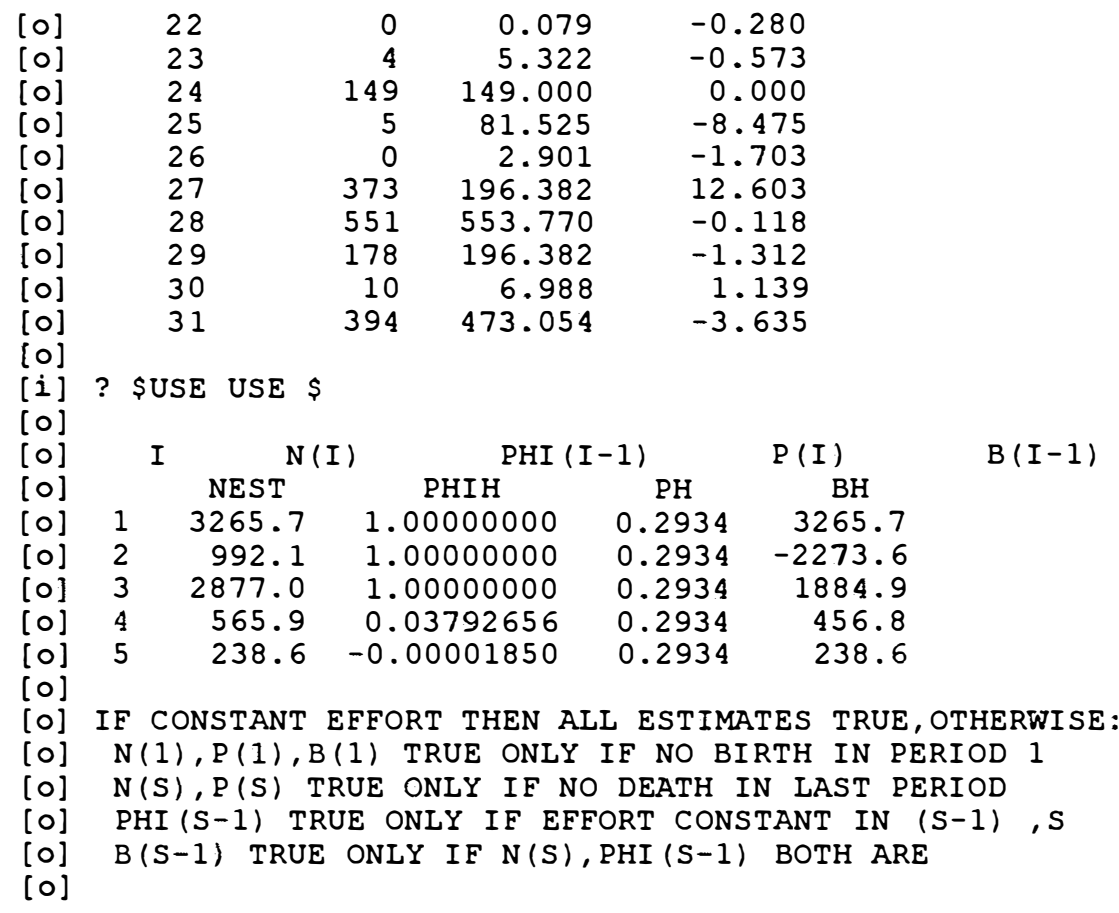

\section{Análise dos dados com $\mathrm{S}=5$ mais a correção}

[0] GLIM 3.77 (copyright) 1984 Royal Statistical Society, London [0]

[i] ? \$UNITS 31 \$DATA R \$READ

[i] \$REA? 0.06250 .06250 .06250 .0625

[i] \$REA? 0.06250 .06250 .06250 .0625

[i] \$REA? $0.0625 \quad 0.06250 .06250 .0625$

[i] \$REA? $0.06250 .06250 .0625 \quad 70.0625$

[i] \$REA? $0.06250 .0625 \quad 3.0625 \quad 9.0625$

[i] \$REA? $1.06250 .0625 \quad 4.0625 \quad 149.0625$

[i] \$REA? $5.0625 \quad 0.0625 \quad 373.0625 \quad 551.0625$

[i] \$REA? 178.062510 .0625394 .0625

[i] ? \$INPUT 7 CR1 CR5 \$

[i] File name? RECAP.GLM

[i] \$MAC EST

[i] $\$ C A L \& \bar{E}=2 * \star(8 S+8 K-1): 8 F=2 \star \star(-8 K): 8 J=8 S+8 K$

[i] $\quad \$ C A L M(z J)=8 F V(1)+8 F V(z E+1)$

[i] $\$ C A L A F T=A F T *(2-8 G L(2,8 E))$

[i] $\$ C A L A A(\& J)=8 C U(A F T \star \& F V)$

[i] $\$ C A L B E F=B E F^{\star}(2-8 G L(2,8 F))$

[i] $\$ C A L B B(1-8 \mathrm{~K})=8 \mathrm{CU}(\mathrm{BEF} \star 8 \mathrm{FV})$

[i] $\$ C A L \quad 8 \mathrm{~K}=8 \mathrm{~K}+1$

[i] \$ENDMAC

[i] \$MAC USE

[i] $\$ C A L A F T=1: B E F=1: 8 K=1-8 S$

[i] SVAR \&S AA BB M PERM PHIH

[i] $\$ C A L A A=1: M=1$

[i] \$WHILE \& K EST

[i] $\$ C A L \operatorname{PERM}=8 \mathrm{GL}(8 \mathrm{~S}, 1)-1: \operatorname{PERM}(1)=8 \mathrm{~S}: \operatorname{BB}(1)=8 \mathrm{FV}(1)$

[i] $\quad \$ C A L A A(\& S)=B B(1): C C=A A(P E R M): M(\& S)=C C(\& S)$

[i] $\$ C A L \mathrm{PH}=8 \mathrm{FV}(1) / \mathrm{M}$

[i] $\quad$ CAL TEMP $=\mathrm{PH}: \operatorname{TEMP}(1)=\operatorname{TEMP}(2) \quad: \operatorname{TEMP}(z \mathrm{~S})=\operatorname{TEMP}(z \mathrm{~S}-1)$

[i] \$SORT TEMP 


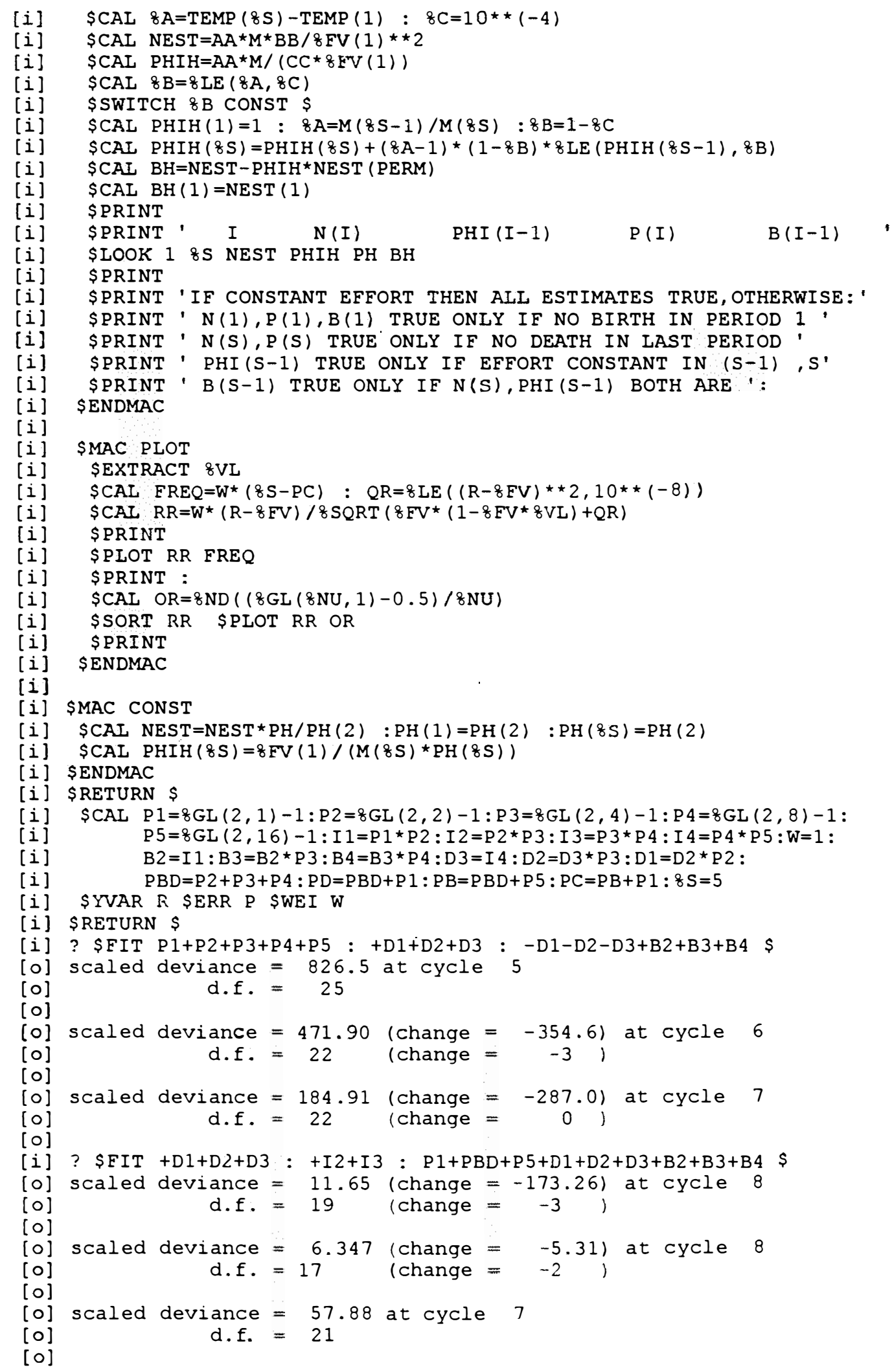


Análise do modelo selecionado com parâmetros de nascimento e morte

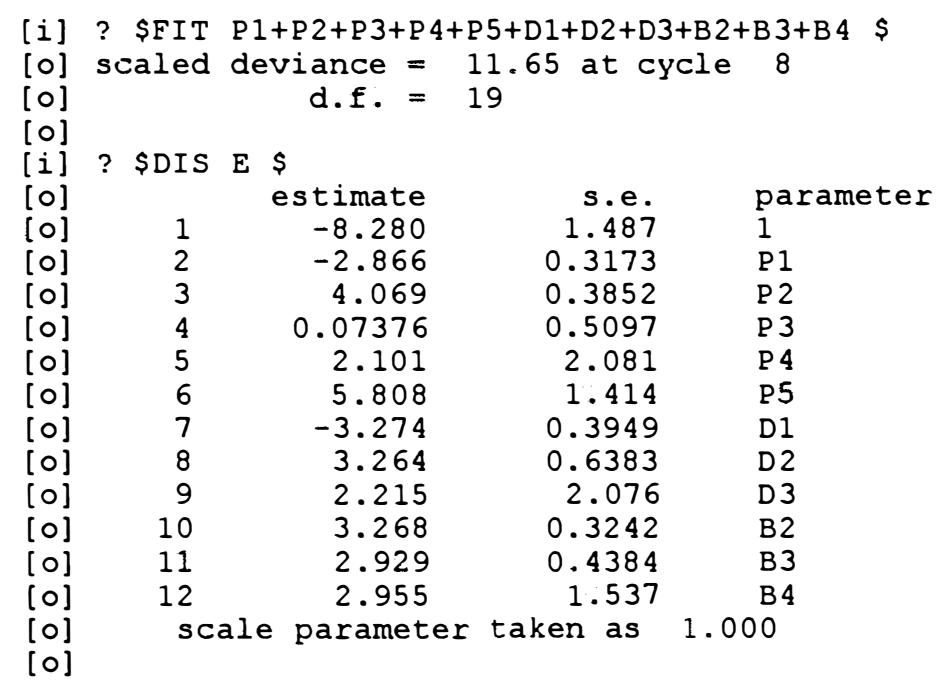

\section{Reajuste do modelo sem o parâmetro D1.}

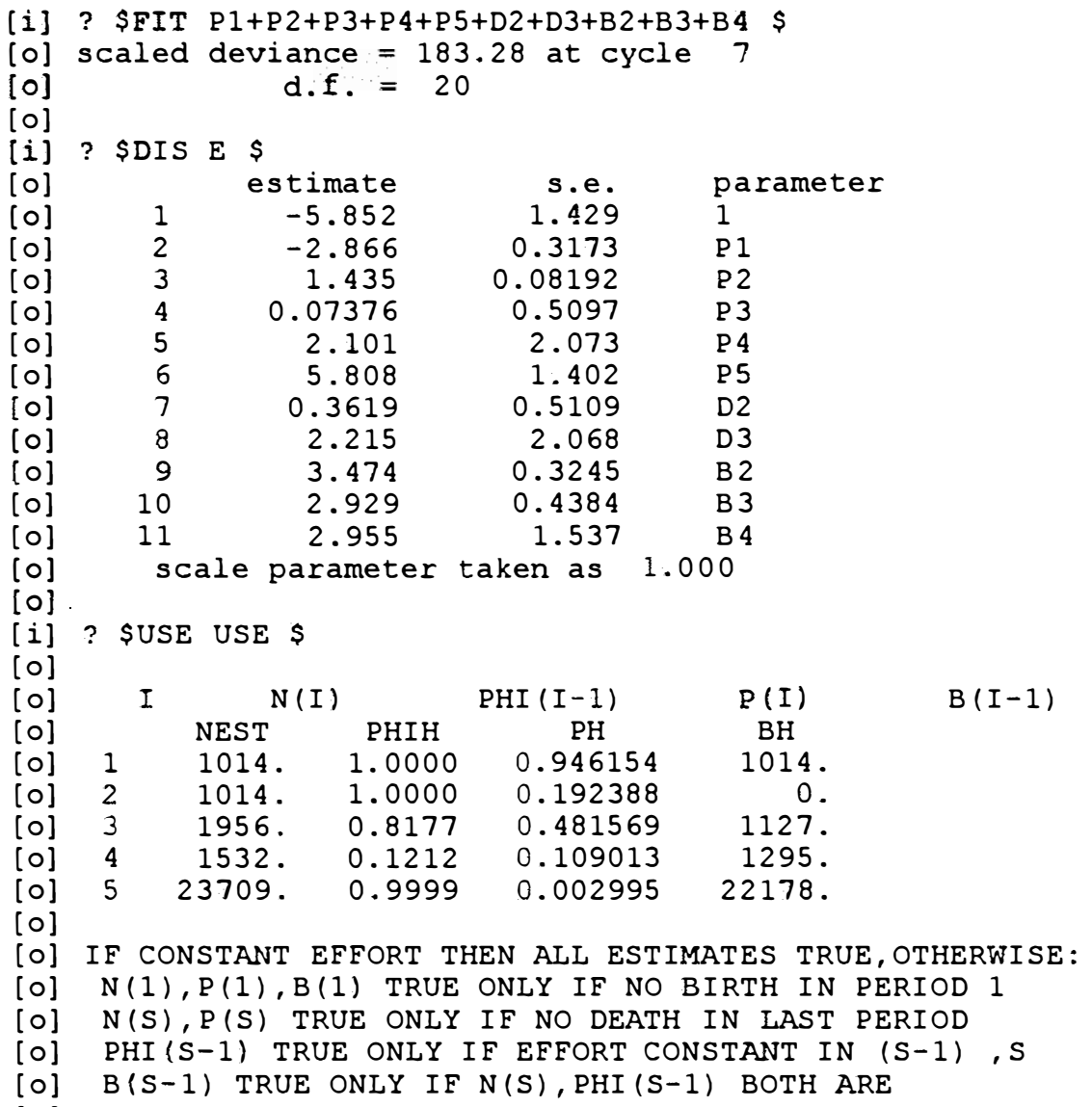


Análise do modelo com constante esforço de amostragem

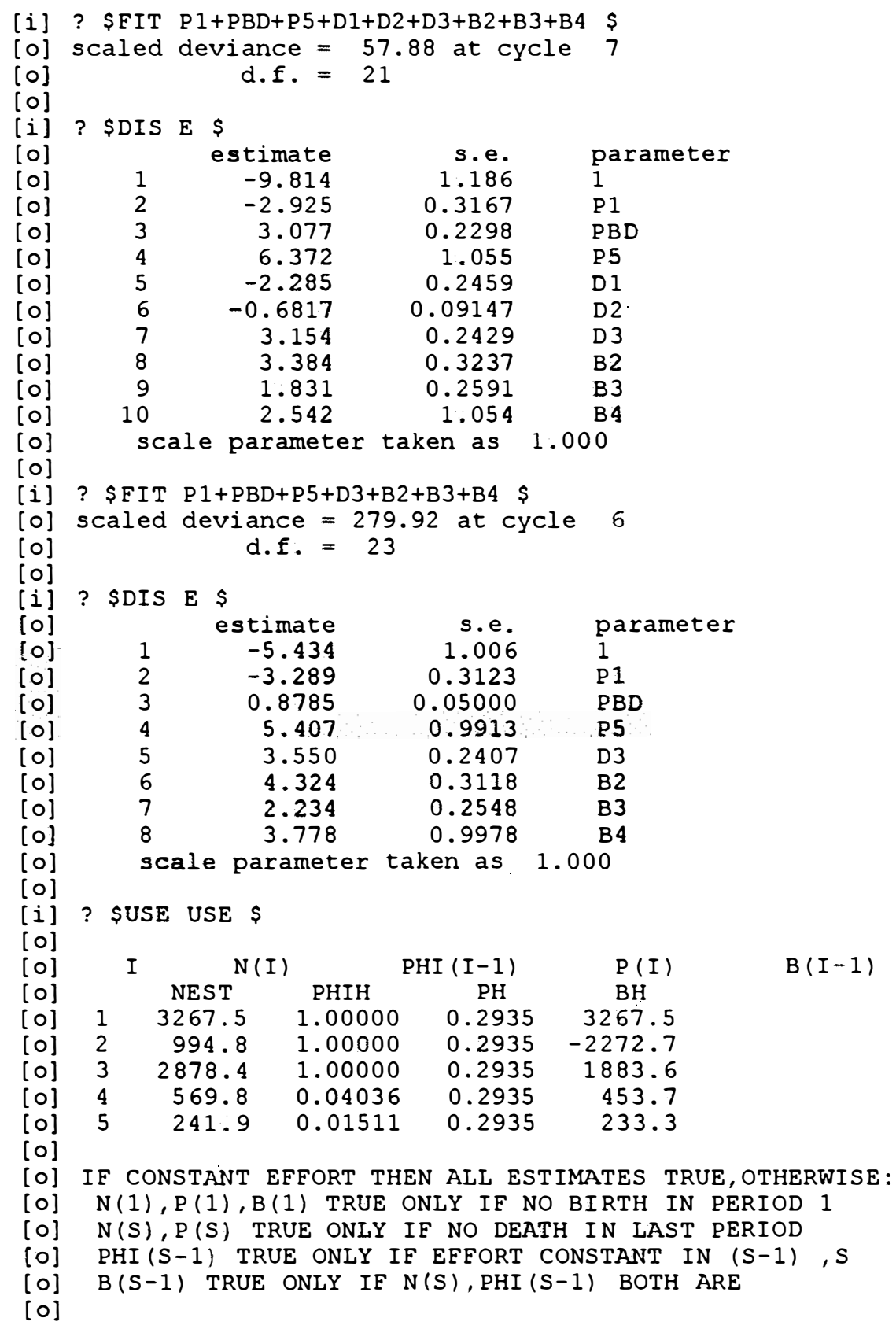

Verificação dos resíduos do modelo com parâmetros de nascimento e morte

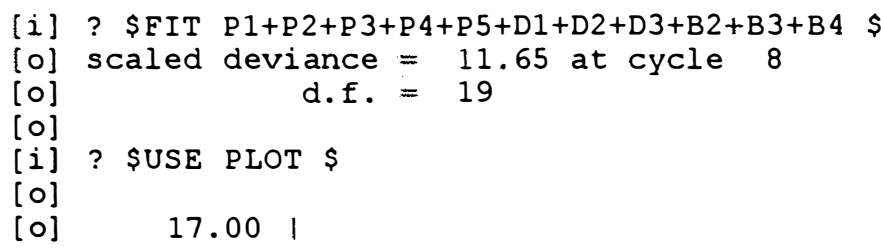




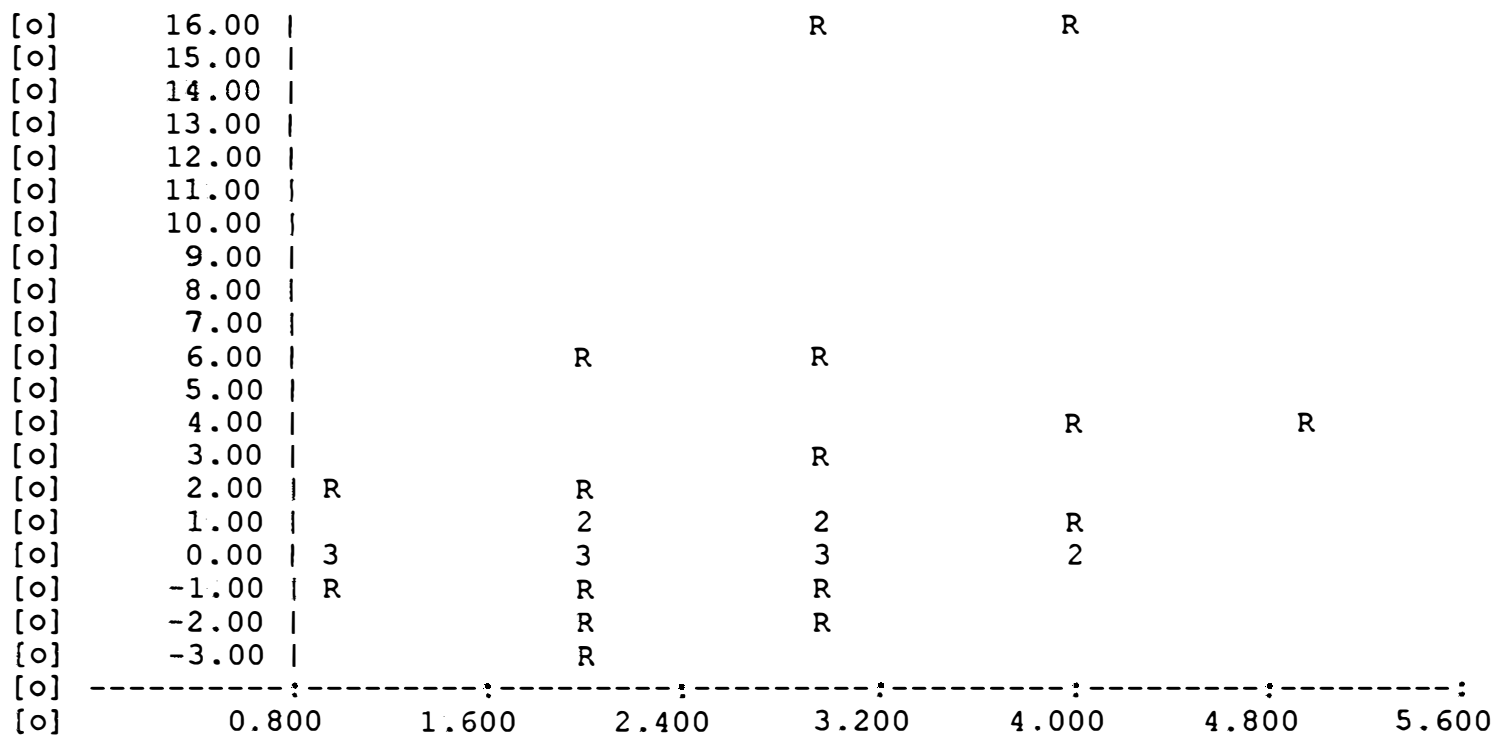




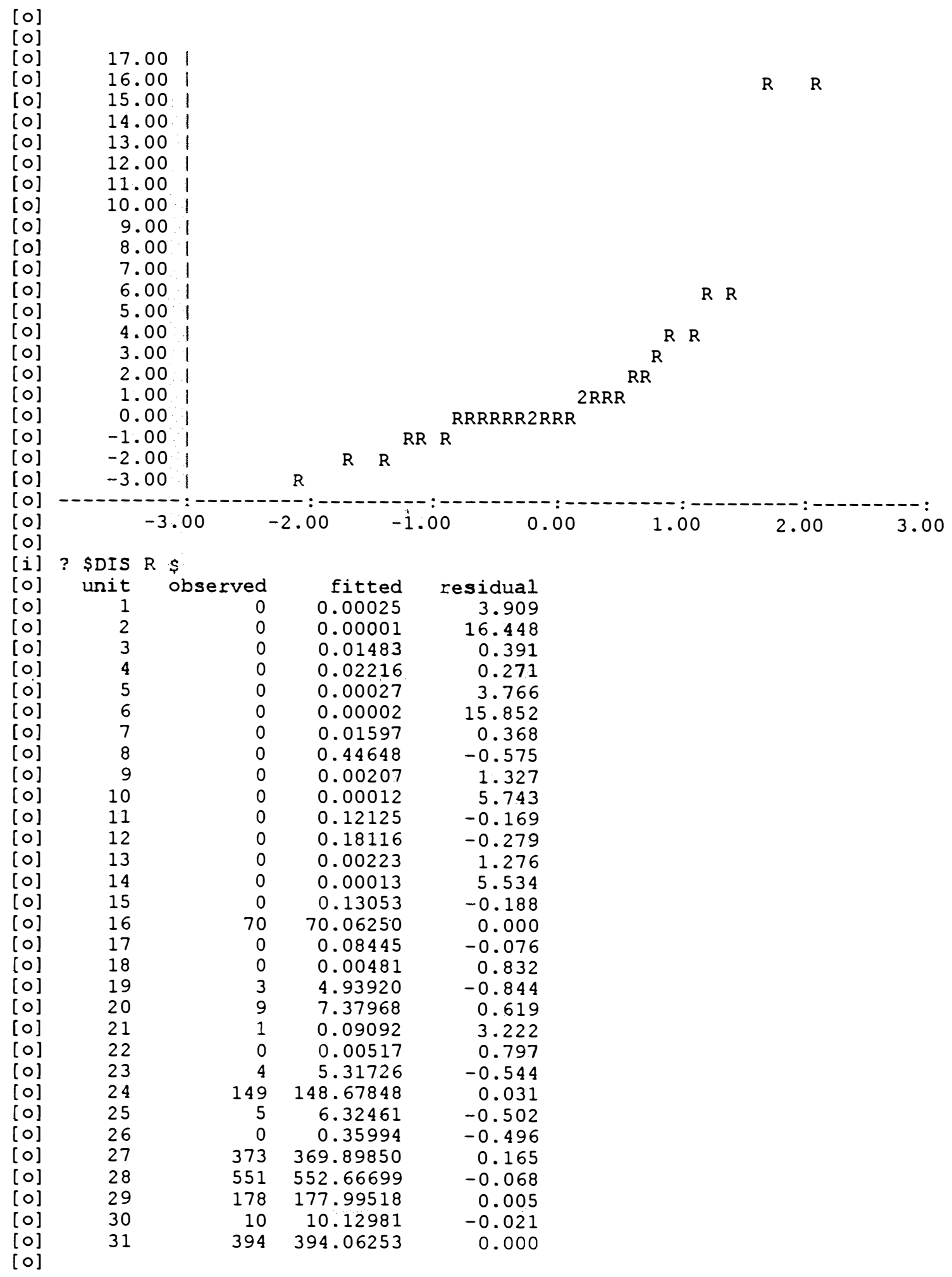




\section{Análise dos dados com agrupamento dos anos 90-91 ( $\mathrm{S}=4)$ mais a correção}

[0] GLIM 3.77 (copyright) 1984 Royal Statistical Society, London

[0]

[i] ? \$UNITS 15 \$DATA R \$READ

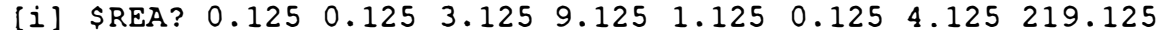

[i] \$REA? $5.125 \quad 0.125 \quad 373.125 \quad 551.125 \quad 178.125 \quad 10.125 \quad 394.125$

[i] ? \$INPUT 7 CR1 CR4 \$

[i] File name? RECAP.GLM

[i] \$MAC EST

[i] SCAL $8 E=2 \star \star(8 S+8 K-1): 8 F=2 \star \star(-8 K): 8 J=8 S+8 K$

[i] $\quad S \operatorname{CAL} M(8 J)=8 \mathrm{FV}(1)+8 \mathrm{FV}(8 \mathrm{E}+1)$

[i] $\$ C A L A F T=A F T \star(2-8 G L(2,8 E))$

[i] $\$ C A L A A(8 J)=8 C U(A F T * 8 F V)$

[i] $\quad \$ C A L \quad B E F=B E F^{\star}(2-8 \mathrm{GL}(2,8 F))$

[i] $\$ C A L B B\left(1-\frac{8}{} \mathrm{~K}\right)=8 \mathrm{CU}(\mathrm{BEF} \star \delta \mathrm{FV})$

[i] $\$ C A L$ \& $\mathrm{K}=8 \mathrm{~K}+1$

[i] \$ENDMAC

[i]

[i] $\$ \mathrm{CAL} \operatorname{PHIH}(z \mathrm{~S})=8 \mathrm{FV}(1) /(\mathrm{M}(8 \mathrm{~S}) \star \mathrm{PH}(z \mathrm{~S}))$ 


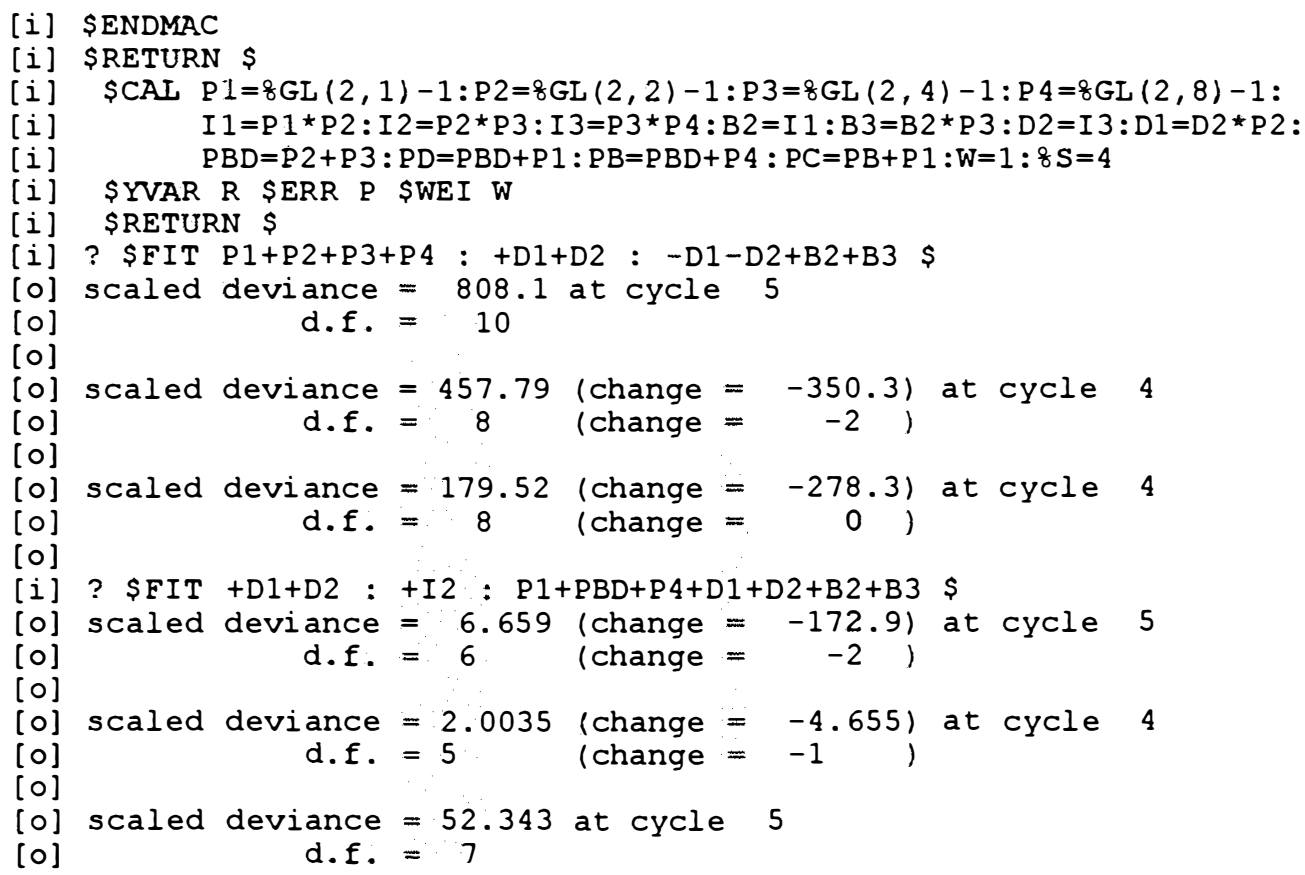

Análise do modelo selecionado com nascimento e morte mais "trapdependence"

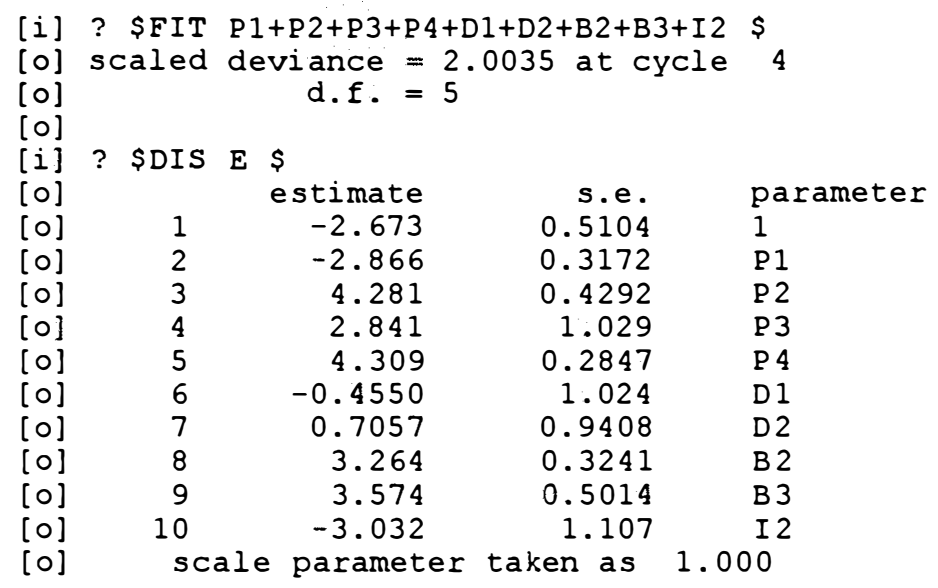

\section{Reajuste do modelo sem o parâmetro D1}

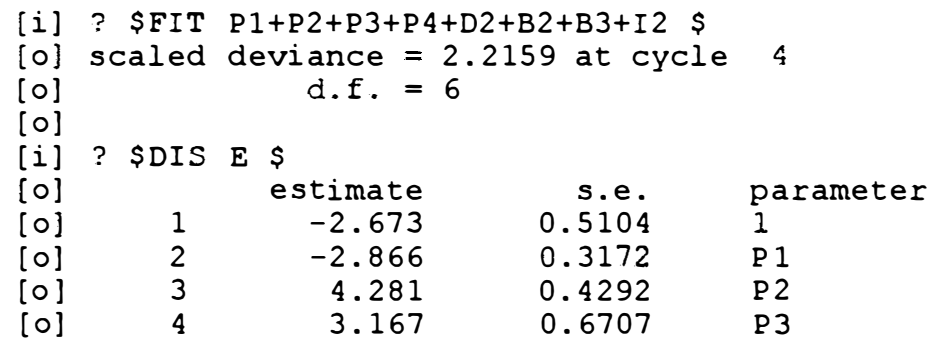




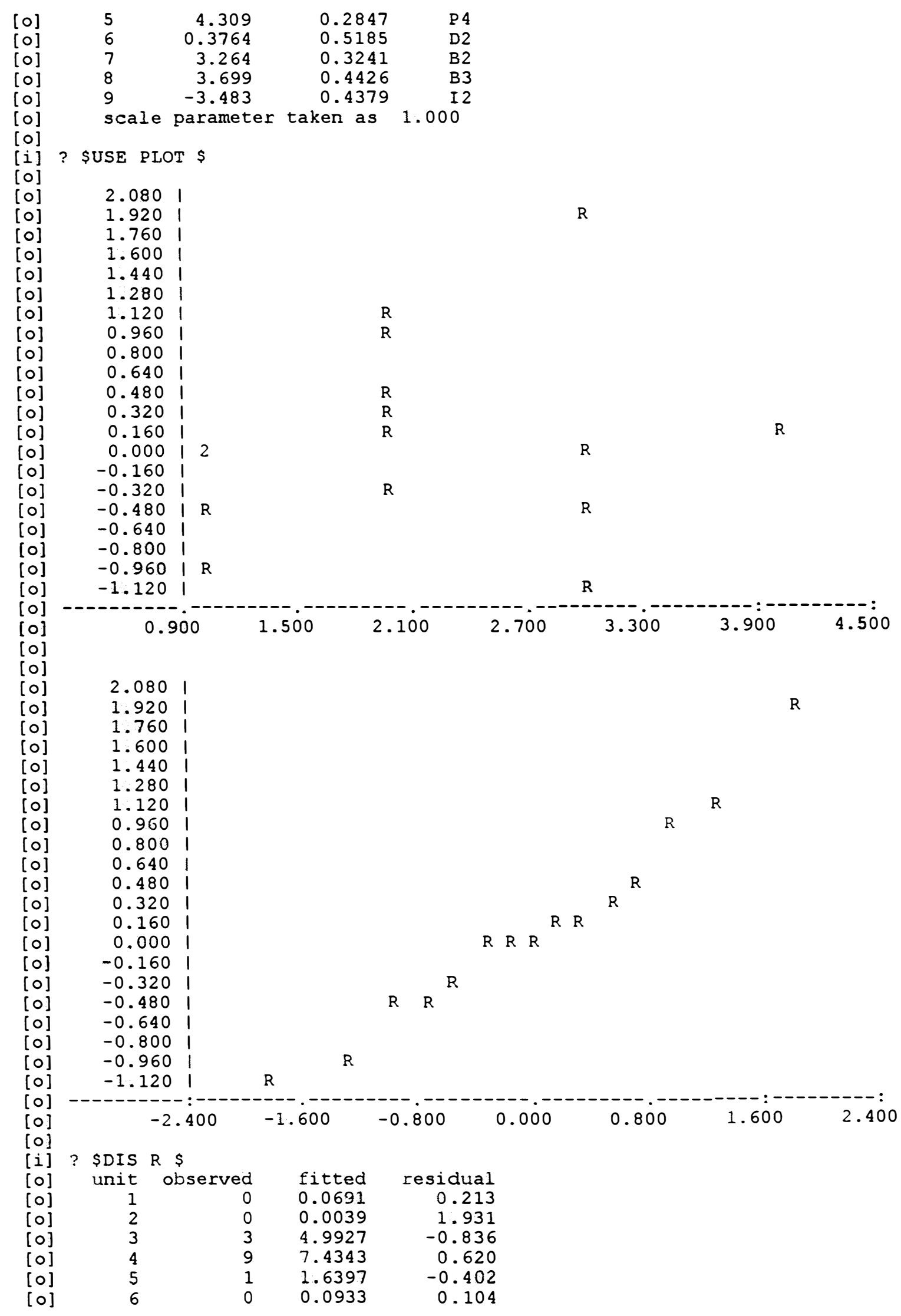




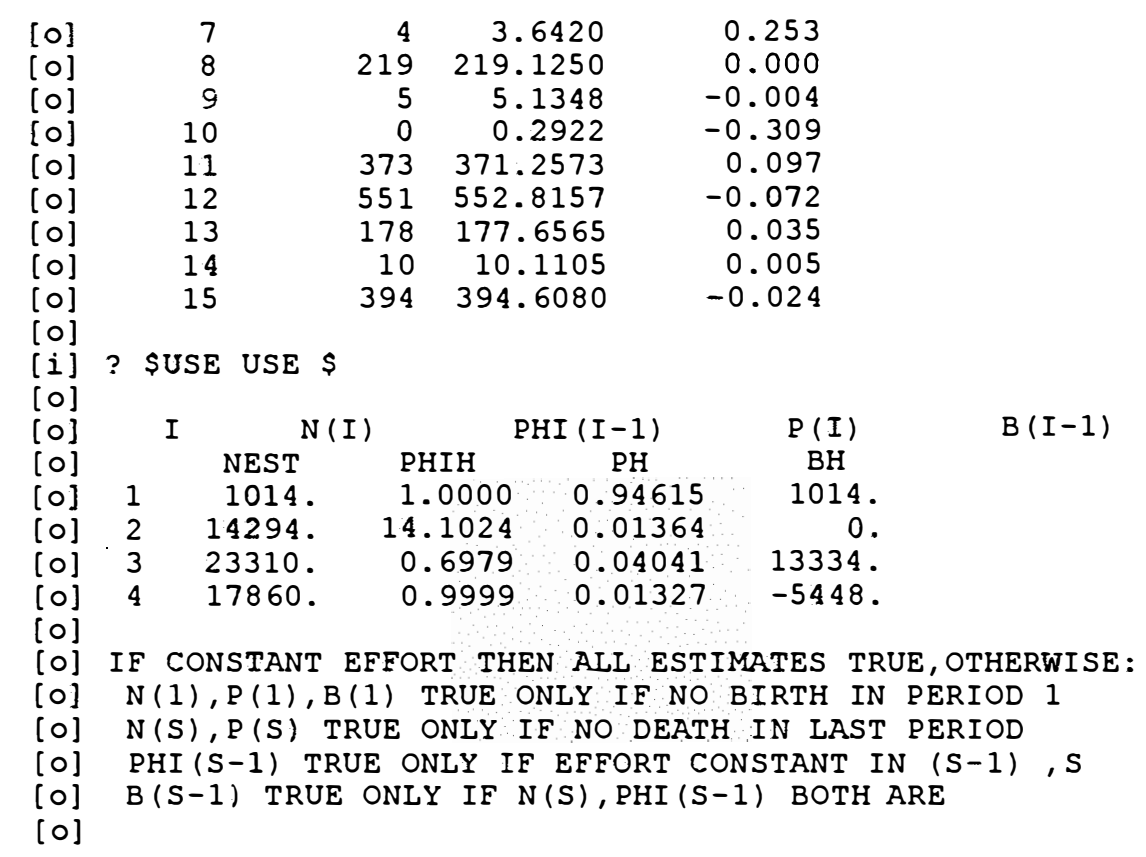

\section{Análise do modelo com constante esforço de amostragem}

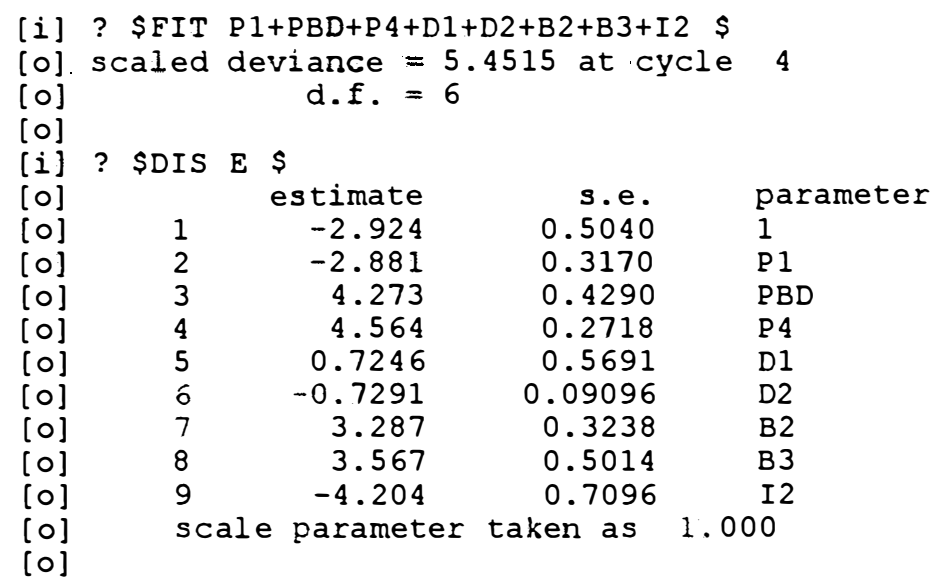

\section{Reajuste do modelo sem o parâmetro D2}

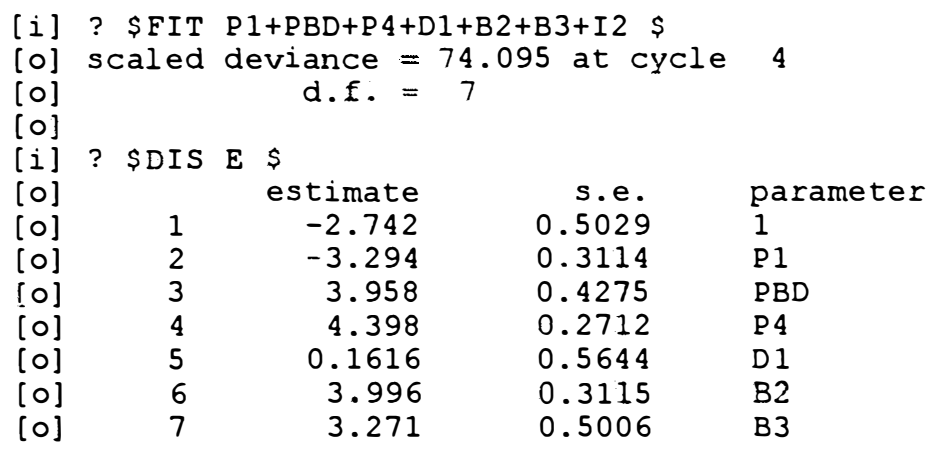




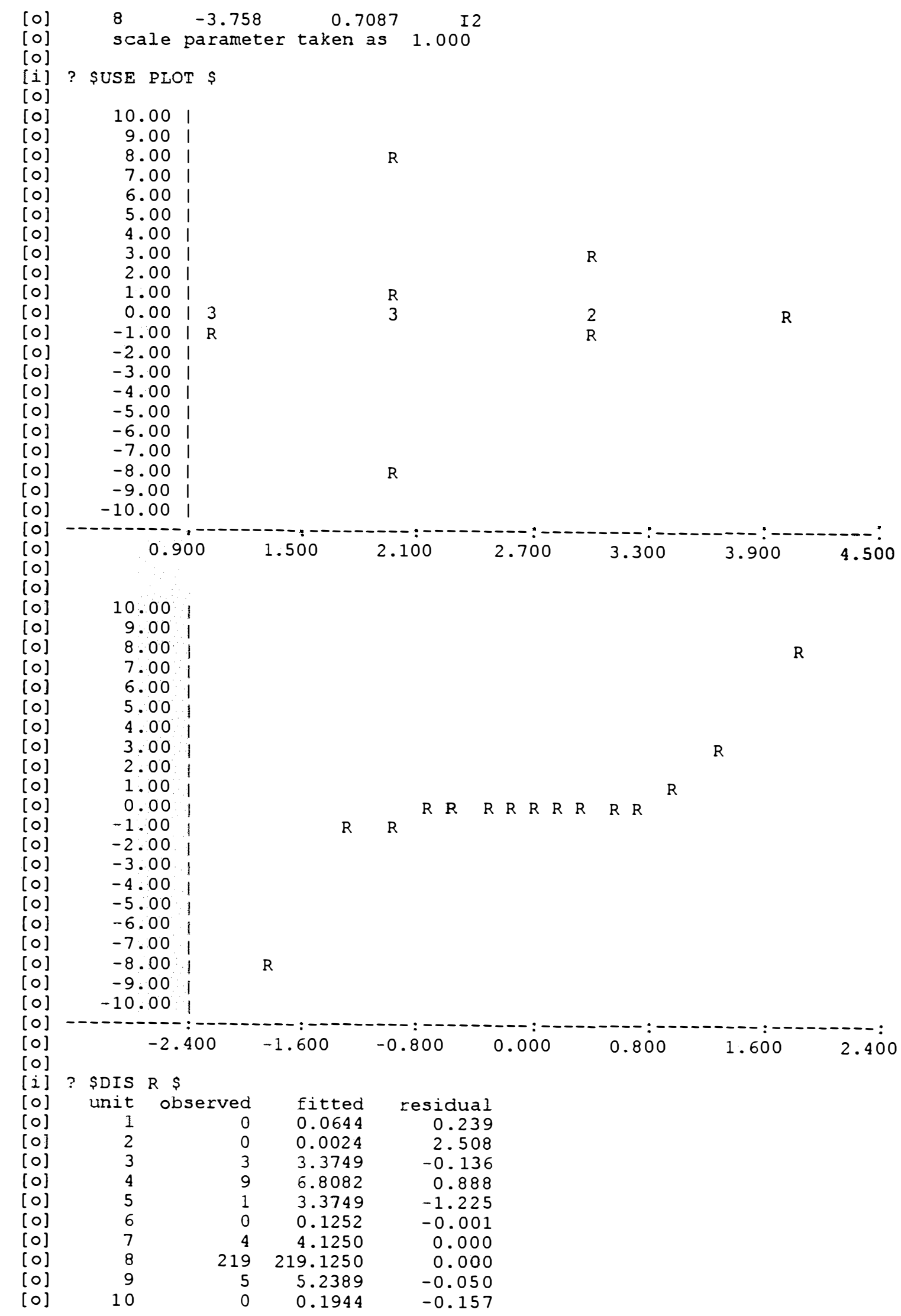




$\begin{array}{llrrr}{[0]} & 11 & 373 & 274.3484 & 5.964 \\ {[0]} & 12 & 551 & 553.4417 & -0.098 \\ {[0]} & 13 & 178 & 274.3484 & -5.809 \\ {[0]} & 14 & 10 & 10.1781 & -0.017 \\ {[0]} & 15 & 394 & 394.1249 & 0.000\end{array}$

[i]? SUSE USE \$

[0]

[0] I

[0]

[0]

[0] 2

I $\quad \mathrm{N}(\mathrm{I})$

PHI (I-1)

151180 .

15665 .

1.0000

(

$P(I)$

$B(I-1)$

[0] 345014.41 .0000

15.7503

0.01874

0.01874

0.01874

12648 .

0.6485

0.01874

51180

$-790433$.

29349 .

[0]

[0] IF CONSTANT EFFORT THEN. ALL ESTIMATES TRUE, OTHERWISE:

[0] $\mathrm{N}(1), \mathrm{P}(1), \mathrm{B}(1)$ TRUE ONLY IF NO BIRTH IN PERIOD 1

[0] $N(S), P(S)$ TRUE ONLY IF NO DEATH IN LAST PERIOD

[0] PHI (S-1) TRUE ONLY IF EFFORT CONSTANT IN $(\mathrm{S}-1)$, $S$

[0] B(S-1) TRUE ONLY IF N(S), PHI (S-1) BOTH ARE

[0]

\section{Análise do modelo com nascimento e morte mais "trap-dependence" com $\mathrm{S}=5$}

[o] GLIM 3.77 (copyright) 1984 Royal statistical Society, London

[0]

[i] ? \$UNITS 31 \$DATA R \$READ

[i] SREA? 0.06250 .06250 .06250 .06250 .06250 .06250 .06250 .0625

[i] \$REA? $0.0625 \quad 0.0625 \quad 0.0625 \quad 0.0625 \quad 0.06250 .06250 .0625 \quad 70.0625$

[i] SREA? $0.0625 \quad 0.0625 \quad 3.0625 \quad 9.0625 \quad 1.0625 \quad 0.0625 \quad 4.0625 \quad 149.0625$

[i] SREA? $5.0625 \quad 0.0625 \quad 373.0625 \quad 551.0625 \quad 178.0625 \quad 10.0625 \quad 394.0625$

[i] ? \$INPUT 7 CR1 CR5 \$

[i] File name? RECAP.GLM

[i] \$MAC EST

[i] $\$ C A L ~ \& E=2 * \star(z S+8 K-1): 8 F=2 \star \star(-8 K): z J=8 S+8 K$

[i] $\quad \$ C A L M(8 J)=8 F V(1)+8 F V(8 E+1)$

[i] $\$ C A L$ AFT $=$ AFT * $(2-8 \mathrm{GL}(2,8 E))$

[i] $\quad \$ C A L A A(z J)=8 C U(A F T \star \& F V)$

[i] $\$ C A L B E F=B E F \star(2-8 G L(2,8 F))$

[i] $\quad \$ C A L B B(1-8 K)=8 C U(B E F \star z F V)$

[i] $\$ C A L ~ \& K=8 K+1$

[i] \$ENDMAC

[i] \$MAC USE

[i] $\$ C A L A F T=1: B E F=1: \& \mathrm{~K}=1-8 \mathrm{~S}$

[i] \$VAR \& $\mathrm{SAA} B \mathrm{BB}$ PERM PHIH

[i] $\$ C A L A A=1: M=1$

[i] \$WHILE $8 \mathrm{~K}$ EST

[i] $\quad$ CAL PERM $=8 \mathrm{gL}(8 \mathrm{~S}, 1)-1: \operatorname{PERM}(1)=8 \mathrm{~S}: \operatorname{BB}(1)=8 \mathrm{FV}(1)$

[i] $\$ C A L A A(\& S)=B B(1): C C=A A(P E R M): M(\& S)=C C(\& S)$

[i] $\$ C A L \mathrm{PH}=8 \mathrm{FV}(1) / \mathrm{M}$

[i] $\$ C A L \operatorname{TEMP}=\mathrm{PH}: \operatorname{TEMP}(1)=\operatorname{TEMP}(2): \operatorname{TEMP}(z S)=\operatorname{TEMP}(z S-1)$

[i] \$SORT TEMP

[i] $\$$ CAL $\& A=T E M P(\& S)-T E M P(1): ~ \& C=10 * \star(-4)$

[i] $\$ C A L N E S T=A A * M \star B B / \& F V(1) \star \star 2$

[i] $\$ C A L \mathrm{PHIH}=\mathrm{AA} \star \mathrm{M} /(\mathrm{CC} \star 8 \mathrm{FV}(1))$

[i] $\quad \$ C A L \& B=8 L E(\& A, \& C)$

[i] \$SWITCH \&B CONST $\$$

[i] $\$ \mathrm{CAL}$ PHIH $(1)=1$ : $8 \mathrm{~A}=\mathrm{M}(8 \mathrm{~S}-1) / \mathrm{M}(8 \mathrm{~S})$ : $8 \mathrm{~B}=1-8 \mathrm{C}$

[i] $\quad \$ C A L \operatorname{PHIH}(\& S)=\mathrm{PHIH}(8 \mathrm{~S})+(8 \mathrm{~A}-1) \star(1-8 \mathrm{~B}) \star 8 \mathrm{LE}(\mathrm{PHIH}(z \mathrm{~S}-1), 8 \mathrm{~B})$

[i] $\quad$ CAL BH=NEST - PHIH*NEST (PERM)

[i] $\quad \$ C A L B H(1)=N E S T(1)$

[i] \$PRINT 


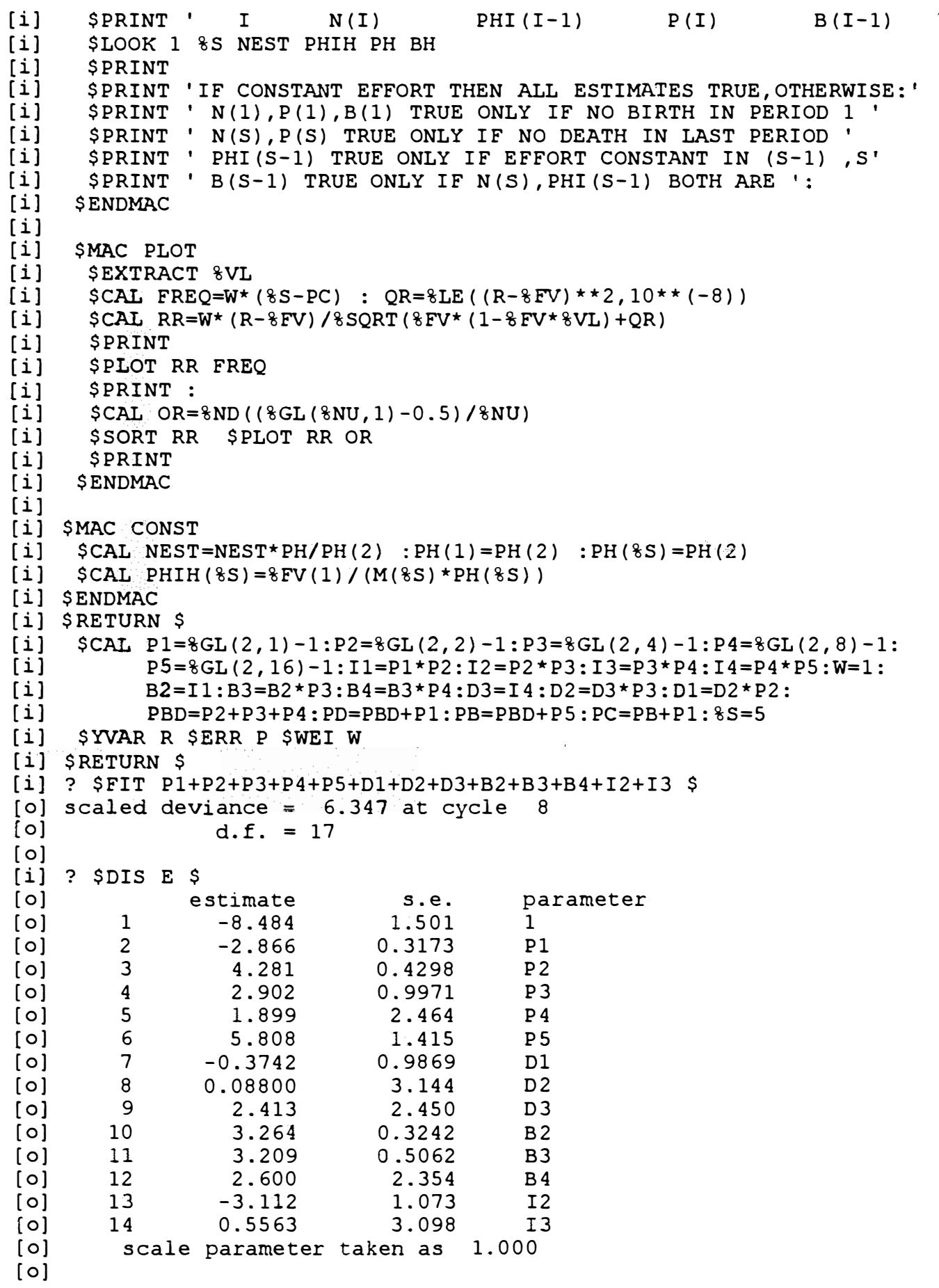

\section{Reajuste do modelo sem o parâmetro D1}

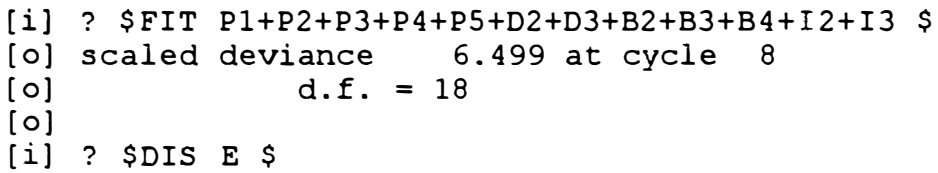




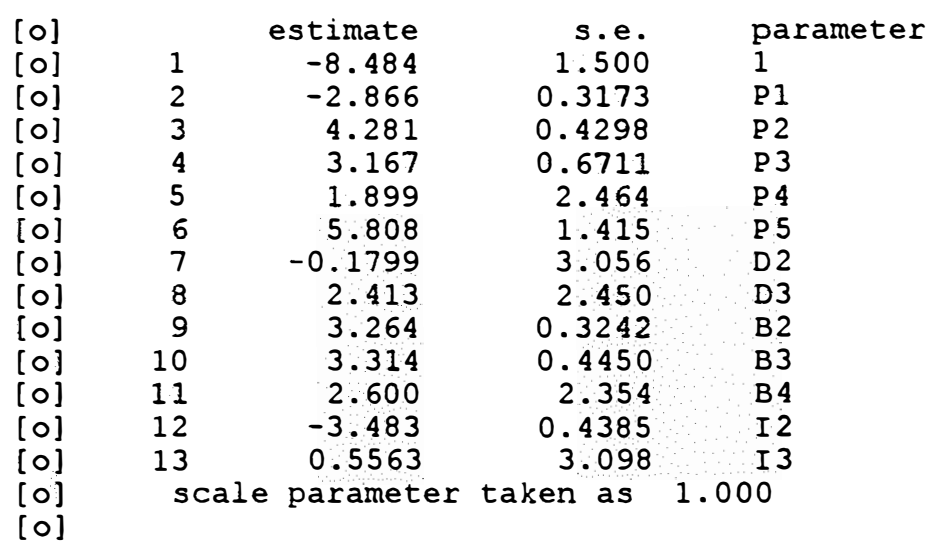

\section{Reajuste do modelo sem os parâmetros D1 e D2}

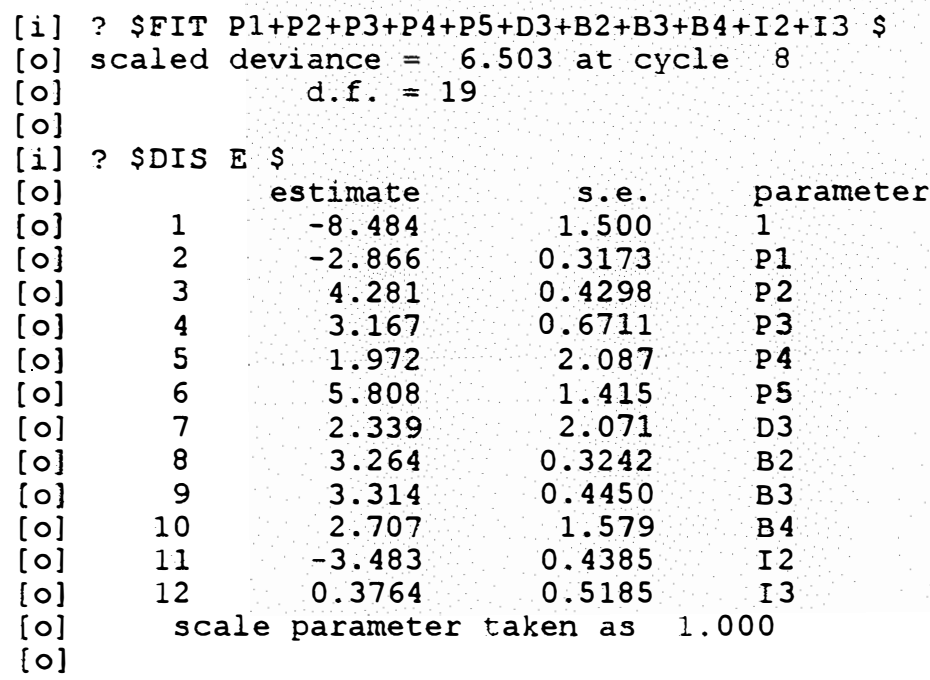




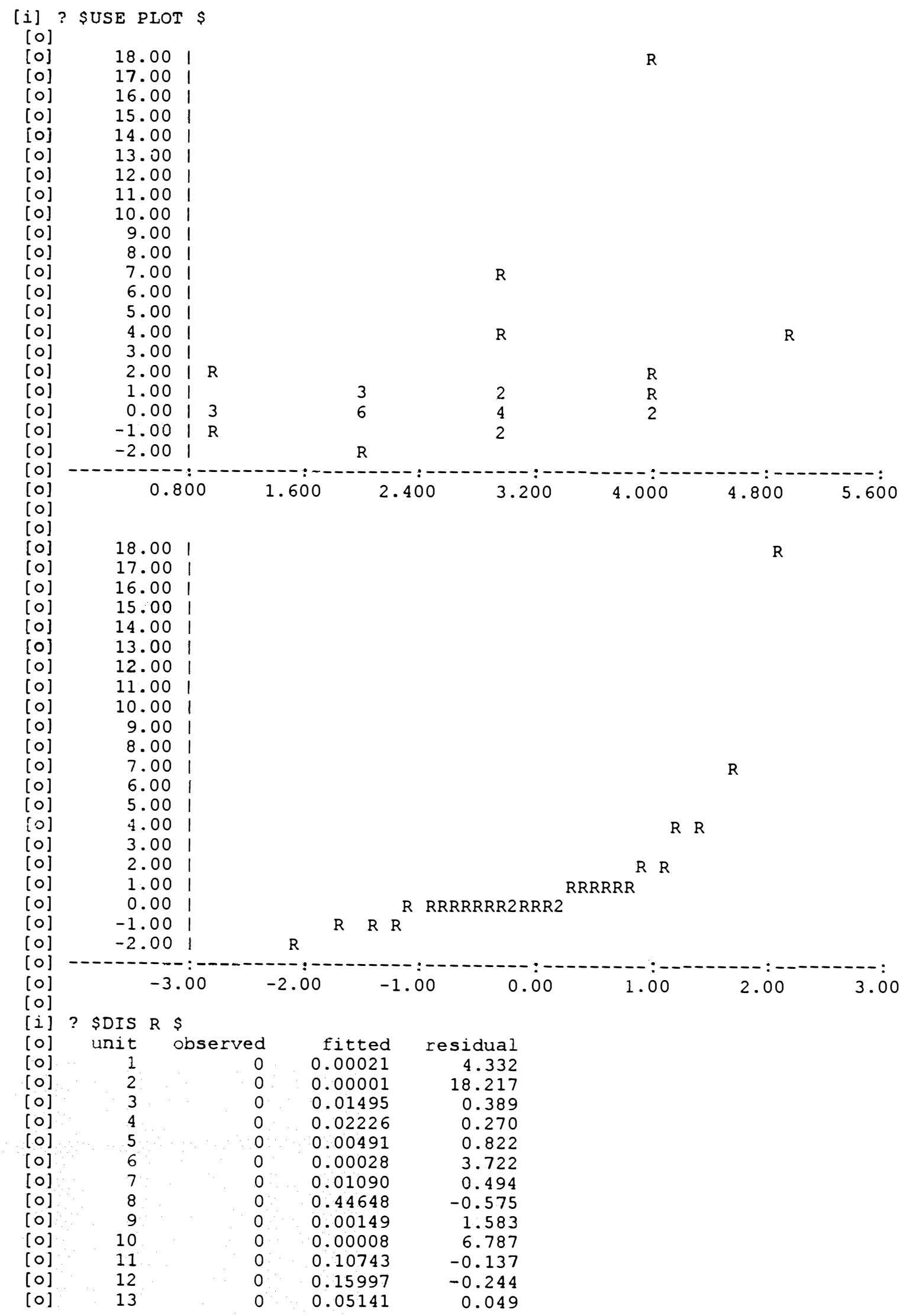




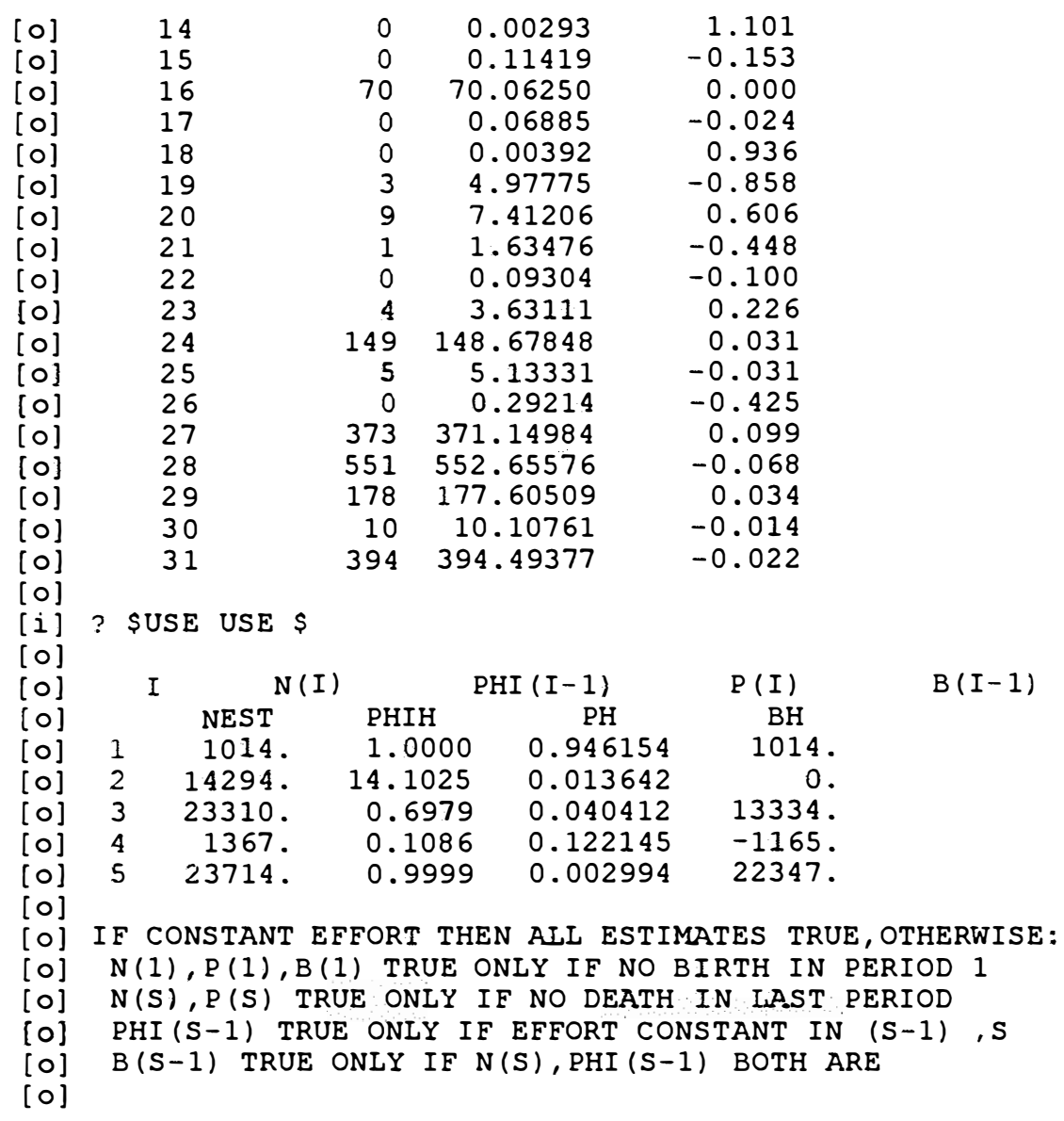

Análise de heterogeneidade do modelo com parâmetros de nascimento e morte mais "trap-dependence"

Remoção da observação 1 cuja história de captura é 11111

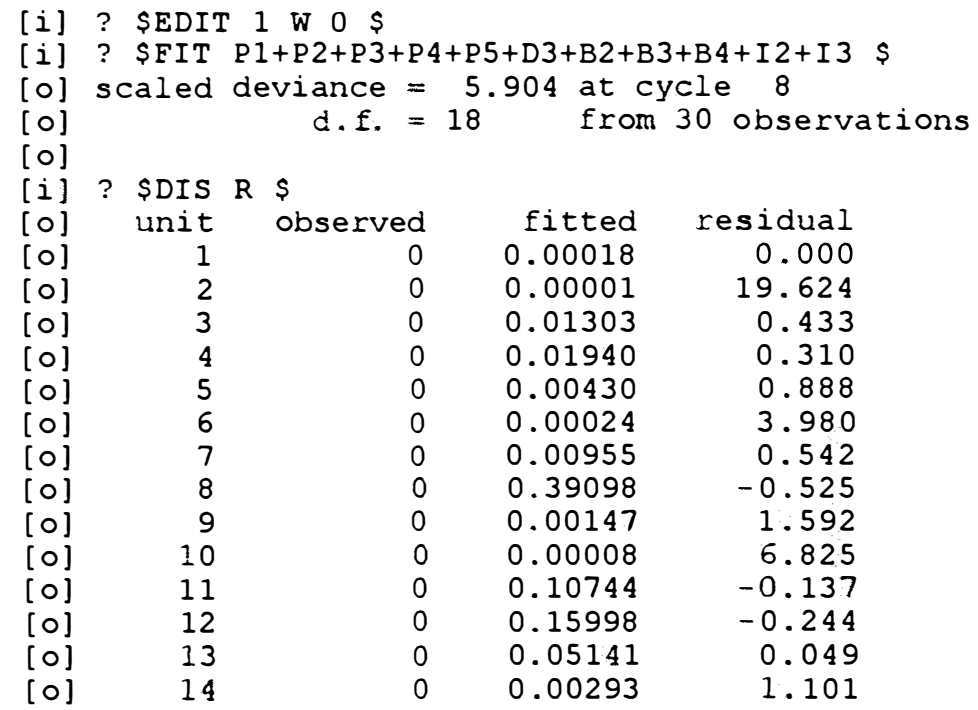




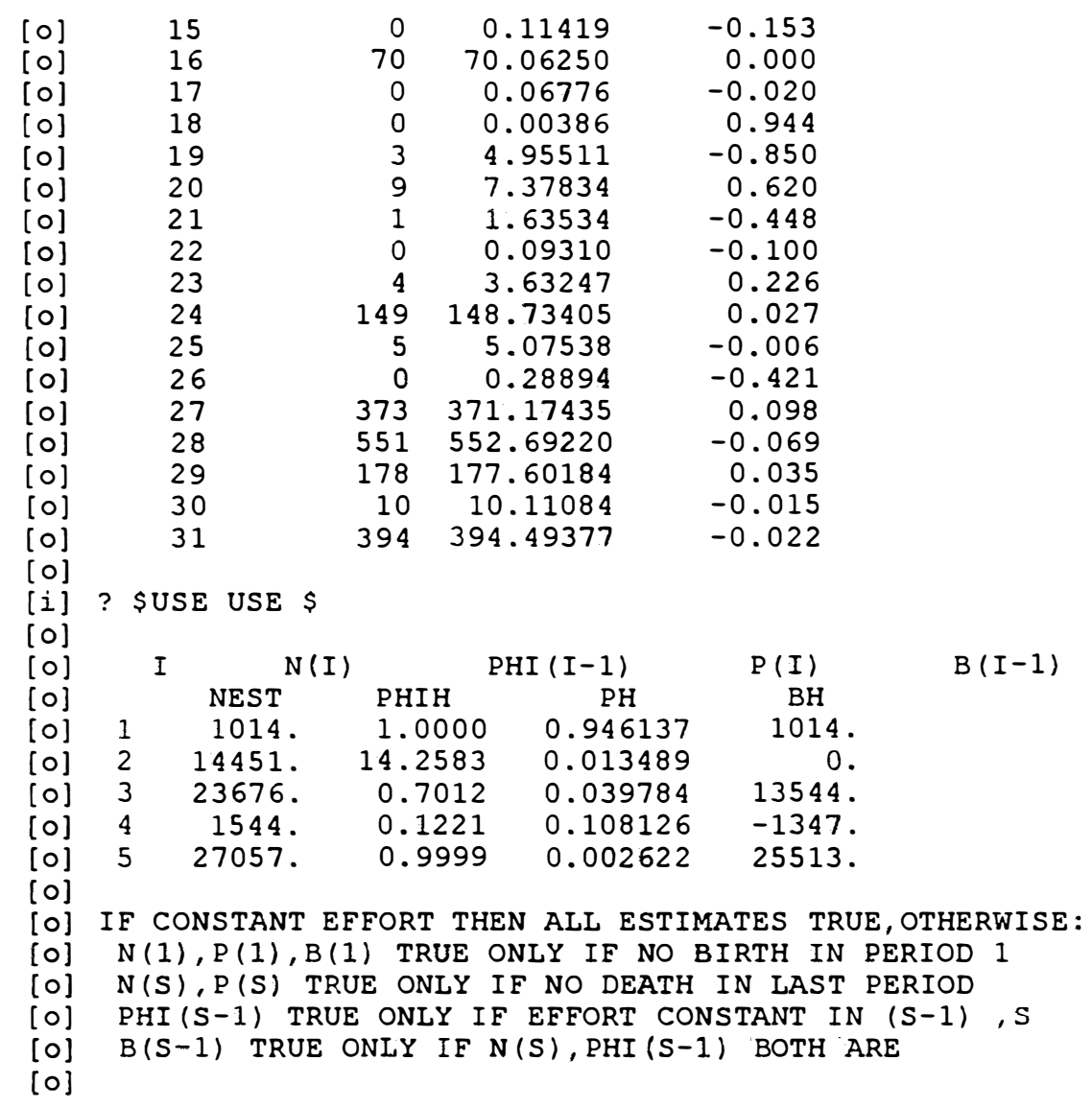

Remoção das observações $1,2,3,5,9$ e 17 cujas histórias de captura são $11111,21111,12111,11211,11121$ e 11112 , respectivamente

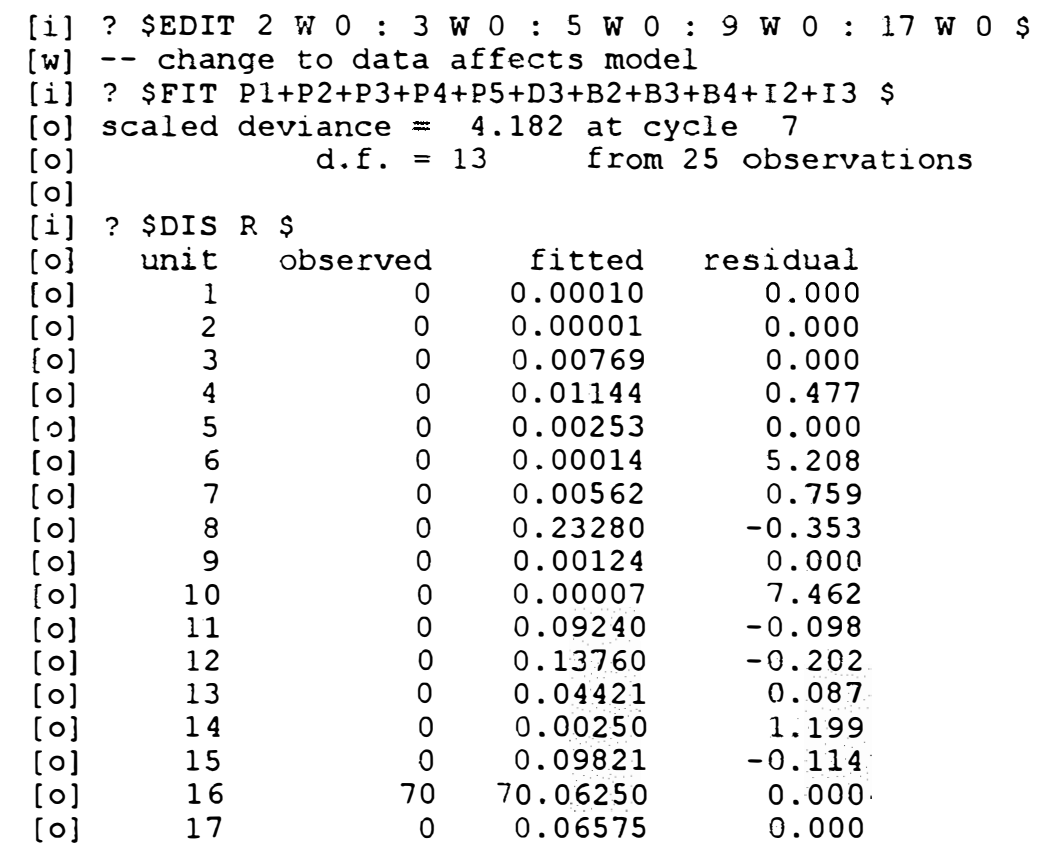




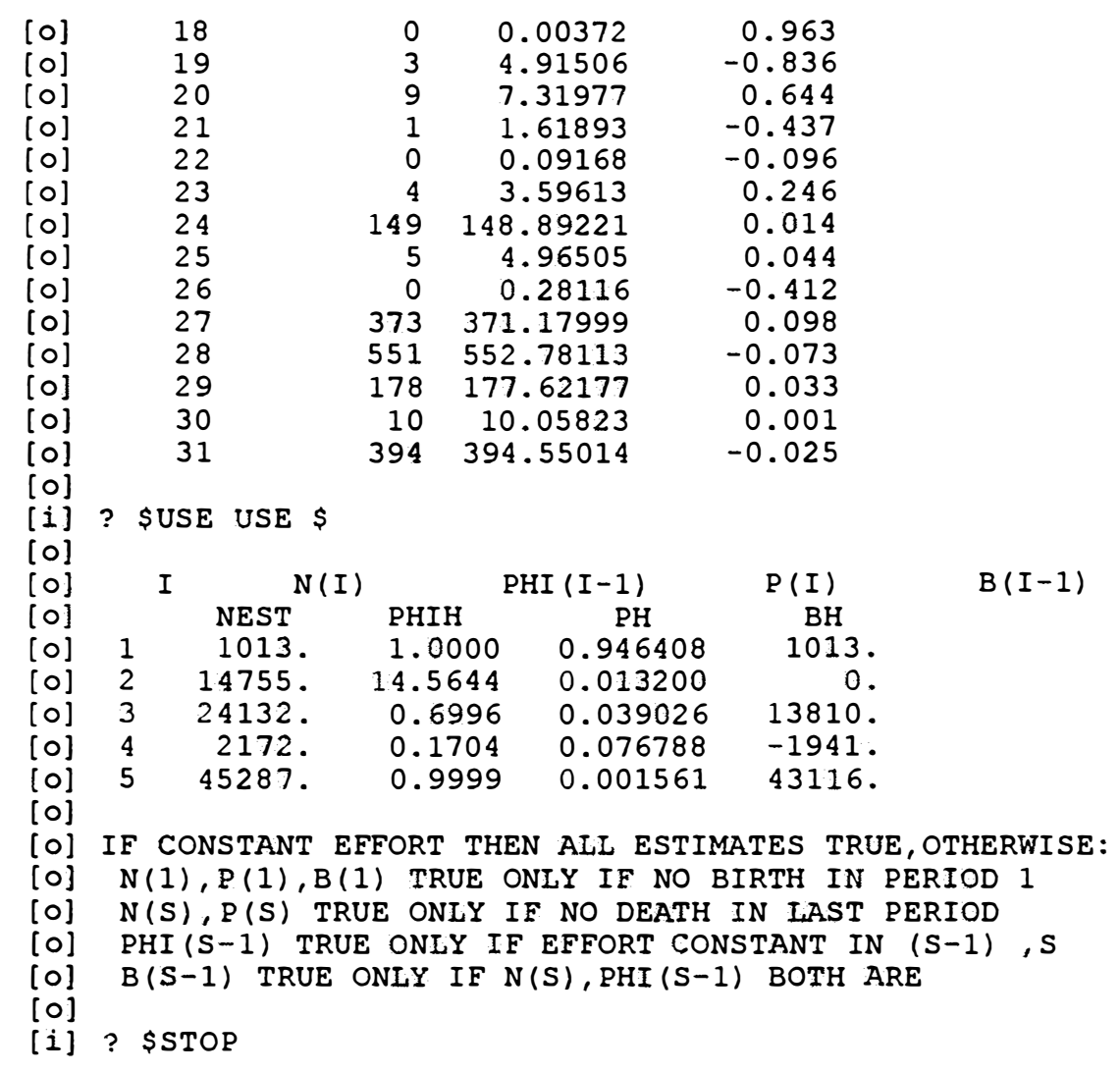

